\title{
Pour un bilan de l'historiographie sur le Moyen Âge portugais au XXe siècle
}

Bernardo Vasconcelos e Sousa, Stéphane Boisselier

\section{Citer ce document / Cite this document :}

Vasconcelos e Sousa Bernardo, Boisselier Stéphane. Pour un bilan de l'historiographie sur le Moyen Âge portugais au XXe

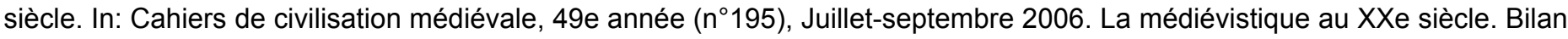
et perspectives. pp. 213-256;

doi : $10.3406 /$ ccmed.2006.2940

http://www.persee.fr/doc/ccmed_0007-9731_2006_num_49_195_2940

Document généré le 01/06/2016 


\title{
Résumé
}

Au XXe s., l'historiographie médiévistique portugaise est passée par plusieurs phases contrastées. Un long XIXe s., jusqu'aux années 1920, dominé par la figure d'A. Herculano, assure à la recherche méthodique de solides bases heuristiques et conceptuelles, fortement inspirées par l'historiographie allemande. Mais, par la suite, jusqu'aux années 1970, ce capital n'est pas valorisé comme il aurait pu l'être : le médiévisme portugais se replie sur une histoire nationaliste (les " origines de la nation », les " grands hommes », les événements militaires glorieux) et fortement marquée par les approches juridico-institutionnelles en histoire sociale, les universitaires sont contraints de se rapprocher du régime salazariste et se coupent donc des évolutions en cours dans le reste de l'Europe. Malgré la pénétration, dès les années 1960, des courants historiographiques " français " (issus des Annales), c'est la décennie 1980 qui, à la suite de la « révolution des œillets », développe la recherche historique universitaire et ouvre la réflexion à de nouvelles perspectives, moins historicistes; I'histoire des villes (avec A. H. Oliveira Marques) ou l'histoire de la noblesse (avec J. Mattoso) deviennent des domaines de pointe de la recherche, à l'échelle européenne ; les chercheurs portugais, entre autres par l'usage de la langue française, s'intègrent dans les grands chantiers internationaux; et des chercheurs étrangers, principalement français, commencent à s'intéresser au Moyen Âge portugais.

\begin{abstract}
During the XXth century, the medievistic portuguese historiography travelled down contrasted phases. A long XIXth century, to the 1920's, with A. Herculano, endows the methodic historical resarch with strong heuristic and conceptual bases, influenced by the germanic historiography. But, later, to the 1970 's, this fund collapses ; the portuguese medievalism retreats into a nationalist history (the " origins of the Nation ", the " great men ", the glorious military facts) marked by the juridico-institutionnal approaches in the social history, the academics are compelled to support the Salazarist system and give themselves away the seientific evolutions in process in the rest of Europe. Despite the penetration, in the 1960's, of the "french " historiographic tendances (in relation with the Annales), there are only the 1980's, after the "carnations' revolution », which expand the universitary historical research and introduce new approaches, less historicistic ; the urban history (with A. H. Oliveira Marques) and the history of aristocracy (with J. Mattoso) become forefront areas of research at the european scale ; the portuguese academics enter in the great international enterprises ; and foreign researchers, especially french, begin to study the portuguese Middle Ages.
\end{abstract}




\title{
Bernardo VASCONCELOS E SOUSA et Stéphane BOISSELLIER
}

\author{
Pour un bilan de l'historiographie sur le Moyen Âge portugais \\ au $\mathrm{XX}^{\mathrm{e}}$ siècle
}

\begin{abstract}
RÉSUMÉ.
$\mathrm{Au} x \mathrm{XX}^{\circ}$ s.. l'historiographic médiévistique portugaise est passée par plusieurs phases contrastées. Un long XIX s. jusqu’aux années 1920, dominé par la figure d'A. Herculano, assure à la recherche méthodique de solides bases heuristiques et conceptuelles. fortement inspirées par l'historiographie allemande. Mais, par la suite. jusqu'aux années 1970. ce capital n'est pas valorisé comme il aurait pu l'être : le médiévisme portugais se replie sur une histoire nationaliste (les « origines de la nation». les "grands hommes», les événements militaires glorieux) et fortement marquée par les approches juridico-institutionnelles en histoire sociale. les universitaires sont contraints de se rapprocher du régime salazariste et se coupent donc des évolutions en cours dans le reste de l'Europe. Malgré la pénétration. dès les années 1960. des courants historiographiques "français" (issus des Annales). c'est la décennie 1980 qui, à la suite de la "révolution des æillets », développe la recherche historique universitaire et ouvre la réflexion à de nouvelles perspectives, moins historicistes : l'histoire des villes (avec A. H. Oliveira Marques) ou l'histoire de la noblesse (avec J. Mattoso) deviennent des domaines de pointe de la recherche, à l'échelle européenne : les chercheurs portugais, entre autres par l'usage de la langue française. s’intègrent dans les grands chantiers internationaux; et des chercheurs étrangers. principalement français, commencent à s’intéresser au Moyen Âge portugais.
\end{abstract}

\begin{abstract}
ABSTRAC"I
During the xxth century, the medievistic portuguese historiography travelled down contrasted phases. A long XIxth century, to the 1920 's, with A. Herculano, endows the methodic historical resarch with strong heuristic and conceptual bases, influenced by the germanic historiography. But. later. to the 1970's, this fund collapses : the portuguese medievalism retreats into a nationalist history (the "origins of the Nation", the "great men ". the glorious military facts) marked by the juridico-institutionnal approaches in the social history, the academics are compelled to support the Salazarist system and give themselves away the scientific evolutions in process in the rest of Europe. Despite the penetration. in the 1960's. of the "french" historiographic tendances (in relation with the Annales). there are only the $19800^{\circ}$ s, after the "carnations" revolution ". which expand the universitary historical research and introduce new approaches, less historicistic: the urban history (with A. H. Oliveira Marques) and the history of aristocracy (with J. Mattoso) become forefront areas of research at the european scale: the portuguese academics enter in the great international enterprises: and foreign researchers, especially french, hegin to study the portuguese Middle Ages.
\end{abstract}

Au long du $\mathrm{XX}^{\mathrm{c}}$ s. le médiévisme a été un des secteurs privilégiés par l'historiographie portugaise. soit en termes d’étude soit par le nombre de publications. De ceci. il n`a pas découlé nécessairement une correspondance directe entre la quantité et la qualité des travaux produits, notamment parce qu'ont varié. au long des années, les raisons et intentions qui ont engendré un intérêt particulier envers le Moyen Âge. À l'origine de cet intérêt, il y avait une situation hautement prometteuse : le XIX siècle avait légué les éléments nécessaires pour un alignement sans complexes avec ce qui se faisait de mieux alors en Europe. Ce capital devait. du reste. perdurer au long des décennies. bien que de plus en plus soumis à l'inévitable dépréciation que le passage des années imposait. jusqu à atteindre une vraie reprise dans les deux dernières décennies du $\mathrm{XX}^{\mathrm{c}} \mathrm{s}$. 


\section{Le legs du XIX $x^{e}$ siècle}

L'impulsion décisive pour l'émergence, au Portugal, d'une historiographie dotée de concepts rigoureux et d'une méthodologie appropriée a été donnée par Alexandre Herculano (1810-1877), encore aujourd'hui unanimement considéré dans le pays comme la figure tutélaire de la discipline historique. Outre une vaste et multiforme œuvre comme romancier, poète et publiciste, Herculano s'est distingué par son activité d'éminent historien. spécialement voué au temps médiéval. En 1846, 1847, 1850 et 1853 sortaient les quatre volumes de son Histoire du Portugal, qui ne dépasserait pas le règne d'Alphonse III (1248-1279)'. En 1856, fruit d'un considérable travail de recherche et de collecte de documentation. Herculano publiait les deux premiers volumes des Portugaliae Monumenta Historica $a^{2}$, une collection de sources médiévales directement inspirée des Monumenta Germaniae Historica. Avec son travail deérudition et de construction de synthèses, Herculano appliquait de manière systématique les règles de la méthode historique, avec l'intention d'atteindre la vérité à travers la rigueur de la critique. D'autre part, sa préoccupation allait bien au-delà d'une simple description d'événements. en cherchant à capter l" "histoire de la société ", surtout dans ses sources institutionnelles et politiques, sans cesser de porter attention à des aspects aussi sensibles que les motivations des groupes sociaux et leurs formes d'expression. Avec Herculano a eu lieu ce qui déjà a été considéré comme une vraie "révolution" dans la façon de concevoir et de produire l'histoire comme une discipline, au Portugal:

Libéral dans le champ politique, romantique en matière littéraire et historiciste dans la recherche et dans l'analyse du passé portugais. Herculano a connu et a été profondément influencé par certains des meilleurs historiens du XIX ${ }^{c}$ s. La marque d'Augustin Thierry est présente, dès lors, dans ses Lettres sur l'Histoire du Portugal, publiées en $1842^{4}$ et qui ont emprunté le titre des Lettres sur l'Histoire de France. De même, l'influence de François Guizot est notoire dans les travaux d'Herculano, peut-être même dans une plus grande mesure que celle de Thierry. La connaissance qu'Herculano a assimilée de la production historiographique européenne ne s'est pas limitée. néanmoins, à des auteurs français. Lecteur attentif d'auteurs espagnols, anglais et italiens, il a été particulièrement sensible à l'érudition allemande (de Von Savigny)", dans une démonstration d'ouverture d'esprit et de cosmopolitisme peu communs dans le Portugal de son temps. La sévérité méthodologique d'Herculano et son culte de la vérité historique l'ont conduit à mettre en causc et à démonter ccrtains des plus importants "mythes des origines » du royaume portugais. De ceci découle que la publication de son Histoire du Portugal a suscité une vive polémique. avec de féroces attaques dirigées contre l'historien par des représentants des secteurs les plus traditionnalistes et conservateurs de la société portugaise?

1. Dernière édition. História de Portugal desde o começo da monarquia até o fim do reinado de Afonso III. Notas críticas de José Mattoso. Lisbonne. Livraria Bertrand. 1980/81. 4 vol. (2 -4 éd. 1862-76).

2. Portugaliae monumenta historica. Scriptores, Lisbonne. Academia Real das Sciências de Lisboa.1856 et Portugaliae monumenta historica. Leges et consuetudines, I. Lisbonne. Academia Real das Sciências de Lisboa. 1856 : les autres volumes. tous publiés par l'Académie rovale des Sciences de Lisbonne. sont Diplomata ct cartae. 1 en 1867. Leges et consuetudines. II (fasc.1) en 1868 et Inquisitiones. I en 1888 . Tous ces volumes ont été réimprimés par Kraus Reprint (Nendeln) en 1967.

3. Voir A. H. de Oliveira MArolt:s, dans son "Introdução" à l'Antologia da Historiografia Portuguesa. I - Das Origens a Herculano. Lisbonne. Europa-América. 1974. p. 7-52.

4. Consultables dans leur rédition : Alexandre Herclitavo : "Estudos de história portuguesa. 'Cartas" sobre a história de Portugal. 1842 », dans ID.. Optisculos, IV. éd. introd. Jorge (1 storIo et José Manuel Garcia. Lisbonne. Editorial Presença. 1985.

5. Joaquim Barradas de (Anvalno. As ideias Políticas e Sociais de Alexandre Herculano, Lishonne. Seara Nova. 1971 (2 éd.) el li)., Da História-Crónica à Historia-Ciéncia. Lisbonne. Livros Horizonte. 1972. surtout p. 108-115.

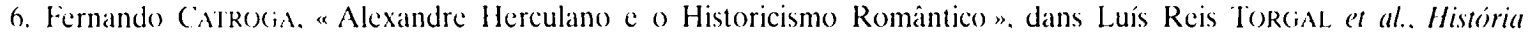
da história em Portugal. Sécs. XIX-XX. Lisbonne. Córculo de leitores. 1996 (Grandes temas da nossa história). p. 55-58.

7. Sur les positions alors en conflit. voir Ana Isabel Bisscr. O Milagre de Ourigue e a História de Portugal de Alexandre Herculano. Lima Polémica Oitocentista. Lishonne. INIC. 1987. 
Mais les répercussions de l'action d'A. Herculano dans le secteur de l'histoire médiévale ont eu des effets multiplicateurs très positifs auprès d'un appréciable éventail d'historiens de la fin du $\mathrm{XIX}^{\mathrm{c}} \mathrm{s}$. et du début du XX's. Entre les noms les plus représentatifs de cet intérêt pour la recherche sur le Moyen Âgc, il cst obligatoirc de rapporter celui de Henrique da Gama Barros (1833-1925), auteur d'une cuvre monumentale sur l'administration centrale et les institutions politiques mais développant aussi d'importants aspects sociaux et économiques relatifs aux siècles XII à $\mathrm{XV}^{\star}$. Publiée dans une première édition entre 1885 et 1922, cette œuvre sera rééditée, en version complète et annotée, au milieu du $\mathrm{xx}^{\mathrm{c}}$ s. en constituant, pendant des décennies et conjointement avec l'Histoire du Portugal de Herculano. l'authentique vade mecum des médiévistes portugais. Méritent aussi une mention spéciale Costa Lobo (1840-1913). Alberto Sampaio (1841-1908) et Anselmo Braamcamp Freire (1849-1921), les deux premiers souvent considérés comme "fondateurs " d'une histoire économique et sociale du Moyen Âge". et le troisième se détachant surtout par son œuvre dans le domaine de la généalogie l" et par la fondation, en 1903, de l'Archivo Historico Portuguez (Lisbonne, 1903-1921). revue spécialisée qui s’est consacrée principalement à la publication de documents et qui a compté avec la collaboration des plus importants noms du temps.

Au tournant du XIX et du XX' $X^{c}$ s., l'influence d'Herculano continuait à donner ses fruits à travers un ensemble d'auteurs significatif, qui, en se consacrant à l'ćtude du Moyen Âgc, combinaicnt la recherche des sources et l'application des règles de la méthode historique avec un effort d'interprétation novatrice. Les incursions dans des secteurs spécialisés comme celui de l'histoire économique et sociale, source de publications de qualité, ont fait des dernières décennies du XIX" et des premières années du $\mathrm{XX}^{\mathrm{c}} \mathrm{s}$. une des périodes les plus riches de la production historiographique portugaise. Mais ce qui semblait être une promesse de développement soutenu de la recherche et de la synthèse sur le Moyen Âge portugais finirait, dans une large mesure, par avorter.

\section{Première moitié du $\mathrm{XX}^{\mathrm{e}}$ siècle ${ }^{11}$}

Surtout à partir des années 20 et 30, l'historiographie portugaise a été marquée, d'une manière générale, par un fort courant nationaliste qui valorisait le temps de l'expansion d'outre-mer (les «Découvertes»), combiné avec un discours apologétique sur l'action des monarques portugais, surtout les plus directement liés à ce même processus d'expansion. Dans le contexte de l'histoire médiévale - génériquement conçue comme concernant la période des «origines de la nation" - on assista au bourgeonnement d'œuvres de caractère fortement idéologique, tendant à promouvoir une identification entre le régime politique de la dictature qui gouvernait alors le pays (entre 1926 et 1974) et ce qui était présenté comme les valeurs essentielles et éternelles de la nation. Parmi les sujets d’élection de cette historiographie officielle, se détachaient les questions liées aux "origines de la nationalité ". l'action militaire et le rôle protecteur, presque paternel, du roi, ainsi que la défense voilée ou déclarée de ce qui était décrit comme un processus linéaire de centralisation politique conduite par la couronne. Période privilégiée précisément pour être

8. História da administração pública em Portugal nos séculos $X I I$ a $X V, 2$ éd. Torquato de Sousa SoArFs. Lisbonne. Sá da Costa. s.d. $[1945 / 54]$. 11 vol. Une bonne introduction à cette cuvre monumentale se trouve dans Armando Luis de Carvalho HowiM. "Gama Barros. historiador das instituições administrativas ". dans ID.. Portugal nos finais da Idade Média : estado, instituiçóes, sociedade politica. Lisbonne. Livros Horizonte. 1990 (Horizonte histórico. 28). p 35-47.

9. A. de Sousa Silva costa LoBO. História da sociedade em Portugal no século XV [Preface de José MArroso]. Lisbonne. Edições Rolim. 1984 (Raízes) [1' éd. 1903]: les principaux travaux d’A. SA.Mparo (As póvoas maritimas no) Norte de Portugal et As villas no Norte de Portugal. parus en 1923) sont réédités dans ID.. Estudos históricos e éconómicos. Vol. I-II. Lishonne. Vega. 1979.

10. Voir surtout son énorme somme Brasōes da sala de Sintra. L isbonne. 1899-1905. 3 vol.. constamment rééditée depuis par l'Imprensa Nacional-Casa da Moeda.

11. Pour des raisons de place et parce que l'objectif de cet article n'est pas de présenter un catalogue d'ocuvres médiévistiques élaborées au cours du $x \times$ s. nous naurons pas ici la prétention d’être exhaustifs quant aux auteurs et titres cités. Nous laisserons de côté des domaines aussi importants que l'histoire de la littérature. de lart. de la philosophie et. dans une large mesure. larchéologie. à travers lesquels se sont pourtant produits de significatifs progrès de l'historiographie portugaise. surtout dans les dernières années du $x \mathrm{x}$ s. 
celle des origines. le Moyen Âge servait. dans les interprétations officielles, comme temps primordial et légitimateur des valeurs idéologiques de type nationaliste et autoritaire. dont les racines se trouveraient à l'aube de la monarchie portugaise ${ }^{12}$. Les grandes commémorations officielles "des Centenaires ", en 1940) (célébration de la «fondation de la nationalité " en 1140, et de la "restauration de l'indépendance " par rapport à la domination espagnole en 1640), ont constitué un point haut de cette conception pragmatico-utilitaire de l'histoire. D'autre part. parmi les auteurs qui ne s`identifiaient pas avec la ligne alors dominante, il faut détacher António Sérgio et Jaime Cortesão, qui. sans être des médiévistes ni. à la limite, des historiens, ont tenté des essais de type fortement critique et problématisant sur l'histoire portugaise. y compris sur les temps médiévaux ${ }^{13}$.

Dans le champ de l'érudition, le travail de Rui de Azevedo conduirait à la publication d'un très important ensemble de sources documentaires indispensables à l'étude des origines politiques du royaume du Portugal ${ }^{14}$. La recherche académique, elle aussi à forte tendance érudite, avait à l'Université de Coimbra. surtout dans sa Faculté des Lettres mais aussi dans celle de Droit, un fort noyau de médiévistes qui ont fait école. en constituant des références de première grandeur. Lexpression de cette réalité a été la création. en 1941. de la Revista Portuguesa de História, sans aucun doute la plus importante publication périodique alors existante dans le secteur de l'histoire et qui continuera à être éditée jusqu'à nos jours. Cette revue, au long des décennies de 1940. 50 et 60. donnera une spéciale importance au Moyen Âge. tant par la quantité que par Ia qualité des articles publiés. Parmi les auteurs de présence la plus régulière dans les pages de la revue. il y avait des médiévistes comme Damião Peres's. Pierre David"s. Torquato de Sousa Soares, Avelino de Jesús de Costa ou Salvador Dias Arnaut ${ }^{1}$. Certains de ceux-ci auront encore un rôle décisif dans l'édition de sources historiques et dans la participation à des cuvres collectives. notamment l'Histoire du Portugal généralement désignée comme "de Barcelos » (du lieu d'édition), parue entre 1928 et 1937 et intégrée dans la susdite commémoration "des Centenaires »" : Damião Peres a été son coordinateur. et l'œuvre s'est maintenue. pratiquement jusqu'aux années 80) du $\mathrm{XX}^{*}$ s., comme l'Histoire du Portugal de référence, la plus consultée dans les facultés ou dans les bibliothèques publiques. Dans les chapitres relatifs au Moyen Âge se détachait la collaboration

12. Voir notamment fortunato de At..Mt:IDA. História de Pormugal. récemment rééditée en 6 vol.. Lishonne. Bertrand. 2003 (la 1" éd. à compte d’auteur, parut à Coimbra, en 1922/29): - ID.. História da lgreja ém Portugal. nouv. éd. dir. Damião Preris. Porto. Portucalense editora. 1967/71. 4 vol. (la 1' éd. date de 1910/28). De même. Alfredo PIMlsivis, IdadeMédia (Problemas \& Soluçeens). Lishonne. Ediçôes Ultramar. 1946. Le cas extrême est celui du publiciste João AMI:Aı.. dans son História de Portugal. Porto. Livraria Tavares Martins. 1940.

13. António Str(io). Breve interpretação da história de Portugal. Ediçäo crítica. Lisbonne. Sá da Costa. 1972. plusieurs fois réimprimé dans cette édition (texte écrit en 1923 comme "Introdução histórica" au (iuta de Portugal (dir. Raúl

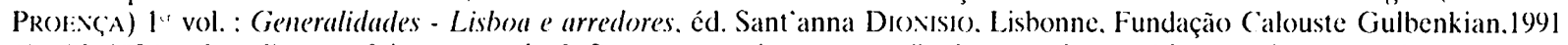
(1" éd. 1924): dans l'(xuvre foisonnante de J. CORTESÃo. voir surtout "()s factores democráticos na formação de Portugal ". écrit comme introduction à lHistória do regimen republicano em Portugal (dir. Luís de MONTaINor). Vol. I. Lisbonne. 1930) (texte constamment rédité. comme livre indépendant ou dans les « ceuvres complètes " de laauteur).

14. Documentos medievais portugueses. Documentos régios. Vol. I : Documenos dos condes pormugalenses e de D. Afonso Henriques A.D. 1095-1185. éd. Rui de A71:VI:1). Lisbonne. Academia portuguesa de história. 1958/62 (Publicaçóes comemorativas do duplo centenário da fundação e da restauração de Portugal). 2 vol. et Doctumentos medievais portugutueses. Documentos particulares. Vol. III-IV. éd. Rui de Azr:vilDo el Avelino de Jesús da Costa. Lisbonne. Academia portuguesa de história. 1940/80. 2 vol., auxquels on peut joindre Documentes de D. Sancho I (1/74-1211). Vol. I. éd. Rui de Az1:V1:Do) et al. Coimbra. Universidade de Coimbra. 1979.

15. Quoique ayant produit une (euvre sur des époques diverses. il est laauteur d'un petit livre médiéviste (toujours sur les origines du pays...) publié en 1938 et qui a connu une énorme diffusion dans les décennies suivantes, aussi bien dans les milicux universitaires que dans le grand public : Como Nasceu Portugal. 7 éd. rev.. Porto. Portucalense Editora. 1970.

16. Voir la bibliographic finale.

17. Respectivement Subsidios para o Estudo da Organização Municipal da Cidade do Porto durante a Idade Média. Barcelos, 1935. O bispo D. Pedro é a organizaçăo da diocese de Braga. 2 éd. refondue et augm. Irmandade de S. Bento da Porta Aberta. Braga. 19997, 2 vol. [1" éd. Coimbra. 1959]. et A Crise Nacional dos Fïns do Século XIV. I - A Sucessão) de D. Fernando. (oimbra. Faculdade de letras. 1960).

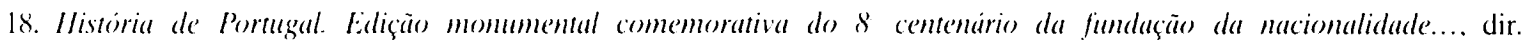
D. Pt:Rt:S. Porto /Barcelos. Portucalense Editora. 1928/37. 7 vol.. plus un vol. dindex et un de Suplemento. Porto. 1954. Le Moven $\hat{\Lambda} g e$ est traite dans les vol. I et II. publiés en 1928 et 1929. Fst sorti également un Suplemento II. Porto. 1981. sans intérêt pour la période médiévale. 
de Manuel Paulo Merêa, spécialiste d'histoire du droit et des institutions ${ }^{10}$. Les années 30 verraient encore la publication de deux autres euvres collectives qui. sans atteindre la diffusion de la précédente. incluaient des collaborations importantes dans le secteur des études médiévales ${ }^{2 \prime \prime}$.

Malgré le nombre et. même. la grande érudition de certains des historiens qui se consacraient au Moyen Âge. il restait quelques fragilités structurelles dans la recherche historique. La situation des archives publiques ne s'était pas améliorée par rapport à l'état où elles se trouvaient au temps d'A. Herculano. et. sauf dans des cas absolument ponctucls. on continuait à manquer d'éditions soignées et rigoureuses de fonds documentaires de première importance ou même d'éditions critiques des chroniques royales et d'autres sources narratives. Les principales archives publiques centrales. la Torre do Tombo. à Lisbonne. détentrices d'une vaste et très riche documentation médiévale, ne disposaicnt presque pas d’instruments de description documentaire ni même d’un Ginide général de leurs fonds. D’autre part. le système universitaire. avec une insuffisante fréquentation d'étudiants et avec un corps enseignant sans contacts internationaux et très fermé sur lui-même, était. avec de rares exceptions, complètement éloigné des débats historiographiques. des innovations conceptuelles et méthodologiques, qui, depuis la décennie de 1930. se faisaient sentir. par exemple en France, ou même de la bibliographie spécialisée d'origine étrangère. Le "culte de l'Histoire Originaire", également défendu par les autorités officielles, n'avait pas sa correspondance dans une action systématique d'organisation et de valorisation des archives, d'édition de sources historiques ou de financement institutionnel de la recherche.

\section{Des années 50 à la décennie 1970}

Les faiblesses institutionnelles rapportées devaient se maintenir au long des décennies suivantes. bien que le panorama de la production historiographique ait commencé lentement à se modifier, surtout à partir des années 1960. Dans une large mesure, ces innovations ont été introduites par un ensemble de médiévistes de l'Université de Lisbonne. Les travaux de Virginia Rau et d'A. H. de Oliveira Marques, ainsi que la publication du Dictionnaire d'Histoire du Portugal, dirigé par Joel Serrão, viendraient ouvrir de nouvelles voies pour le développement de l'histoire médiévale portugaise. En bref. commençait un processus d'assimilation des thèmes et des problématiques présents depuis longtemps dans l'historiographie étrangère. Sous cet aspect, Virginia Rau a eu un rôle vraiment pilote dans le contexte de l'histoire économique et sociale, surtout par la thématique abordée. Son contact direct avec les historiographies française et allemande, sa constante mise à jour bibliographique, sa présence régulière dans des réunions scientifiques internationales lui ont fourni une vision suffisante et ouverte sur l'histoire qui se pratiquait alors dans les centres de recherche européens les plus avancés et quil importait de faire entrer au Portugal. Parmi ses travaux écrits entre les années 40 et 60 , certains des plus importants ont été réédités dans la décennie 8(0:. Quant à Oliveira Marques, ses études les plus importantes tournaient aussi autour d'aspects d'histoire économique et sociale. particulièrement sur l'histoire agraire. le commerce et la vie quotidienne": en dénotant dans cette phase une claire influence des Annales.

19. Voir ses Estudos de História do Direito. Coimbra. 1923. ou son "xuvre de jeunesse "Introdução ao Problema do Feudalismo em Portugal. Coimbra. 1912.

20. Historia do regimen republicano em Portugal. dir. Luís de Mostalion. Lisbonne. 1930/35 et História da expansäo portugleesa no mundo. dir. António Balao ét. al. Lisbonne. Editorial Álica. 1937/40, dont le premier vol. inclut des contributions de Rui de Azevedo et de T. de Sousa Soares.

21. Feiras Medievais Pormuguesas. Subsidios para o seu Estudo: Sesmarias Medievais Portuguesas: Estudos sobre a História do Sal Português: et Estudos de História Medieval. réédités à Lisbonne par l'Editorial Presença. en 1982/86.

22. De cet auteur. voir surtout Introdeçäon à história da agricultura em Portugal. A questäo ceréalifera durante a Idade Média. Lisbonne. ('osmos. 1978 (A marcha da humanidade) [1'éd. 1962] : Hansa e Portugal na Idade Médlia. Lisbonne. Presença. 1993 [1 éd. 1959]: A sociedade medieval portuguesa. Aspectos da vida quotidiana. Lisbonne. Sá da Costa. 1987 [1 éd. 1963] et ses Ensaios de história medieval portugltesa. Lishonne. Editorial Vega. 1980) [2 éd.] (Documenta historica. 5). réunissant d’importantes études élaborées dans les années 1950 et début 60). parmi lesquelles se détachent "Ideário para uma História Económica de Portugal na Idade Média". qui présentait une proposition détude spécialisée dans ce domaine rassemblant la hibliographie nationale et étrangère pertinente (parfaitement actualisée pour l'époque). et l'article sur "A Populaçāo Portuguesa nos Fins do Século XIII". 
Illustrant bien le renouvellement qui était en cours dans l'historiographie portugaise, le Dictionnaire d'Histoire du Portugal, publié entre 1960 et 1971, incluait une collaboration très diversifiée, tant de médiévistes consacrés (par exemple, T. de Sousa Soares, A. de J. da Costa, S. Dias Arnaut, V. Rau, Oliveira Marques) que de certains nouveaux chercheurs, beaucoup d'entre eux formés par l'Université de Lisbonne et qui iraient jouer un rôle important dans la période suivante ${ }^{33}$. L'influence du Dictionnaire sera décisive dans la formation des nouvelles générations d'universitaires portugais des cours d'histoire, au long des décennies 1970 et 80 ; son succès et ses successives réimpressions, dans un pays où le marché éditorial était très étroit, attestent bien l'impact que l'œuvre a eu et ses effets multiplicateurs, à terme, dans la modernisation de l'historiographie portugaise. Autre signe du processus d'ouverture en train de se dérouler, la réalisation des Premières Journées Luso-Espagnoles d'histoire médiévale, qui ont eu lieu à Lisbonne, en 1972, sur le sujet de la pauvreté et de l'assistance. La thématique choisie, les perspectives d'abordage, le nombre de participants avec des communications de qualité, et le projet d'établissement de contacts institutionnels avec les médiévistes d'Espagne rendaient bien compte de l'effort pour s'aligner sur les avances de l'historiographie internationale médiéviste".

Datent aussi de cette période certaines des plus importantes contributions de spécialistes d'autres secteurs de la connaissance pour élargir le contexte des études sur le Moyen Âge. C'est ce qui s'est produit avec les travaux d'António José Saraiva et de Luís Filipe Lindley Cintra, à l'égard de l'histoire de la littérature et de la culture, dans le premier cas".5 ou à l'égard de la philologie et de l'historiographie, dans l'autre ${ }^{2 h}$. De même, V. Magalhães Godinho, un moderniste qui enseignait dans des universités françaises, profondément lié aux conceptions des Annales, et qui, par sa vaste œuvre consacrée à l'expansion d'outre-mer portugaise ${ }^{77}$, ne cesserait d'influencer les médiévistes, surtout ceux qui se consacraient au bas Moyen Âge (en particulier dans le domaine économique). D'autre part, la tradition d'études sur le Moyen Âge des spécialistes du droit aurait un de ses plus importants représentants dans Marcello Caetano, avec un ensemble de travaux de référence sur la société et les institutions urbaines, sur les réunions de Cortes (les parlements médiévaux) ou sur l'histoire même du droit ${ }^{2 x}$.

Dans le début de la décennie 1970 se multipliaient les indications de changement et de régénération de l'historiographie, dans une large mesure illustrés par le Dictionnaire d'Histoire du Portugal. Quelque chose de semblable pourrait se dire, à cet égard, sur l'Histoire du Portugal, d'Oliveira Marques, dont le premier volume, qui incluait le temps médiéval, a été publié en 1972, en attei-

23. Dicionário de história de Portugal, dir. Joel SERRÃo. Lisbonne. Iniciativas editoriais, 1961/71, 4 vol.

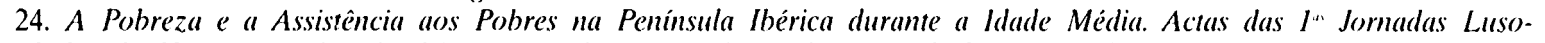
Espanholas de História Medieval. Lisbonne. Instituto de Alta Cultura. 1973. 2 vol. Cet important rassemblement scientifique avait eu pour précédent. également de grande dimension. celui réalisé en 1959 à Braga, qui avait compté avec la présence de nombreux chercheurs étrangers venus surtout d'Espagne : Actas do Congresso Histórico de Portugal Medievo. Braga. 1963. 1964 et 1965 (3 vol. : numéros spéciaux de la revue Bracara Augussia).

25. História da Cultura em Portugal. vol. I. Lisbonne, Jornal do Foro. 1950.

26. Crónica geral de Espanha de 1344. éd. Luis Filipe Lindley CinTRA. Lisbonne. INCM. 1983/90. 4 vol. (rééd. facsimilé des vol. I-III. Lisbonne. Academia portuguesa de história. 1952/61 (Fontes narrativas da história portuguesa, 2) : le premier volume est une longue introduction à l'édition qui inclut une véritable histoire de la production historiographique des XIII-XIV s. au Portugal]. Autre ceuvre essentielle $A$ linguagem dos foros de Castelo Rodrigo. Sell confronto com a dos foros de Alfaiates, Castelo Bom, Castelo Melhor, Coria. Cáceres e Usagre. Contribuição para o estudo do leonês e do galego-português do século XIII, Lisbonne. INCM, 1984 (Temas portugueses) [1" éd. 1959].

27. Lauteur a grandement participé au Dicionário de História de Portugal, outre ses Documentos sobre a Expansāo Portuguesa, Lisbonne. Edições Gleba et Cosmos, 1944/56, 3 vol. et son étude sur A Economia dos Descobrimentos Henriquinos, Lisbonne, Sá da Costa, 1962.

28. Voir ses études sur "As Cortes de 1.385". de 1951. sur "O Concelho de Lisboa na (rise de 1383-1385 ". de 1953 (toutes deux rééditées dans $A$ (rise Nacional de 1383-1385. Lisbonne. Verbo, 1985), sur $A$ administraçäo municipal de Lisboa durante a $I^{*}$ dinastia (1179-1383). Lisbonne. Livros Horizonte. 1990 (Cidade de Lisboa. 8) [1" éd. 1951]. sur As Cortes de Leiria de 12.54. Lisbonne. Academia Portuguesa da História. 19.54 [rééd. 20(04). ou bien sûr sa classique Ilistória do direito portuguès. Fontes - direito público (1140-1495), Lisbonne. Verbo. 1980 (publiée à titre posthume). 
gnant un énorme succès. surtout auprès du public universitaire et pré-universitaire, ce qui ferait du livre un vrai manuel alternatif aux livres officiels et obligatoires pour l'enseignement dans les lycées ${ }^{2 "}$.

\section{Les années 80 et 90}

Mais le panorama se modifiera décisivement seulement dans la seconde moitié des années 70 et principalement déjà dans la décennie 1980. Les changements politiques et sociaux advenus au Portugal à partir de 1974, avec le remplacement de la dictature salazariste par la République démocratique, ont indéniablement apporté, dans ce champ aussi, une rupture par rapport à la situation précédente. L'accès de larges secteurs de la jeunesse à l'enseignement universitaire et la vertigineuse augmentation de la fréquentation des cours d'histoire, la réforme des licences en 1978. la création de Diplômes d'études approfondies (mestrados) en histoire médiévale et surtout le nouveau climat de libre circulation d'idées venaient élargir les conditions pour le développement de la recherche et pour repenser le médiévisme portugais. Et, de fait, les décennies de 80 et 90 ont été, à cet égard. particulièrement riches, puisqu'on a assisté à un authentique boom dans la recherche et dans la publication d'études relatives au Moyen Âge"." Il importe, néanmoins, de noter que cette croissance - dont existent d'innombrables preuves, qui vont de la multiplication des thèses de DEA et de doctorat jusqu'à l'édition commerciale - fut de nombreuses fois marquée par le poids d'une tradition empirique, extrêmement enracinée dans l'historiographie portugaise médiévale. Il existait, sans aucun doute, des raisons objectives pour lesquelles cela arrivait: le retard hérité de la période précédente s'est manifesté dans les sujets et dans les perspectives d'abordage, mais il se révélait aussi dans la pénurie de collections de sources imprimées ou par le manque d'instruments pour la recherche en archives. D'ailleurs, ce serait seulement à partir des années 80 que viendrait à être entreprise la tâche de publication systématique d'ensembles documentaires aussi importants que les registres des chancelleries royales ou les comptes rendus de Cortes".

Dès la décennie 1970 et dans les suivantes se sont réactualisés quelques débats historiographiques qui révélaient de clairs ajournements conceptuels et qui sont arrivés à susciter de fortes passions. Cela a été le cas de la question de l'existence de la féodalité au Portugal. À son origine, il y avait la position fixée par A. Herculano, toujours commentée par ses partisans - notamment Gama Barros, P. Merêa et, plus récemment, M. Caetano - en niant l'existence du féodalisme dans le royaume portugais et, plus largement, dans la Péninsule ibérique. Oliveira Marques, dans son Histoire du Portugal, et, déjà avant, des auteurs de formation marxiste avaient pris la position

29. História de Portugal. vol. I. Lisbonne. Ágora. 1972 (le sous-titre est "Manuel à l'usage des étudiants et autres curieux de sujets du passé natjonal"). Cette cuvre en 3 vol. a été régulièrement rééditéc. atteignant maintenant une dizaine d'éditions.

30. Pour un bilan de la production historique médiévistique portugaise. voir. avec les nécessaires actualisations. A. H. de Oliveira Marot:s. Guia do estudante de história medieval portuguesa. Lisbonne. Editorial Estampa. 1988 [3" éd.] (Imprensa universitária.15): - José MATtoso. "Perspectivas actuais da investigação e da síntese na historiografia medieval portuguesa (1128-1383)". Revista de história económica e social, 9. 1982, p 145-62: - Luís Adão da FoNS1:C. "La Historiografia Medieval Portuguesa (1940-1984)". dans La Historiografia en Occidente desde 1945. III Conversaciones Internacionales de Historia. Pampelune. 1985. p. 51-67: - Armando L. Carvalho HoMEM et al. : "Por Onde Vem o Medievismo em Portugal ?". Revista de história económica e social, 22. 1988, p. 115-138: - Maria Helena da (ruz. (oril.Ho, "A História Medieval Portuguesa - Caminhos Percorridos e a Percorrer". Media Aetas. 1. 1991. p. 53-68: - Armando L. (arvalho Homs:n. "O Medievismo em Liberdade : Portugal. Anos 70 / Anos 90 ». Signum. Revista da Associação Brasileira de Estudos Medievais. 3. 2001. p. 173-207: - Luís Miguel DiAkTt. "Sociedade e Economia Medievais : Fraquezas e Forças da Historiografia Portuguesa ". Bollentino dell Istituto Storico Italiano per il Medio Evo 106/2. 20)4. p. 273-298: quoique pas consacré exclusivement au Moven Âge. voir aussi le Repertório Bibliográfico da Historiografia Portuguesa (1974-1994). Coimbra. Faculdade de Letras. 1995.

31. Celte tâche a été entreprise depuis 1982. par le Centro de Estudos Históricos de l'Université Nouvelle de Lisbonne. qui a publié les volumes relatifs aux règnes d'Afonso IV. Pedro I". Fernando I". João I". Duarte et Manuel I". On a vu quavaient été précédemment publiés les Documentos de D. Sancho I" en 1979. 


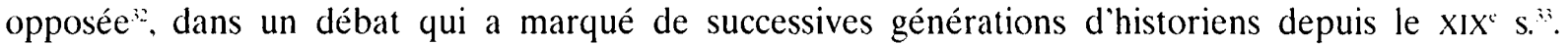
Aussi l'interprétation des événements de 1383-1385, advenus dans le cadre d'une importante crise dynastique et d'une forte conflictualité sociale et politique, a suscité une vive polémique, ravivée à la fin de la décennie 1970 et se prolongeant par la suite.

Confronté à la nécessité de couvrir des étapes qui auraient dû être franchies depuis longtemps voir ce qui a été dit sur le retard dans la publication de sources - et à l'urgence de procéder à l'étude de sujets et de thématiques nouveaux, le médiévisme portugais a cherché à combiner le nécessaire travail érudit avec la recherche monographique et, parfois, avec les premières tentatives de systématisation et de problématisation des données disponibles. Les travaux réalisés et la qualité que beaucoup revêtaient ont permis de significatifs progrès dans plusieurs secteurs de spécialisation. À cela contribuent aussi le renforcement des contacts avec l'historiographie européenne, surtout avec la française et avec celle d'Espagne (et, dans une moindre mesure, avec l'anglo-saxonne), et la conséquente mise à jour en termes bibliographiques, méthodologiques et de problématiques. Les résultats se sont fait sentir rapidement. avec la multiplication des études autour de l'histoire agraire, de l'histoire des villes. de l'histoire de la noblesse. de l'histoire politique, de l'histoire des mentalités...

Bien que les études d'histoire agricole aient eu des pionniers de grand poids dans le panorama historiographique portugais du milieu du siècle et de la décennie 1960 (ce sont surtout les cas déjà signalés de V. Rau et d'Oliveira Marques), c'est à partir de 1980 qu'on a assisté à un investissement continu pour connaître les réalités matérielles de l'économie agraire et les formes de production, la circulation de produits et l'administration agricole dans le Moyen Âge portugais. Dans ce secteur, les travaux de Robert Durand, Maria Helena Coelho et Iria Gonçalves sont venus donner une impulsion décisive à la recherche sur ces sujets, en inaugurant, de manière irréversible, une phase d'élaboration de monographies indispensables pour une connaissance approfondie du monde agricole ${ }^{35}$. L'attention aux différenciations régionales, parfois même micro-régionales, venait, une fois pour toutes, rendre évidente la nécessité d'établir des limites spatiales bien claires dans le traitement de ces matières. Malgré sa dimension relativement restreinte, le Portugal présentait des variations de contexte géographique, économique et culturel qui ne permettent pas de généralisations à l'échelle de ce qui est aujourd'hui l'espace national. Ainsi, et naturellement, la nouvelle historiographie agraire médiévale portugaise tendait à traiter ses sujets dans une perspective régionale ou même locale, en partant, souvent, des fonds documentaires d'une institution de référence, comme dans l'étude d'I. Gonçalves sur le patrimoine séculier du monastère d'Alcobaça, une des plus importantes abbayes portugaises. Mais si, pour les propriétaires ecclésiastiques, existent d'innombrables fonds documentaires, parfois avec une abondante documentation. l'analyse des domaines laïques particuliers se présente nettement plus difficile, en l'absence

32. Au premier rang de ccux-ci se trouve Armando CASTRO, dont l'(xuvre principale est $A$ Evolução Económica de Portugal dos Séculos XII a XV. Lisbonne. Portugália. 1964/70, 9 vol.

33. Une perspective critique de ce sujet est donnéc par Bernardo Vasconcelos e Sousa et Nuno Gonçalo Montriro). "Senhorio e Feudalismo em Portugal (Séculos XII-XIX). Reflexões sobre um Debate Historiográfico", dans Señorio y feudalismo en la Península lírica (Ss: XII-XIX), vol. I. Saragosse. Institución "Fernando el Católico». 1993. p. 175-192.

34. La question n'était pas nouvelle mais fut actualisée en fonction des lectures politiques qui lavaient ravivée: voir. entre autres. António Borges Cofl.HO. A Revolução de 1383. Tentativa de Caructerização. 5 éd. rev. et augm.. Lisbontle. Caminho. 1984 (1" éd. 1965), avec la bibliographic qui y est donnée.

35. Robert D(Rand). Les campagnes portugaises entre Doturo et Tage aux xIr et xIII siècles. Paris. Fundação Calouste Gulbenkian / Centro cultural português, 1982 (Civilização portuguesa. IX) : - Maria Helena da Cruz Cokl.ho. O baixo Mondego nos finais da Idade Média. 2 éd. Lisbonne. INCM. 1989. 2 vol. (Estudos gerais. Série universitária) et Iria Goveçalves. O património do mosteiro de Alcobaça nos séculos XIV e XV. Lisbonne. Universidade Nova de Lisboa. 1989. Voir les travaux postérieurs de Maria Rosa Ferreira MARri:Iros. Propriedade fundiaria e rendas da coroa no reinado de D. Dinis : Guimaräes. Coimbra. Faculdade de Letras. 1990. 2 vol. [polycop.]. de Pedro (iomes Barbosa. Poncoumento e estrutura agricola na Estremadura central. Séc. XII a 1.325. Lisbonne. INIC: 1992 (História medieval. 6) et de Luis ('arlos AMAral. Sä́o Salvador de Grijó na segunda metade do séc. XIV (Estudo de gestäo agrária). Lisbonne. Cosmos. 1994 [éd. de sa thèse de mestrado de 1987]. Les développements récents des études rurales sont décrits par Maria Helena da (ruz Coflno. "Balanço sobre a história rural produzida em Portugal nas últimas décadas". dans A cidade e o campo. Colectânea de estudos. Coimbra, 2001, p 23-40. 
presque complète de documentation jusqu'au XIV ${ }^{c}$ s. Ceci même rend difficile ou. à la limite. impraticable l'application directe de "grilles" d'enquêtes pré-établies en fonction de certains types de sources relativement courantes outre-Pyrénées. Si. dans un premier stade. la zone géographique d'incidence des études sur le monde agricole se plaçait. fondamentalement. au nord du fleuve Tage, avec d'insuffisantes incursions en Alentejo. le sud du pays viendrait à susciter une croissante attention pour dépasser l'ignorance et le silence qui pendant des décennies avaient prévalu quant à ces régions de présence musulmane plus prolongée et marquante: les études élaborées dans la décennie 1990. de pair avec les éléments entre-temps révélés par l'archéologic, ont contribué à d'importants renouvellements tant pour le monde agricole que pour l'urbain, augurant de résultats stimulants pour le début du $\mathrm{XXI}^{\mathrm{e}} \mathrm{s}$. ${ }^{\text {h. }}$. À cet égard, mérite une mention spéciale le travail développé au long de plus de vingt ans par le Campo Arqueológico de Mértola, sous la direction de Claudio Torres.

Lhistoire urbaine a connu également un franc développement, par l'initiative d'Oliveira Marques, qui a établi et mis en pratique un ambitieux plan global de recherche sur les villes médiévales portugaises, en proposant un programme exhaustif pour la connaissance des réalités urbaines ${ }^{37}$, en même temps qu'il créait à l'Université Nouvelle de Lisbonne, en 1981. un séminaire sur les villes médiévales dans lc contextc duquel scraicnt ćlaborées plusicurs monographies de noyaux urbains. Les résultats d'un premier ensemble de travaux dans ce secteur ont été compilés dans l'Atlas des villes médiévales portugaises ${ }^{3 x}$. Fruit de cet intérêt. ont été produites plus de trois dizaines de thèses sur des villes (ou sur certains aspects partiels de celles-ci), avec une particulière incidence de la période du bas Moyen Âge:". Dans une perspective de synthèse, des aspects aussi importants que le paysage urbain ont été traités avec plus grande attention ${ }^{\text {th}}$. Mais, bien que le monde urbain ait attiré un grand nombre de chercheurs, il existe encore aujourd'hui d'importantes lacunes à remplir, en soulignant notamment l'absence de monographies complètes sur Lisbonne et Porto. D'autre part, au lieu de souligner l'opposition entre la ville et la campagne, la problématique des relations entre ces deux "mondes" a commencé à guider beaucoup des travaux produits ${ }^{11}$.

36. Bernardo Vasconcelos e SousA. A propriedade das albergarias de Évora nos finais da Idade Média. Lisbonne, INIC: 1990) (História medieval. 2): - Stéphane Bolssfld.ter. Naissance d'une identité portugaise. La vie rurale entre Tage at Guadiana (Portugal) de l'Islam à la Reconquête $\left(\lambda^{r}-x W\right.$ siécles). Lisbonne. Imprensa Nacional - Casa da Moeda, 1998 (Estudos gerais. Serie universitária): - Christophe PICARD, Le Portugal musulman (vilr-xilr siècle). L'Occident dal-Andalus sous domination islamique. Paris. Maisonneuve el Larose. 2000): - Hermenegildo Fervandes, Entre Mouros e Cristäos. A Sociedade de Fronteira no Sudoeste Peninsular Interior (Séculos XII-XIII). Lisbonne. Faculdade de Letras, 20)(0) [thèse doctor. polycop.]. Parmi les contributions archéologiques, voir Santiago Macias. Mértola Islâmica. Estudo HistóricoArameológico do Bairro da Alcáçova (Séculos XII-XIII). Mértola. Campo arqueológico de Mértola, 1996: - Helena Catarino, O Algarve oriental durante a ocupação islâmica. Povoamento rural e recintos fortificados (n spécial Al-'Ulya. Revista do Arquivo municipal de Loule n 6). Loulé. 1997/98. 3 vol. et Rosa Varela Gomss. Silves (Xelb). Uma Cidade do Gharb Al-Andalus - Arqueologia e História (Séculos VIII-XIII). Lisbonne. Universidade Nova. 1999 (thèse doctor. polycop.].

37. A. H. de Oliveira MARolts. "Introdução à história da cidade medieval portuguesa " el "Cidades medievais portuguesas (Introduçâo metodológica ao seu estudo)". dans ID.. Novos ensaios de história medieval portuguesa, Lisbonne. Editorial Presença. 1988 (Biblioteca de textos universitários. 95). p 13-42 et 43-67 (publiés originellement en 1981 et 1982).

38. A. H. de Oliveira MARotis et al. Atlas de cidades medievais portuguesas tséculos XII-XV). Vol. I. Lisbonne. INIC: 1990), qui inclut les fiches de dix-neuf villes avec les plans respectifs.

39. Voir. à titre dexemple. Maria Ângela Rocha Bl:IRA.'Tl: Evora na Idade Média. Lisbonne. Fundação Calouste Gulbenkian / JNICT. 1995 [thèse doctor. présentée en 1988]: pour une vision complète des thèses de mestrado produites durant cette période. de thématique urbaine ou autre. voir "M.A. Programs and Dissertations in Medieval History at Portuguese Universities". E-journal of Portuguese History. 1. Summer 2003 (www.brown.edu/Departments/Portuguese_ Brazilian_Studies/cjph).

40. C"est surtout le cas de Iria GoN(AINis dans des articles réunis dans Lim olhar sobre a cidade medieval. (ascais. Patrimonia. 1996 (Estudos) et de Amélia Aguiar ANDRAd). Horizontes urbanos medievais. Lisbonne. Livros Horizonte. 2003 (rassemblant des études des années 80 et 90).

41. ("est le cas notamment de Ana Maria Seabra de Almeida RoldrIcit tis. Torres Vedras. A vila e o termo nos finais da Idude Média. Lishonne. Fundação Calouste Gulbenkian/Junta Nacional de Investigação Centífica e Tecnológica, 1995 et des contributions déjà citées d.I. Cionçalves. 
Un autre sujet où s'est vérifié un progrès considérable a été celui de la noblesse, domaine dans lequel l'historiographie portugaise, d'abord influencée par G. Duby et par les recherches allemandes, a acquis une place de premier rang en Europe. La richesse des sources généalogiques médiévales portugaises (les nobiliários ou 《livres de lignages $\gg^{+2}$ ) et leur singularité dans le panorama de la littérature congénère européenne offrent des possibilités de recherche de grande portée. Les études de José Mattoso, initiées dans les décennies 1960 et 70 , ont contribué de façon décisive à un virage. du point de vue méthodologique et conceptuel, en passant d'une pratique étroitement généalogique (il existe, au Portugal, une immense tradition) à un traitement de contextualisation plus générale, concernant l'histoire sociale et l'histoire des mentalités. En portant fondamentalement sur les siècles XI à XIII, cet auteur reprend, maintenant sur de nouvelles bases, la vieille question des origines de la monarchie portugaise et de l'émergence, de l'établissement et de la consolidation du royaume du Portugal comme entité politique indépendante, à l'extrémité occidentale de la Péninsule ibérique. En soulignant le rôle des infanções, cette strate intermédiaire de la noblesse, Mattoso a développé une reinterprétation générale de l'histoire médiévale portugaise. L'appréhension innovatrice du règne d'Alphonse Henri (1139-1185), premier monarque portugais, l'analyse de la structure de la parenté au sein de la noblesse portugaise, et le lien entre les faits de l'histoire politique et les données de l'histoire de la famille ont ouvert de nouvelles voies de recherche et d'analyse $e^{4}$. Dans une œuvre qui a eu un impact décisif parmi les médiévistes portugais. l'auteur appelait à porter l'attention aux contributions de la géographie physique et humaine, de la linguistique et de l'anthropologie, en proposant une interprétation des origines du Portugal fondée sur la complémentarité de deux grands secteurs historico-culturels : le "pays seigneurial " (grosso modo l'Entre Douro et Minho, dans le nord-ouest du Portugal, avec des prolongements dans le nord intérieur) et le "pays municipal» (correspondant sensiblement au centre et, surtout. au sud du Portugal $)^{\text {t4 }}$.

Pour les siècles XII à XIV, les travaux sur la noblesse se sont multipliés, dans une large mesure sous l'orientation de Mattoso $\mathrm{o}^{45}$. Pour le $\mathrm{XV}^{\mathrm{c}} \mathrm{s}$., la recherche pilote a été réalisée par Humberto Baquero Moreno, à partir de l'étude de la conjoncture politique de la bataille d'Alfarrobeira (1449), considérée comme un moment crucial pour la noblesse portugaise de l'époque ${ }^{\text {th }}$. Dans cette même ligne peut être considéré le travail d'Adão da Fonseca sur un membre de la famille royale portugaise qui, en 1463 , est parvenu à s'intituler comte de Barcelone et roi d'Aragon ${ }^{+7}$.

42. Livros velhos de linhagens, éd. Joseph PII: et José Matroso et Livro de linhagens do Conde D. Pedro, éd. José Mattoso, Lisbonne. Academia das Ciências de Lisboa, 1980. 3 vol. (Portugaliae Monumenta Historica. n.s.. I et II).

43. José Matroso, Obras Completas, 5 - Ricos Homens, Infanções e Cavaleiros, Lisbonne. Círculo de Leitores, 2001: l’édition originale, de 1982, portait comme sous-titre A Nobreza Medieval Portuguesa nos Séculos XI e' XII. Dans une perspective différente, voir Armando de Almeida Fernandes. A Nobreza na Época Vimarano-Portucalense. 1 : Problemata. Revista de Guimarães, 1981.

44. ID.. Obras Completas. 2 - Identificação de um País. Oposição. et 3 - Identificação de um País. Composição. Lisbonne. Círculo de Leitores, 2001. Lédition originale. de 1985, portait le sous-titre Ensaio sobre as Origens de Portugal. 1096-1325. Les différenciations régionales sont traitées surtout dans te premier volume.

45. À titre d'exemple voir Luis Filipe Llach Krl:s. A concepçāo nobiliárquica do espaço ibérico (1280-1380), Lisbonne. Fundação Calouste Gulbenkian / JNICT. 1994 (Textos universitários de ciências sociais e humanas) : - Leontina VENTLRA. A Nobreza de Corte de Afonso III. Coimbra. Faculdade de Letras. 1992, 2 vol. [thèse doctor. polycop.]: - António Resende de Ol.ivisar. Depois do Espectáculo Trovadoresco. A Estrutura dos Cancioneiros Peninsulares e as Recolhas dos Séculos XIII e XIV. Lisbonne. Colibri, 1994: - Maria de Lurdes Rosa, O morgadio em Portugal, séculos XIV-XV. Modelos e práticas de comportamento linhagistico, Lisbonne. Editorial Estampa, 1995: - Luís Filipe OLIVFIRA. A Casa dos Coutinhos. Linhagem. Espaço e Poder (1360)-1452). Cascais. Patrimonia. 1999: - José Augusto PIzarro. Linhagens medievais portuguesas. Genealogias e estratégias (1279-1.325). Porto. Universidade moderna/Centro de estudos de genealogia. heráldica. 1999. 3 vol.: - Bernardo Vasconcelos e Sousa. Os Pimentéis. Percursos de uma linhagem da nobreza medieval portuguesa (séculos XIII-XIV). Lisbonne. INCM. 2000) (Temas portugueses): pour un bilan plus complet, renvoyons à José Matroso. "Perspectivas Actuais sobre a Nobreza Medieval Portuguesa ". dans Obras Completas. 1 - Nanquele Tempo. Ensaios de Historia Medievai, Lisbonne. Cúrculo de Leitores, 2000, p. 341-362.

46. A Batalha de Alfarrobeira. Antecedentes e Significado Historico. Coimbra. Universidade de (oimbra. 1979/80). 2 vol. |la 1:" éd. date de 1973].

47. O Condestavel D. Pedro de Portugal, Porto, INIC, 1982 (1"version de 1975). 
Dans les deux cas. quoique les premières versions des études remontent au début des années 70 , leur influence s'est fait sentir seulement dans les années 80 et 90 . Plus récemment sont parus des travaux qui analysent la période de la fin du Moyen Âge et du début des Temps Modernes ${ }^{4 \times}$. ainsi qu'un vaste ensemble d'études sur des Ordres militaires"

D'ailleurs, la liste de sujets, d'auteurs et d'œuvres publiées dans les vingt dernières annnées du $\mathrm{XX}^{\mathrm{c}}$ s. pourrait être allongée avec facilité, en incluant le commerce extérieur, les relations diplomatiques et les débuts de l'expansion maritime en $^{51}$ l'administration et la cour royale ${ }^{\text {sl }}$, l'Église et le clergé $^{52}$. les Cortes $^{53}$, la guerre et l'histoire militaire ${ }^{54}$, des aspects concrets de l'histoire des

48. Voir. entre autres. João Silva de Solsa. A casa senhorial do Infante D. Henrique. Lisbonne. Livros Horizonte. 1991 (Horizonte histórico, 35) et Mafalda Soares da Civis Linhagem, parentesco e poder. A Casa de Bragança (I.3841483). Lisbonne. Fundação da Casa de Bragança. 1990) : un bilan de ces études se trouve dans João Silva de Souss, "A Casa senhorial em Portugal na Idade Média". Revista portuguesa de história. 36/1 (Homenagem aos Professores Luis Mamuel Ferrand de AL.MEIDA e Aniónio de OI.IVtiRA). Coimbra. 2002/033. p. 267-284.

49. Depuis 1997, annuellement. la Fundação Eng. Eugénio de Almeida. de Porto. publie les Militarium Ordinum Analecta. sous la direction de Luís Adão da Fonseca. où sont réunis les résultats des recherches (sous forme de thèses) sur les Ordres au Portugal; six volumes sont parus à ce jour. De même. la Câmara Municipal de Palmela réalise depuis 1989. tous les quatre ans. une série d’importants Encontros Internacionais sobre Ordens Militares, dont les actes sont publiés. Une vision complète de la production historique sur ce thème est donnée par Paula Pinto Costa. "The Military Orders Established in Portugal in the Middle Ages : A Historiographical Overview ", E-journal of Portuguese History, 2 , Summer 2004, à ladresse électronique citée précédemment.

50. Par ex. Ana Maria Pereira Ferreira. A Importação e o Comércio Têxtil em Portugal no Século XV (1.385-1481), Lisbonne. Imprensa Nacional/Casa da Moeda, 1983 (1 version du début des années 70) et Filipe Themudo BarATA, Navegação, comércio e relaçōes políticas : os Portugueses no Mediterrâneo ocidental (1385-1466), Lisbonne. FCG/JNICT, 1998 (Textos universitários de ciências sociais e humanas) : pour les débuts médiévaux de l'expansion maritime, voir Luís Adão da Fonsi:ca. Os Descobrimentos e a Formação do Oceano Atlântico. Século XIV - Século XVI, Lisbonne, Comissão Nacional para as Comemorações dos Descobrimentos Portugueses, 1999. et la bibliographie citce là.

51. Outre la thèse de Leontina VenturA. citée supra, voir surtout Armando L. Carvalho Homem, O Desembargo Régio (1.320-1433). Porto. INIC. 1990 et ses travaux réunis dans Portugal nos Finnais da Idade Média: Estado, Instituições, Sociedade Politica. Lisbonne. Livros Horizonte, 1990), ainsi que Rita Costa Gomes, A corte dos reis de Portugal no final da Idade Média. Lisbonne. Difel. i995 (Memória e sociedade). Plus récemment la thèse doctorale polycopiée de Maria João Branco. Poder Real e Eclesiásticos. A Evolução do Conceito de Soberania Régia e a sua Relação com a "Praxis" Politica de Sancho I e Afonso II. Lisbonne, Universidade Aberta. 1999.

52. Signalons. dans une production en plein essor. José Marouls. A arquidiocese de Braga no século $X V$. Lisbonne. INCM. 1988 (Temas portugueses): - Maria Teresa N. Vizoso, D. Afonso II - Relaçöes de Portugal com a Santa Sé durante o seu Reinado. Coimbra. Faculdade de Letras. 1988. 2 vol. [thèse doctor. polycop.]: - Maria Alegria F. MAROUES. O Papado e Portugal no Tempo de D. Afonso III (1245-1279). Coimbra. Faculdade de Letras, 1990) 2 vol. [thèse doctor. polycop.]: - Saul António Gomes. O Mosteiro de Santa Maria da Vitória no Século XV. Coimbra. Faculdade de Letras. 1990): - Margarida Garcez. Ventura. Igreja e poder no século XV. Dinastia de Avis e liberdades eclesiásticas (1383-1450). Lisbonne. Colibri. 1997 (Colibri história): - Hermínia Vasconcelos VILAR. As dimensóes de um poder. A diocese de Évora na lade Média. Lisbonne. Editorial Estampa. 1999 (Histórias de Portugal, 44): - Alcina Manuela Oliveira MARTINS, $O$ Mosteiro de S. Salvador de Vairão na Idade Média : O Percurso de uma Comunidade Feminina. Porto. Universidade Portucalense. 2001: - Armando Alberto Martins. O mosteiro de Santa Cruz de Coimbra na Idade Média. Lisbonne. Centro de história da Univ. de Lisboa, 20113 (Textos universitários. 2) [thèse soutenue en 1996]: - Luís Miguel RFPAS. Quando a Nobreza traja de branco. A comunidade cisterciense de Arouca durante o abadessado de D. Luca Rodrigues (1286-1299). Leiria. Edições Magno. 2003: - Anísio Miguel de Sousa SARAlva. A Sé de Lamego na primeira metade do século XIV (1296-1349). Leiria. Ediçóes Magno. 2003: un récapitulatif complet et critique de ces travaux dans Hermínia VII.AR. "História da igreja medieval em Portugal : um percurso possível pelas provas académicas (1995-200(0)". Lusitania Sacra. 2 s. ("A historiografia religiosa medieval hoje : temas e problemas"). 13-14. 2001/(022. p 569-581. En 2000), dans le cadre du Centro de Estudos de História Religiosa de l'Université Catholique Portugaise. a été publiéc une ceuvre de synthèse

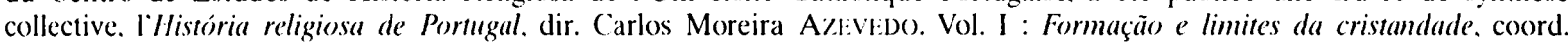
Ana Maria S. A. Rodricitis et. al.. Lisbonne, Círculo de leitores, 2000, et le même Centre a lancé le Dicionário de historria religiosa de Portugal, dir. Carlos Moreira A\%: V: vi:DO, Lisbonne. Círculo de Leitores. 2000), 4 vol.

53. Nombreux travaux ponctuels dispersés dans des revues et actes de colloques: comme travail de fond. voir la thèse du regretté Armindo de Solss. As Cortes medievais portuguesas (1385-1490). Porto. INIC. 1990), 2 vol. (História medieval. 4).

54. João Gouveia Monitraro. A Guerra em Portugal nos Finais da Idade Média. Lisbonne. Editorial Notícias, 1998 et Os castelos pormugueses dos finais da Idade Média. Presença, perfil, conservaçäo, vigilância e comamdo, Lisbonne. Colibri/Faculdade de Letras de Coimbra. 1999. Au niveau de la synthèse. voir la Nova história militar de Portugal. dir. Manuel Themudo Barsta et Nuno Severiano Teixi:IRA. Lisbonne. Círculo de Leitores. 2003, dont le premier volume inclut lc Moven Âge. 
mentalités ${ }^{i \vdots}$. les minorités ethnico-religieuses maures et juives ${ }^{i \hbar}$. la paléographie et la diplomatique $^{57}$. l'épigraphie ${ }^{3 x} .$. Plus que des chiffres, ce que cette réalité reflète est un moment unique dans l'histoire des études sur le Moyen Âge au Portugal. La recherche spécialisée, avec une solide base documentaire et une rigueur érudite. la multiplication de thèses de mestrado et de doctorat comme jamais auparavant, la réflexion judicieuse sur les données disponibles, la mise au jour de problématiques historiographiques, tout a concouru pour un indéniable essor de renouvellements. La quantité et la qualité de colloques et de congrès réalisés. le bourgeonnement de nouvelles revues scientifiques, les progrès, même lents, dans l'accès aux archives ${ }^{\text {s" }}$, l'augmentation de sommes pour la recherche, nombreux sont les indicateurs qui pourront être ajoutés pour illustrer cette conjoncture favorable que l'historiographie portugaise a vécue. Comme le virage "post-moderne" n'a pas eu un grand impact au Portugal, au moins en ce qui concerne le Moyen Âge, un effort de systématisation et de synthèse sans parallèle dans les décennies précédentes a correspondu aux avancées heuristiques obtenues. Ce n'a pas été par hasard que sont parues récemment plusieurs Histoires du Portugal, avec le Moyen Âge occupant une place prééminente dans l'économie générale des œuvres. Deux des plus importantes sont même dirigées par des médiévistes (Oliveira Marques et J. Mattoso). en devenant des livres de référence incontournables dans le panorama historiographique et éditorial du pays ${ }^{\text {ht. }}$.

55. À titre d'exemple. Luís Miguel Ribeiro de Oliveira DuARTr. Justiça e criminalidade no Portugal médievo (1459-1481). Lisbonne. FCCG/FCT. 1999 (Textos universitários de ciências sociais e humanas). ou les essais de Luís KrLs. Passado. memória e poder na sociedade medieval portuguesa. Estudos. Redondo. Patrimonia. 1994 (Patrimonia histórica). ou encore Armando de Sousa Pl:kl:IRA. Representações da guerra no Portugal da Reconquista (séculos XI-XIII). Lisbonne. Comissão Portuguesal de História Militar, 2(k)3. Curieusement les attitudes par rapport au sacré. dont l'étude a été renouvelée par l'anthropologic historique dans de nombreux pavs. sont un domaine encore presque vierge au Portugal (à l'exception de José MArToso). dir. O reino dos mortos na Idade Média peninstular. Lisbonne. Sá da Costa. 1996): saluons la thèse doctorale pionnière. toute récente et encore inédite. de Maria de Lurdes RosA. "As almas herdeiras". Fundação de capelas fímebres e afirmaçäo da alma como sujeito de direito (Portugal 140()-1.52I). Paris/Lisbonne. EHESS/Universidade Nova de Lisboa. 200$) 5$.

56. Maria José Ferro Tavares fut la principale instigatrice des études sur ces minorités ethnico-religieuses aux XIV"$X V^{*}$ s. : voir surtout ses "Judeus e mouros no Portugal dos séculos XIV e XV (Tentativa de estudo comparativo) ". Revista de história económica e social. 9. 1982, p 75-89 et Os judeus em Portugal no sécule $X V$. Lisbonne. Universidade Nova de Lisboa. 1982: - Maria Filomena Lopes de BArros. A comuna muçulmana de Lisbóa. Sécs. XIV e XV. Lisbonne. Hugin. 1998 (Biblioteca de estudos árabes. 4) [sa thèse doctorale. Temposs é espaçes de mouros. A minoria muçulmana em Portugal. Évora. 2004. est encore inédite).

57. Maria José de Azevedo SANros. Da visigólica à carolina. A escrita ém Portugal de 882 a 1172 (Aspectos técnicos e culturais). Lisbonne. FCG/JNIC'I. 1994 et Ler e Compreender a Escrita na Idade Média. Coimbra. Colibri. 2000): António Joaquim Ribeiro Gitrirra. Os Diplomas Privados em Portugal dos Séculos IX a XII. Gestos e Atitudes de Rotina dos seus Autores Materiais. Lisbonne. Centro de História da Universidade de Lisboa. 20033: - Bernardo SA-Nogiti:IRA. Tabelionado e Instrumento Público em Portugal. Génese e Implantação (1212-1279). Lisbonne. Faculdade de Letras. 1996. 3 vol. [thèse doctor. polycop.]: - Saul António GoMes. In Limine Conscriptionis. Documentos, Chancelaria e Cultura no Mosteiro de Santa Cruz de Coimbra. Séculos XII a XIV. Coimbra. Faculdade de Letras. 2000), 2 vol. fthèse doctor. polycop.] : - Maria Cristina Almeida e Ctivin. A Chancelaria Arquiepiscopal de Braga, 1071-1244. La Corogne. Toxosoutos. 2005: - Maria Helena da (ruz (o):Lio) et al. Estudos de diplomática portuguesa. Lisbonne. Colibri/Fac. de Letras da Univ. de Coimbra, 2001 (Estudos, 37).

58. Mário Jorge BARroca. Epigrafia medieval portuguesa (862-1422). Lisbonne. F(G/F(T, 2000), 4 vol.

59. En 1998 commença finalement à être publié le Guia Geral dos Fundos da Torre do Tombo. Primeira Parte Instituiçòes de Antigo Regime. Lisbonne. Instituto dos Arquivos Nacionais/Torre do Tombo (3 vol. parus entre 1998 et 20)(0). la publication continuant actuellement).

60. Dès 1977 parut le premier volume, relatif au Moven Âge. de l'Histíria de Portugal de l'historien moderniste Joaquim Veríssimo Strrão. Lisbonne. Verbo: en 1983 fut lancée l'História de Portugal dirigée par José Hermano SARAIVA. Lisbonne. Alfa, avec les volumes 2 et 3 consacrés au Moyen Âge. comptant des collaborateurs variés. comme J. MATT(OSO) ou A. CAStro: en 1987 commmença la publication de la Nova História de Portugal. dirigée par Joel Serrào et A. H. de Oliveira Maroles. Lisbonne. Presença, avec la sortie du volume IV : Portugal na Crise dos Séculos XIV e XV. précisément de la plume d'Oliveira Marolts puis en 1993 du volume II : Das Invasóes Germanicas à "Reconquista" coordonné par Oliveira MAroliss et en 1996 du volume III : Portugal em Definiçấo de Fronteiras. Do Condado Portu-

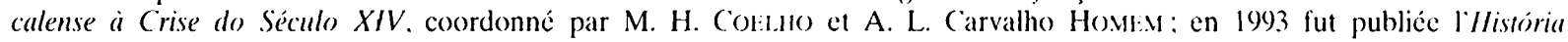
de Portugal dirigée par João Mrisisi. dont le volume IIl est relatif à l’époque médiévale. Amadora. Ediclube: en 1992 commença la publication de l'História de Portugal dirigée por J. Matroso. dont les volumes I : Antes de Portugal et II : A Monarquia Fetudal (1096-1480). coordonnés el largement écrits par J. MATroso (1992 et 1993). traitent du Moven Âge. Dans un pays de dix millions d'habitants. cette dernière ceuvre a obtenu un succes immense. avec plus de cent mille exemplaires vendus. 


\section{Bilan et perspectives}

Sur le plan heuristique, la recherche médiévistique portugaise récente s’est dotée (enfin) d'instruments adéquats (publication, sans équivalents ailleurs, des sources épigraphiques et de certains corpus spécifiques ${ }^{n}$, multiplication de guides de recherche ${ }^{62}$. effort sans précédent d'édition des sources littéraires latines ${ }^{(i)}$ ), poursuivant et rajeunissant (en intégrant la dimension de la literacy) la tradition érudite qui avait doté le Portugal d'une édition intégrale de ses plus anciennes chartes: mais certaines lacunes étonnantes entravent encore le travail (absence de véritables dictionnaires du galégo-portugais et du latin médiéval «portugais", retard considérable dans l'édition des diplômes pontificaux relatifs au pays, inexistence - après la disparition de l'éphémère Estudos medievais de Porto - d'une revue d'histoire médiévale), sans parler des insuffisances de la diffusion éditoriale des études, qui limitent dramatiquement la connaissance de l'historiographie portugaise à l'étranger. Par ailleurs, sans opposer les spécialités, le prestige dont jouit l'histoire des formes (littéraires et artistiques), dans un pays à forte tradition d'humanités comme le Portugal, restreint quelque peu le vivier des recherches sur les dimensions "sociales" (au sens le plus large) du monde médiéval : l'engouement des jeunes générations s'explique par le fait que l'anthropologie historique, au Portugal, a bien plus renouvelé l'histoire de la littérature et de l'art que l'histoire sociale.

Sur le plan épistémologique, se pose d'abord le problème de la répartition chronologique des recherches (outre leur répartition régionale, déjà évoquée) : comme un État portugais spécifique ne naît que vers 1140 (ou, au plus tôt, vers 1096), tout le haut Moyen Âge "léonais " (ou, comme partout en Ibérie, andalou) est considéré comme de l'histoire étrangère, et suscite peu de vocations ; la disparition, avec la chute du salazarisme, des conceptions nationalistes des origines du Portugal n'a pas beaucoup changé les orientations historiographiques à cet égard. Tout le débat sur la féodalité portugaise a été largement faussé, avant J. Mattoso, par l'insuffisance des recherches sur les $\mathrm{X}^{\mathrm{C}}-\mathrm{XI}^{\mathrm{c}}$ siècles ${ }^{h \mathrm{~h}}$. Un autre problème est le "complexe d'infériorité " par rapport à l'Espagne : longtemps source d'ignorance des renouvellements historiographiques espagnols, cette attitude conduit maintenant à adopter, parfois sans critique suffisante, comme des "modèles ", les questionnements élaborés dans le pays voisin. Si l'histoire sociale des élites (au-delà de la noblesse) est actuellement renouvelée par la méthode prosopographique (sur les élites administratives et cléricales, dans des domaines animés par A. L. de Carvalho Homem ou Ana Maria Rodrigues) ${ }^{h 5}$, certains secteurs pionniers de la modernisation des études médiévales portugaises, comme l'histoire économique, imprégnée de conceptions d'économie politique (transposées sans nuances à l'histoire médiévale par l'école des Annales), peinent à diversifier leurs approches - et c'est encore plus sensible pour l'histoire des techniques, qui est bloquée dans son essor par les impasses conceptuelles de l'ethnographie des années 1950/70. En revanche, l'histoire du politique, débarrassée des approches juridico-institutionnelles, a produit des æuvres majeures : de même, les études

61. ("est le cas des suppliques adressées aux pontifes depuis le territoire portugais (Montmenta Portugaliae Vaticana. Suiplicas dos pontificados... Documentos publicados com introdução e notas. éd. António Domingues de Sousa Costa. of.m., Braga/Porto [/Rome]. Editorial franciscana.. 1968/82. 5 vol.) ou des plus anciennes chartes notariées portugaises (Portu-

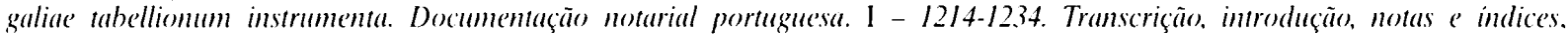
éd. Bernardo de Sá Nogiterta. Lishonne. Centro de história da Univ. de Lisboa. 2005 (Fontes para a história de Portugal. 1).

62. Ainsi. le très récent " Guide historique des Ordres religieux au Portugal " (Ordens religiosas c'm Portugal das origens a Trento. Gilia Histórico. dir. B. Vasconcelos e SolSA. Lisbonne. Livros Horizonte. 20(15) ou l'Atlas Histórico de Portugal e do Liltramar Portughếs. dir. A. H. de Oliveira Marotits et João José Alves Dias. Lishonne. Centro de Fstudos Históricos. 2003.

63. Cet effort se déploie. sous l'impulsion d’Aires Nascimento. dans la collection Obras clássicas da literatura portuguesa. Literatura medieval. publice par Colibri.

64. Des effets de mode et de svstème. comme l"énorme machine de la célébration du cinquième centenaire des "Découvertes" (contournement de lä́frique. découverte du Brésil el conquêle de l'Inde). ont renforcé depuis 1987 (et surtout 1997) la focalisation sur le xis.

65. In exemple avec le volume Elites e redes clientelares na Idade Media. Problemas metodológicos. Actas do colíquios. éd. Filipe Themudo BNRATA. Lisbonne. Colibri/(IDEHUS. 2001 (Biblioteca - Estudos e colóquios. 2). 
de la dimension spatiale des phénomènes sociaux, qui transforment efficacement les approches élaborées ailleurs (la Siedlungsgeschichte, l'incastellamento, les concepts géographiques ${ }^{\text {tho }}$ ) pour les appliquer à l'univers documentaire portugais (par exemple, au manque de sources administratives) $)^{h}$.

Mais le bilan très positif des années 80 et 90 ne doit pas obscurcir les difficultés et même les signes de crise qui, déjà à cette occasion, ont commencé à poindre. Le renouvellement du corps enseignant universitaire et des chercheurs qui a eu lieu à partir des années 80 a patiné sous les effets conjugués de la crise budgétaire, qui empêche les universités d'enrôler de nouveaux éléments pour rajeunir leur corps enseignant et de la quasi inexistence de centres de recherche vraiment indépendants des universités (type CNRS français). Aussi l'idée d'une "crise des sciences humaines " a commencé à faire son chemin au Portugal, idée en règle générale assimilée à l'étroitesse des débouchés professionnels, comme si le chômage de jeunes licenciés ne touchait pas à égalité les humanités et les sciences "pures", l'histoire et les mathématiques, la philosophie et l'ingénierie... D'autre part, à cause de ses exigences techniques et de spécialisation (la paléographie, le latin. la «sensibilité » pour la critique de la documentation...), l'intérêt pour le Moyen Âge a crû moins fortement, ces dernières années, que celui, par exemple, pour l'époque contemporaine, principalement pour le $\mathrm{XX}^{\mathrm{c}}$ s. Il est vrai que, dans une perspective réaliste mais non conformiste, ce panorama ne connaîtra pas de grandes modifications dans un futur proche, pour le moins dans un sens positif. Ce qui augmente la responsabilité de ceux qui se consacrent à l'étude du Moyen Âge, afin que puissent être lancés de nouveaux projets de recherche et que soient colmatées les lacunes qui continuent à subsister. La question de la coopération internationale, à travers la circulation de chercheurs et l'établissement de liens de collaboration institutionnels entre des universités et des centres de recherche, constitue un défi essentiel pour la nouvelle génération de médiévistes portugais.

Après quelque euphorie, le temps est maintenant à l'appréhension, surtout parce que la situation n'est pas facile pour ceux qui se trouvent au début de leur parcours académique et de recherche. Mais les travaux qui continuent à être développés ${ }^{\prime s}$, une claire institutionnalisation des études médiévales et leur reconnaissance sociale empêchent que le défaitisme ne s’abatte sur les médiévistes portugais. Si nous n'en sommes plus maintenant au point de départ (comme, d'une certaine façon, c'était le cas au milieu de la décennie 1970), nous sommes loin d'être arrivés à la fin d'un voyage qui déjà est bien long... Disons que le médiévisme portugais se trouve devant un carrefour, sinon "au milieu du gué ». Les prochains temps seront décisifs pour percevoir où le chemin le mènera.

66. On connaît linfluence déterminante du géographe $O$. Ribeiro sur les médiévistes portugais.

67. Voir Amélia Aguiar ANDRAD1:. Vilas, poder régio e fronteira : o exemplo do Entre L.ima e Minho medieval, Lisbonnc. Universidade Nova, 1994 [dissert. Doctor. polycop.] et les articles réunis dans $A$ construçüu medieval des terrikório. Lisbonne. Livros Horizonte, 2001, divers travaux de M. J. Barroca. Stéphane Bolsstillilt: Le peuplement médiéval dans

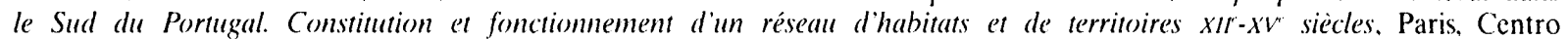
cultural Calouste Gulbenkian. 2013, la thèse de Manuel Sílvio Alves Conde. Uma paisagem humanizada. O Médio Tejo nos finais da Idade Média. Cascais. Patrimonia. 2000, 2 vol., ou l'étude du premier recensement de la population portugaise par João José Alves DIAs. Gentes e espaços (em torno da população port!guesa na primeira metade do século XVI). Vol. 1. Lisbonne, FCG/ JNICT, 1996.

68. Est en cours de publication. au Círculo de Leitores. une collection de biographies des rois du Portugal qui est aussi un grand succès éditorial. au regard de la dimension du marché portugais. Pour les rois du Moyen Âge sont déjà sortis les livres sur Sancho I" (Maria Joâo Bravco). Afonso II (Hermínia Vasconcelos VIl,AR). Sancho II (Hermenegildo Fernandes). Afonso III (Leontina VI:NTURA). Dinis (José Augusto PIZARro). Afonso IV (Bernardo Vasconcelos e Sol'SA). Pedro I" (Cristina PINI:NTA). Fernando I" (Rita Costa (jomes). João I" (Maria Helena da ('ruz (olltho) et Duarte (Luís Miguel Di irTt:). La biographic du premier roi. Afonso Henriques. sera écrite par J. Mattoso. 


\section{Annexe \\ La recherche médiévistique française sur le Portugal médiéval \\ (et bibliographie des travaux en langue française sur l'histoire médiévale portugaise)}

\section{Les conditions institutionnelles et sociales ${ }^{\text {hy }}$}

Les historiens français ont la chance de posséder, avec la Casa de Velázquez. une institution d'appui aux recherches historiques (et d'autres sciences humaines et lettres) universitaires sur le domaine ibérique, incluant théoriquement le Portugal: quoique la vocation ibérique (donc sans exclusive) de cette institution soit évidente, aussi bien dans l'esprit de ses fondateurs que dans ses statuts, qui envisagent l'Espagne au sens de l'Hispania antique, les recherches médiévistiques d'envergure sur le Portugal réalisées dans ce cadre restent très rares". S'ajoutent à cela deux obstacles pour le chercheur français désireux de se préparer en France à travailler sur le Portugal : - le problème de la langue, car il est beaucoup plus facile d'apprendre le castillan que le portugais en France (et il reste assez difficile de travailler en portugais sur la seule base de la langue castillane):

- la difficulté à se documenter personnellement (indépendamment des institutions) à cause de l'absence presque totale de diffusion des éditions portugaises en France (mais aussi, plus généralement, hors du Portugal): et cet obstacle-là reste important même pour les chercheurs français qui sont devenus spécialistes du Portugal - mais qui mènent évidemment leur carrière en France.

Mais un dernier handicap constitue le principal obstacle sur la route des médiévistes français vers le Portugal : c'est que les milieux universitaires fonctionnent largement comme des réseaux, avec la rigidité qu'implique toute organisation réticulaire ; ainsi, par la simple force d'inertie du centrage madrilène originel, il y a eu perpétuation de l'orientation "espagnole ", et la plupart des médiévistes français spécialistes de la Péninsule et âgés d'une cinquantaine d'années ou plus ont travaillé en relation avec J. Gautier-Dalché, Ch.-E. Dufourcq et Ph. Wolff, qui sont les premiers médiévistes à avoir développé en France des recherches de "nouvelle histoire " (qui était alors largement l'histoire économique et sociale) portant sur le domaine ibérique, ce qui a orienté "l'école française " médiéviste ibérisante vers la Castille et la couronne d'Aragon (C. Carrère, J-P. Cuvillier, P. Bonnassie, P. Guichard, D. Menjot, C. Guilleré, M-C. Gerbet, P. Sénac...). Pour toutes ces raisons. les recherches sur le Portugal restent le fruit d'initiatives isolées, comme d'ailleurs les recherches sur le reste de la Péninsule mais sans la cohérence et la dynamique que confère la masse.

Pourtant. d'autres circonstances culturelles et sociales. celles-ci très favorables, auraient dû promouvoir l'orientation vers le Portugal, principalement la large ouverture des chercheurs portugais

69. On trouvera quelques considérations sur la place des non Portugais dans l'historiographie portugaise (mais pas spécifiquement médiévistique) des $X I x^{-}-X X$ s. dans "A história de Portugal vista de fora ". dans Luís Reis Tor(ial. et al.. Ifistória da história em Pormgal. Sécs. $X I X-X X$. Lisbonne. ('írculo de leitores. 1996 (Grandes temas da nossa história). p. $345-361$.

70. Des raisons propres à l'institution expliquent partiellement cette lacune : pendant longtemps. la règle de l'obligation de résidence a Madrid fut asse\% rigide. ce qui eut pour conséquence la concentration des travaux "sur le terrain " (y compris en archives) dans les zones castillanes. De plus. en tant qu institution d'appui à des chercheurs déjà orientés. la (asa de Velázque\% ne pouvait modifier ces tendances historiographiques. Lassouplissement administratif a permis une dissémination géographique supérieure mais le primat "espagnol" est resté important. pour deux raisons : l'installation a Madrid des structures daccueil. notamment de la bibliothèque mais aussi du réseau de relations avec les universitaires espagnols. incite les chercheurs à rester dans le cadre espagnol. 
à l'historiographie et à la langue françaises ainsi que l'existence d'une importante communauté d'origine portugaise en France : une circonstance institutionnelle s'y ajoute, c'est l'implantation en France d'un organe spécifique de la Fondation Gulbenkian : si ce "Centre Culturel Calouste Gulbenkian" (ancien "Centre culturel portugais de la Fondation Gulbenkian») n’a pas une vocation exclusivement scientifique, il a toujours constitué pour les universitaires français intéressés par la culture portugaise un formidable point d'appui par sa bibliothèque parisienne, par l'organisation de séminaires et colloques, par l'octroi de bourses d'études et plus encore par ses éditions (qui ont en outre l'avantage d'être diffusées à la fois en France et au Portugal).

Il est vrai que, en ce qui concerne les luso-descendants, on constate que les étudiants d'origine portugaise sont trop bien intégrés dans la société française (jusqu'à ignorer la langue de leurs origines) pour manifester un intérêt spécifique envers leurs racines. Plus généralement, il est très difficile d'amener les étudiants à l'histoire médiévale et, parmi les quelques courageux, il est encore plus difficile de les faire travailler sur un domaine extérieur à la région d'implantation de leur université. Les quelques étudiants que l'on réussit à amener à des sujets «portugais » en mestrado sont obligés de s'initier à la langue dans leur année de recherche (cf. le problème signalé plus haut) - mais on peut espérer que la réforme LMD, avec un mastère en deux ans, améliorera la situation -, et ils s'intéressent surtout à l'expansion maritime (à la fois par curiosité intellectuelle mais aussi parce qu'il existe des textes traduits et de nombreuses études en français).

Si le bilan est loin d'être nul, le résultat de tout ceci se résume en deux données, que l'on interprétera variablement selon le point de vue adopté :

- sur la trentaine de médiévistes de langue française (enseignants-chercheurs ou chercheurs titulaires de l'enseignement supérieur) travaillant ou ayant récemment travaillé sur la Péninsule ibérique médiévale ${ }^{71}$, trois seulement (R. Durand, C. Picard et S. Boissellier) consacrent leurs travaux principalement à l'aire portugaise, ce que ne justifient ni l'abondance comparée des sources originales ni la place du Portugal dans la Péninsule médiévale (y compris en prenant des critères aussi réducteurs et anachroniques que le nombre d'habitants et la superficie):

- sur les six synthèses universitaires en langue française consacrées à la Péninsule ibérique médiévale, en incluant al-Andalus, trois sont des histoires de l'Espagne médiévale et excluent de ce fait le Portugal (celles de M.-C. Gerbet, B. Leroy et les chapitres médiévaux de l'Histoire des Espagnols dir. B. Bennassar)"2 et les trois autres, qui sont d'ailleurs excellentes (cclles de P. Guichard, D. Menjot et $\mathrm{A}$. Rucquoi), sont rédigées par des auteurs dont la base de recherche n'est pas le Portugal, comme si la vocation à embrasser l'ensemble de la Péninsule ne pouvait venir, dans l'opinion des éditeurs français, que d'un point de vue espagnol et surtout castillan.

Il ne s'agit naturellement pas de polémiquer, ni en réveillant d'anciens conflits Dieu merci dépassés, ni même en opposant des intérêts matériels et scientifiques au sein même du microcosme médiévistique français. Au-delà de son identité politique depuis le XII ${ }^{\circ}$ s., le Portugal est, culturellement, un pays tout aussi «ibérique " que le reste de la Péninsule - malgré les doutes parfois émis à ce sujet, privilégiant une identité atlantique -, mais il se trouve que l'histoire, depuis l'unification de la plus grande part de la Péninsule à la fin du Moyen Âge (depuis l'union de la Castille et de la Couronne d'Aragon), a séparé son destin politique du reste de l'ensemble ibérique, plus nettement que celui des autres "provinces" de l'actuelle Espagne ; l'organisation politique et administrative et la langue actuelles font donc de la recherche sur le Portugal une spécificité et on peut en citer une preuve institutionnelle : depuis la bibliothèque madrilène de

71. F. Amigues, P. Araguas, R. Arié, M. Aurell, D. Baloup. J.-P. Barraqué. A. Bazzana. S. Boissellier. P. Burési. L. Bolens. M. Charageat. D. Coulon, S. Coussemacker, P. Cressier. C. Denjean, T. Deswarte. R. Durand, F. Foronda. J. Gautier-Dalché. M.-C. Gerbet. P. Guichard, C. Guilleré. J. Hadziiossif. P. Henriet. P. Josserand. B. Leroy. C. Martin. G. Martinez-Gros. C. Mazzoli. D. Menjot. J.-P. Molénat. J. Passini, C. Picard. A. Rucquoi. P. Sénac. E. Tixier-Caceres. J. Tolan. M. Zimmermann. auxquels on peut joindre, dans des sections darabe. F. Clément. V. Lagardère, D. Urvoy et J.-P. Van Staevel ainsi que M. Méouak qui enseigne en Espagne.

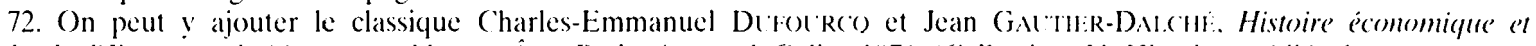
sociale de l'Espagne chrétienne au Mojén Âge. Paris. Armand Colin. 1976 (Collection U. Histoire médiévale). 
la Casa de Velázquez, il est possible d’aborder sérieusement toutes les régions médiévales de la Péninsule, sauf précisément le Portugal.

Cette marginalité portugaise ne vaut pas que pour les médiévistes; d'une part, elle vaut aussi pour les historiens universitaires français des autres périodes (exceptée la plus forte tradition lusitaniste des antiquisants et "wisigothisants", liée à l'importance des sources archéologiques et au monopole du latin dans les sources écrites, avec des figures comme celles de R. Étienne, A. Tranoy, P. Sillières, C. Domergue, J.-G. Gorges... ou, plus récemment, C. Martin) ; d'autre part, parmi les grands pays développant depuis le $\mathrm{XIX}^{\mathrm{c}}$ s. une recherche quelque peu "colonialiste" sur les États européens méditerranéens moins riches (Grèce, Péninsule ibérique et Italie), souvent appuyée par des institutions anciennes et prestigieuses comme les Écoles françaises de Rome et d'Athènes, on note une même maigreur des recherches sur le Portugal médiéval - comme du côté français, les travaux anglais, allemands, nord-américains ou même japonais sont infiniment plus nombreux sur l'Italie ou l'ensemble castillano-aragonais ou même sur l'Europe orientale chrétienne que sur le Portugal. Par un paradoxe qui n'est qu'apparent, c'est actuellement d'un pays. l'Espagne - qui est elle-même un ancien "colonisé » par les puissances septentrionales que viennent actuellement le plus d'études étrangères sur le Portugal médiéval (avec des noms aussi prestigieux que C. Sánchez Albornoz et A. García y García ou, plus récemment, C. de Ayala Martínez ou J. López Quiroga...); il est vrai que les pays ayant engendré un Portugal autonome au début du XII S. sont jusqu'à cette date des provinces asturo-léonaises.

On pourrait d'ailleurs formuler les mêmes remarques à propos des recherches menées par les philologues romanistes, pour lesquels l'universalité du latin n'est pourtant pas un facteur explicatif ; les textes médiévaux portugais sont rarement édités et traduits par des "lusistes " étrangers, qui préfèrent se consacrer au siècle d'or portugais (à partir des "fondateurs " Camões et Gil Vicente) ou aux textes médiévaux, littéraires ou juridiques, en castillan (ainsi les "écoles» de linguistes éditeurs développées dans le sillage de G. Tilander, en Suède, de W. Mettmann, en Allemagne $^{7 s}$, ou de J. Roudil, en France).

Malgré les pesanteurs académiques que l'on vient d'évoquer, on reste surpris que les facteurs favorables ne l'emportent pas; quoique en recul (pour des raisons principalement linguistiques), l'ouverture des historiens portugais aux courants historiographiques venus de France, drainant nombre d'entre ceux-là vers des centres de recherches français, a suscité de nombreux contacts personnels, mais n’a pas entraîné un intérêt en retour des Français pour le terrain portugais?t.

\section{Bilan des travaux réalisés ${ }^{75}$}

Dans les travaux médiévistes français sur la zone portugaise, il existe trois catégories : a. - ceux des chercheurs ayant travaillé principalement sur des zones non portugaises et ayant abordé ponctuellement le Portugal; b. - ceux ayant englobé le Portugal (dans des études portant sur la totalité de l'Occident médiéval ou de la Péninsule ibérique) sans s'y consacrer spécifiquement : c. - ceux portant principalement ou spécifiquement sur le Portugal.

73. Significativement. la grande ceuvre éditoriale de ce savant est la publication d'une ceuvre en galégo-portugais mais produite dans un contexte castillan. les Cantigas de Santa Maria.

74. La faiblesse de ces réseaux sobserve à travers le bon baromètre que constituent les "Semaines détudes médiévales" du Centre d’Études Supérieures de ('ivilisation Médiévale (Poitiers) : alors qu'elles ont été fréquentées. entre 1954 et 2002. par 15 chercheurs et 137 doctorants espagnols. elles nont accueilli que 10 étudiants portugais!

75. Signalons préalablement une exclusion (qui šimpose particulièrement dans la bibliographie jointe. sauf exception), celle des recherches philologiques médiévistes. qui sont naturellement d'un intérêt majeur pour l'histoire de la culture médiévale portugaise mais ne relèvent pas de notre approche historiographique. Depuis Ferdinand Denis au XIX s.. des spécialistes français des langues romanes. comme P. Le Gentil. s̈ils ne les ont pas édités. ont au moins travaillé sur des textes portugais médiévaux : parmi cux. les véritables spécialistes de la langue portugaise se sont consacrés plutôt. comme on la dit. à la littérature moderne: les chercheurs sur les textes médiévaux en langue portugaise (comme J. Steunou. P. Blasco ou J. Roudil) ont généralement conservé une orientation "romaniste " plus globale pour des raisons scientifiques évidentes mais aussi parce qüils travaillent dans des cadres pédagogiques et scientifiques à dominante "espagnole». 
a. - Parmi les premiers, on trouve des études ponctuelles sur les élites médiévales "internationales ". les commerçants. les étudiants et les religieux, c'est-à-dire des sujets que l'on rencontre dans des documents d'archives non portugaises : ainsi, les articles de C. Verlinden, Y. Renouard, $\mathrm{Ph}$. Wolff ou J. Heers sur les évêques français ou les commerçants italiens au Portugal ou des travaux sur les Portugais présents en France, notamment dans le domaine de l'histoire dynastique (avec les princesses portugaises) et intellectuelle (avec les étudiants). La vogue actuelle de l'histoire religieuse peut conduire aussi des chercheurs à aborder ponctuellement des dossiers "portugais» de documents savants en langue latine dans le cadre de l'étude plus globale d'un Ordre religieux (voir l'article d'I. Heullant) ou d'un problème doctrinal ou technique (P. Henriet ou F. Dolbeau). En outre, l'histoire de l'art, comme l'étude des textes en latin et des structures matérielles, bénéficie d'un langage international, celui des codes esthétiques et des techniques, qui permet à certains de ses experts d'aborder ponctuellement tel dossier «portugais».

Le rayonnement dont ont joui les écoles médiévistes de langue française (française et belge) a amené quelques-uns de leurs membres à s'intéresser au Portugal médiéval sous la forme de direction de recherche : l'exemple important le plus récent, en 1981 (outre les premiers travaux de M. Farelo au Québec, qui relèvent de la thématique «internationale » des universités médiévales), est la thèse de troisième cycle d'A. M. Rodrigues sur la collégiale de Torres Vedras, qui a été réalisée dans le cadre de l'Université de Paris IV, mais on pourrait remonter, pour établir cette tradition, jusqu'à la thèse de linguistique (faisant évidemment largement référence à l'époque médiévale) en Sorbonne de J. Leite de Vasconcelos et passer par la thèse de J. Mattoso, dirigée par L. Genicot, pour aboutir (dans un domaine parallèle à l'histoire médiévale) aux éditions des traductions médiévales portugaises des compilations alphonsines par J. de Azevedo Ferreira sous la direction de J. Roudil ; mais on est là dans le domaine de l'influence, en quelque sorte «involontaire ", de l'historiographie française à l'étranger, qui n'entre pas dans mon propos et qui a été abondamment développée par de nombreux ouvrages d'historiographie, aussi bien dans le pays émetteur que dans les pays récepteurs.

Pour en terminer avec ces apports plus ou moins directs, on peut noter que, curieusement, la facilité que procure l'uniformité de la langue latine (jusque dans la seconde moitié du XIII" $\mathrm{s}$.. moment de l'adoption du portugais comme langue écrite dans la plupart des institutions médiévales, à la suite de la chancellerie royale) n'a guère suscité, même ponctuellement, de travaux français sur les sources narratives «franques» qui parlent du Portugal (hormis l'article de R. Ricard sur la prise de Lisbonne); on aurait pu aussi espérer mieux que l'entrefilet de S. Corbin sur l'action d'un futur roi portugais (Afonso III) dans le comté de Boulogne et à la cour de France et surtout mieux qu'un silence quasi total sur les origines «françaises " (bourguignonnes) de l'État portugais - qui est à l'opposé de l'intérêt qu'ont suscité les origines angevines de plusieurs dynasties occidentales - alors que ce dernier thème pourrait susciter des problématiques actuelles fructueuses, comme les pratiques juridiques, institutionnelles et culturelles (chartes de franchises, immunités ecclésiastiques. rituels féodaux), et en tout cas plus fécondes que les classiques considérations dynastiques et diplomatiques. Paradoxalement, les rapports entre le Portugal et la Bourgogne/Flandres ont attiré l'attention de deux chercheurs français (J. Paviot et M. Sommé) pour le $X^{c}$ s., sur la base de sources exclusivement françaises et quand ces relations entre États ne s'inscrivent plus que dans le cadre de l'histoire purement internationale.

b. - Parmi les chercheurs ayant abordé le Portugal comme l'élément d'un ensemble plus large (en excluant évidemment les synthèses, dans lesquelles la connaissance du Portugal médiéval les rares fois où il est présent! - est presque toujours de deuxième ou troisième main), on trouve naturellement des études d'arabisants sur la zone occidentale d'al-Andalus, c'est-à-dire pour l'époque où la plus grande partie de la Péninsule ibérique constitue une unité et où les spécificités culturelles et politiques du futur "Portugal " sont moins marquées quaprès l'apparition du comté puis du royaume portugais: il est inutile de détailler ces travaux. il faudrait mentionner toute l'école française sur le monde musulman occidental, depuis R. Dozy (Hollandais mais écrivant principalement en français) jusqu’à $P$. Guichard et $V$. Lagardère; les seuls travaux d'un arabisant consacrés principalement au Gharb sont ceux de C. Picard (mais deux de ses livres récents, sur 
l'Atlantique musulman, ne sont pas centrés sur le Portugal, tout en lui réservant évidemment une large place) $)^{7 \%}$.

La pensée et la vie de religieux d'origine portugaise, de dimension internationale, depuis saint Martin de Dume/Braga, ont focalisé depuis longtemps des études de tous les pays et dans toutes les langues (dont le français): ainsi Pedro Hispano (le pape Jean XXI) ou évidemment saint Antoine, dont il faut bien reconnaître qu'il est plus de Padoue que de Lisbonne". On peut noter également une inclusion du Portugal, là encore, dans des travaux sur des sujets "internationaux " (donc principalement sur des sujets liés à l'Église) mais ne portant pas principalement sur la documentation portugaise: ainsi, de façon assez marginale, la présence des étudiants portugais dans les recherches sur les "nations" des universités françaises, les contributions portugaises aux finances pontificales (dans la thèse de J. Favier sur la fiscalité papale) ou encore l'attitude d'Alexandre III envers le royaume naissant du Portugal (dans la biographie de ce pape par M. Pacaut). Plus intéressante est l'inclusion, logique, du futur Portugal dans les travaux français relatifs à l'Espagne wisigothique (les thèses de S. Theillet et C. Martin); mais on hésite à faire figurer ces travaux sur les hautes époques médiévales dans l'historiographie relative au "Portugal ", car ils posent le problème épistémologique de l'histoire "nationale " - peut-on parler du Portugal en tant qu'entité avant l'apparition d'une structure collective (l'État monarchique territorial) ? et ceci se reflète d'ailleurs dans la nature des sources de ces études, qui sont celles d'un "empire " wisigoth unifié, sans véritable spécificité régionale (en-dehors de l'éphémère royaume suève, dont la documentation propre est des plus minces et qui ne peut, en outre, être considéré comme un ancêtre du Portugal).

Dans cette catégorie de chercheurs, celui qui a englobé le plus systématiquement le Portugal dans ses travaux, au point d'en connaître les sources de première main, est $C$. Verlinden, notamment dans sa grande histoire de l'esclavage médiéval; on peut aussi noter l'apport important de M. Defourneaux sur les influences françaises au Portugal, dans un ouvrage portant sur l'ensemble de la Péninsule, éclairant principalement, outre quelques aspects dynastiques de la question, le problème de la substitution de la liturgie romaine à la liturgie hispanique. Ces travaux englobant le Portugal sont très utiles pour diffuser la connaissance du Portugal médiéval dans le public universitaire français car les ouvrages qui lui sont consacrés exclusivement ont une diffusion beaucoup plus limitée $e^{7 x}$.

Enfin, des spécialistes d'histoire africaine (y compris le Maghreb) et d'histoire de la navigation ont inclus certains problèmes relatifs à l'expansion portugaise dans lcurs recherches, notamment dans les années 1960) : ces chercheurs ayant souvent une formation de linguistes ou d'historiens de la littérature, voire d'africanistes, ont produit des études d'érudition sur des points précis (notamment l'édition et la traduction de sources), dans un domaine une fois de plus "international», où l'exotisme et les vastes perspectives de l'unification du monde interdisent d'adopter un point de vue strictement "portugais": ainsi, R. Mauny, R. Ricard, Ch.-M. de Witte, plus récemment J. Paviot et $M$. Vergé-Franceschi. Ces travaux, très nombreux et constituant le principal

76. On pourrait dire à peu près la même chose des recherches en langue française sur le "Portugal " wisigothique: elles ne sont jamais spécifiquement consacrées à cette zone. mais beaucoup dentre elles l'abordent plus ou moins comme l’élément d'une unité globale (ainsi les travaux bien connus de X. Barral i Altet sur les monnaies. de J. Fontaine. de S. Teillet, tout récemment de (. Martin ou. dans un cadre beaucoup plus large. de P. Riché sur l'éducation).

77. Cette bibliographic. pléthorique. ne sera pas compilée. sauf rare exception, car elle n’éclaire en rien la civilisation portugaise: en effet. les spécialistes non portugais de la philosophie ou de l'ecclésiologie médiévales šintéressent précisément à ce quill y a d'universel dans la pensée et laction de ces personnages. et seuls les auteurs lusophones étudient leur formation ou leurs sources portugaises.

78. De même, récemment. P. Josserand développe des études sur les Ordres militaires en (astille qui abordent quelque peu le Portugal: en participant aux colloques de Palmela (qui coordonnent les recherches portugaises sur les Ordres militaires), il a surtout contribué a rapprocher les chercheurs travaillant sur les Ordres militaires ibériques. (éci est un excellent exemple du róle que la vocation ibérique de la Casa de Velázquez lui permet de jouer auprès de nos collègues portugais (rôle quelle tient dailleurs déjà en Espagne en organisant des manifestations en dehors de toutes rivalités régionalistes). 
apport de la recherche historique française en histoire "portugaise ». ne sont donc pas mentionnés dans la bibliographie.

c. - La troisième catégorie n'inclut pas de chercheurs très nombreux mais représente la masse principale des travaux portant strictement sur le Moyen Âge portugais (loin derrière, toutefois, les travaux publiés en français par des chercheurs et érudits portugais).

Sans remonter jusqu'aux Chroniques chevaleresques de l'Espagne et du Portugal et aux premiers volumes (d'histoire médiévale) de l'ouvrage intitulé Le Portugal. L'univers pittoresque de Ferdinand Denis (Paris, 1839 et 1846) - qui est historiquement le premier véritable chercheur en histoire (travaillant de première main) lusophile mais non pas strictement médiéviste ${ }^{7 y}$ - on peut considérer que $P$. David a produit la première œuvre médiévistique française consacrée notablement au Portugal; cette œuvre est constituée par une série d'études ponctuelles dans la tradition de l'érudition (une prodigieuse érudition, d'ailleurs), principalement parce que P. David, chanoine, avait une formation ecclésiastique. Ses travaux sont consacrés à l'histoire religieuse (notamment la liturgie) et, plus généralement, à l'étude des textes savants (narratifs), par exemple en reconstituant les plus anciennes annnales du royaume portugais (étude qui reste utilisée par tout le monde): mais il faut noter la ponctualité de ses travaux, à la fois par tradition érudite mais aussi parce qu'il s'est intéressé au Portugal en quelque sorte par hasard, s'y étant réfugié durant la Deuxième Guerre mondiale $e^{\mathrm{x} t}$. Néanmoins, P. David a influencé plusieurs des plus importants médiévistes portugais des années 1950/70 (des érudits ecclésiastiques tels que A. de J. da Costa ou I. da R. Pereira mais aussi un médiéviste de formation purement universitaire comme T. de Sousa Soares); il a eu aussi un disciple français, Maur Cocheril. moine cistercien, dont les travaux, eux aussi dans la tradition érudite, ne sont pas très connus par les milieux universitaires français parce qu'il était lui aussi un historien ecclésiastique et parce qu'il a travaillé en partie en histoire de l'art et en histoire moderne (ses ouvres principales étant le "routier des abbayes cisterciennes du Portugal» et l'édition du récit latin d'une tournée d'inspection des abbayes portugaises par un visiteur français ${ }^{\mathrm{xl}}$ ). En résumé, le rôle de $\mathrm{P}$. David. sans véritable postérité parmi les historiens universitaires français, est plus fondateur au Portugal qu'en France, et ses domaines d'études, l'histoire religieuse et les textes savants, le rattachent aux traditions internationalistes d'érudition latine et d'archéologie chrétienne évoquées plus haut.

Les médiévistes de formation universitaire en sont venus plus tardivement à se consacrer au Portugal médiéval, dans les années 1970 (les deux pionniers étant R. Durand et G. Pradalié) : c'est l'explosion de l'histoire économique et sociale, médiévale et moderne, en France à partir des années 1950 qui a poussé les médiévistes français à rechercher les fonds d'archives les plus riches jusqu'aux pays voisins; le Portugal médiéval est vu désormais dans sa substance même et non plus depuis Rome ou du point de vue d'une histoire intellectuelle internationale. Dans cette optique, les chercheurs français sur le Portugal ne sont pas en retard par rapport à ceux travaillant spécifiquement sur l'Italie (depuis Y. Renouard, P. Toubert et J. Heers), l'Espagne (depuis J. GautierDalché et C. Carrère) ou l'Allemagne (depuis Ch. Higounet) dans ces mêmes thématiques.

R. Durand et G. Pradalié ont commencé leurs recherches en même temps, le premier en histoire rurale, le deuxième en histoire urbaine, ce qui est très représentatif des principaux courants historiographiques français; il est à noter que, en tant que pionniers, ils ont dû prendre des directeurs de recherche et des jurys non spécialistes du Portugal. Malheureusement, la recherche

79. Son oeuvre a suffisamment marqué les intellectuels portugais pour inspirer une História de Portugal... segundo o plano de Ferdinand Denis. dir. Manuel PINHFiro Chagas. en 8 vol.. publiée à Lisbonne dans les années 1867/74. D’autres lusophiles français (N. de Lä (lède. Alphonse Rabbe ou Amédée Paquis) ont écrit aux XVIII et XIX s. des "Histoires du Portugal " mais ce sont de simples compilations.

80. On peut voir une notice bio-bibliographique détaillée de l'auteur par Avelino de Jesús da costa. "L'abbé Pierre David». Bulletin des études portugaises et de l'Institut français au Porlugal. n.s. 19. 1955/56. p. 293-312: son apport proprement scientifique est commenté dans la même revue par SOARES. 1955/56 (voir bibliographie in fine).

81. Il faut noter que. en dehors de cette édition. ses recherches historiques se sont fondées essentiellement sur des sources imprimées. 
principale de G. Pradalié sur Coimbra n'a pas abouti, pour des raisons professionnelles; ses précédents travaux d'ensemble sur Lisbonne et sur le monastère franciscain de Santarém sont restés inédits en français et n'ont été publiés qu'en traduction portugaise, ce qui a rétréci leur audience en France et donc le "vivier» de médiévistes susceptibles de s’intéresser au Portugal; mais son livre sur Lisbonne, bien que ce soit une œuvre de jeunesse, reste abondamment utilisé et cité au Portugal même.

L'œuvre de R. Durand, malgré une édition trop peu diffusée de sa thèse, a, entre autres mérites, contribué à intégrer des données relatives au Portugal dans les ouvrages médiévistiques généraux français actuellement utilisés, notamment dans le domaine de l'histoire rurale (par exemple les synthèses de R. Fossier) mais aussi de l'histoire générale, dans la mesure où il a écrit trois livres de diffusion importante, Vivre alı village... (récemment réédité), une Histoire du Portugal dans une collection pour grand public et une synthèse sur les relations entre chrétiens et musulmans en Méditerranée occidentale à l'occasion d'un concours d'enseignement français. Le premier et le dernier de ces ouvrages ${ }^{\mathrm{xz}}$ (avec le livre sur le Gharb de C. Picard) fournissent la base de ce que la plupart des médiévistes français savent de sérieux sur le Portugal médiéval, outre les rares articles, de la même plume. sur des sujets portugais insérés dans le Dictionnaire encyclopédique du Moyen Âge. De plus, deux éléments de ses recherches, qui se fondent sur les originalités de la situation médiévale portugaise, ont constitué un apport épistémologique de premier ordre, qui est "passé » dans l'historiographie française (notamment par l'utilisation de l'ouvrage Vivre au village) et y a exercé une influence appréciable : en 1999, l'introduction historiographique de $\mathrm{R}$. Fossier à une journée d'hommage à $\mathrm{R}$. Durand a rappelé que l'organisation de l'espace (à laquelle il a consacré une partie de sa thèse et de nombreux articles) est une clé fondamentale pour comprendre l'organisation sociale et qu'elle est étudiable à travers des sources écrites; en outre, avant beaucoup d'autres, il a renouvelé l'étude des communautés rurales, très au-delà des études classiques de "franchises", en montrant qu'elles peuvent préexister à une implantation d'une seigneurie politique.

La décennie suivante (années 1980) a vu le début des travaux de Christophe Picard sur le "Portugal» musulman, eux aussi orientés principalement vers l'histoire sociale (tout en intégrant beaucoup plus que d'autres l'histoire politique, à cause de la spécificité des sources arabes); ses recherches ont débouché sur plusieurs ouvrages de synthèse, les deux déjà cités sur l'Atlantique musulman et surtout son récent Portugal musulman qui est le premier ouvrage consacré exclusivement au Portugal médiéval publié par un éditeur français à diffusion assez large et qui offre la totalité des connaissances sur le Gharb accessibles en France. Ses travaux constituent en outre un apport méthodologique important à la réflexion des médiévistes islamisants : l'étude minutieuse de textes écrits et de données archéologiques lui a permis notamment de nuancer (et d'adapter au Gharb) les théories de P. Guichard, lesquelles se sont imposées si largement en Espagne et en France que l'on a tendance à les appliquer un peu mécaniquement.

Outre les travaux en cours de jeunes chercheurs (C. Aillet, dans le cadre d'une recherche plus large sur les mozarabes, ou M. Grangé. sur la base de fouilles archéologiques devenues assez internationales), S. Boissellier est le Français dernier venu dans le médiévisme portugais : un peu à contre-courant d'une historiographie médiévistique française qui s'oriente de plus en plus vers l'histoire religieuse et culturelle, il a travaillé principalement en histoire socio-économique et matérielle du monde rural, en complétant l'appréhension des problèmes sociaux par quelques réflexions sur l'idéologie politique et l'hagiographie ou par l'édition de sources". Au-delà de ces

82. Robert D(RAND en collah. av. Monique Bol'RIN. Vivre au village au Moven Âge. Les solidarités parsannes du 11. au 1.3 siécle. Paris. Messidor/Temps actuels. 1984 (La passion de 1'histoire) [rééd. Rennes. PU. R. 2001] et Musulmans et chrétiens en Méditerranée occidentale $\lambda^{\prime \prime}$-xill siécles. Comtacts et échanges. Rennes. Presses Universitaires de Rennes. 2000).

83. Comme membre de la (asa de Velázquez. la possibilité de résider deux ans au Portugal pour effectuer des recherches doctorales (outre de nombreux autres séjours. dont un. d'une année. avec une bourse de la Fondation Gulbenkian) lui a permis de réaliser un asse\% gros travail de dépouillement dans des conditions très favorables. rarement offertes aux chercheurs ayant besoin de fréquenter les archives portugaises. 
quelques lignes qui sont un appel à développer la recherche historique française sur le Portugal médiéval, il a tenté de fournir quelques renseignements utiles à cet effet et de susciter, sinon des vocations, au moins de l'intérêt pour une histoire injustement méconnue en présentant les sources médiévales portugaises et en traduisant de nombreux textes dans un volume (en collaboration) dont on trouvera les références plus bas.

\author{
Bernardo VASCONCELOS E SOUSA \\ Institut d'Études Médiévales \\ Université Nouvelle de Lisbonne \\ (FCSH) \\ avenida de Berna, $26 \mathrm{C}$ \\ $P$ - 1069-(061 LISBOA
}

Stéphane BOISSELLIER

CÉSCM - Université de Poitiers

22, rue de la Chaîne, BP 603

F - 86022 POITIERS

\section{Bibliographie}

La bibliographie qui suit a pour seule fonction de servir à tous ceux qui pourraient s'intéresser à l'histoire du Portugal médiéval sans en dominer la langue : s'adressant à des collègues spécialistes d'histoire de l'Occident médiéval, elle exclut les travaux philologiques (sauf ceux qui nous semblent servir directement à l'histoire, selon un critère qui reste, avouons-le, assez peu rigoureux) et ceux consacrés aux "grandes découvertes", mais elle intègre ceux qui portent principalement sur les relations du Portugal médiéval avec d'autres régions (sans prétention à l'exhaustivité dans ce domaine car la recension a été menée principalement dans les revues portugaises). Nous n'avons pas mentionné les articles de dictionnaire, sauf quand ils constituent de véritables synthèses développées (principalement ceux du Dictionnaire d'histoire et de géographie ecclésiastiques) ${ }^{\star *}$.

En dehors des œuvres françaises analysées ci-dessus, l'essentiel des travaux francophones émane des savants et universitaires portugais ayant écrit dans cette langue (en particulier A. L. de C. Homem, M-H. Coelho, L. F. L. Cintra, H. B. Moreno, I. da R. Pereira et plus encore J. Mattoso et A. M. Rodrigues); leur abondance illustre l'ouverture de la recherche portugaise à la culture française (outre son ouverture à l'historiographie française, qui est sans rapport avec la langue employée), ce qui est un heureux héritage de l'époque où toute jeune fille portugaise de bonne famille se devait de "tocar piano e falar francês" ". Dans le dernier demi-siècle, quelques conditions matérielles de diffusion sont venues appuyer cette francophonie : d'abord, tant qu'elle a paru, la Revue des études portugaises et brésiliennes (dont le titre a varié entre les années 1940 et 1970) publiée par l'Institut français de Lisbonne a accueilli nombre de travaux philologiques et quelques travaux historiques, non seulement ceux des Français travaillant sur le Portugal mais aussi ceux de Portugais; ensuite, la revue Arquivos do Centro cultural português et les colloques sur l'histoire portugaise publiés et organisés par la Fondation Gulbenkian dans son Centre parisien, largement destinés à un lectorat francophone, ont favorisé l'emploi de la langue française par leurs participants ; enfin, l'usage du français comme langue "officielle» de certaines institutions scientifiques internationales (en particulier du Comité international de Diplomatique) a conduit les médiévistes portugais qui en sont membres ou participent aux colloques organisés par ces institutions à publier leurs recherches dans cette langue.

84. Le Dictionnaire encyclopédique du Moyen Âge, dir. André Vauchiz., Paris, Le Cerf, 1997. 2 vol., n’offre que les entrées Alcobaça. Alphonse Henri. Batalha. Braga. Coümbre. Martin de Braga et Portugal (excluant curieusement Avis [dynastie]. Henri le Navigateur. Isabelle [sainte]. Lisbonne et Sainte-Croix de Coimbra). Le Dictionnaire du Moyen Âge. dir. Claude Gnuvard et. al.. Paris, PUF, 20(2), qui fait une très large place aux lettres et à la philosophie. est encore plus pauvre mais offre en revanche quelques notices sur la littérature médiévale galégo-portugaise.

85. Cette mode afrancesada a cu ses plus forts effets, au début du XX s., jusque dans le domaine historique puisque de nombreuses découvertes archéologiques (de sites romains) étaient publiées, au Portugal même, directement en français par leurs auteurs portugais: il suffit de parcourir António Mesquita de Fk(it t:IRl:Do. Subsidios para a bibliografia da historia local portuguesa, Lisbonne. Biblioteca nacional Lisboa, 1933, pour trouver ce genre de publications. 
Bien que ce soit un de nos objectifs, cette bibliographie ne peut prétendre à l'exhaustivité. Les travaux produits par des universitaires français sont assez faciles à répertorier (d'autant plus qu'ils sont peu nombreux), grâce à des bilans bibliographiques périodiques, réalisés dans diverses revues pour les périodes les plus anciennes ("bulletins historiques" consacrés à l'historiographie, pas seulement française, sur l'Espagne médiévale) $)^{\mathrm{sh}}$ et surtout dans des publications institutionnelles spécifiquement françaises (liées en particulier au Comité français des sciences historiques puis à la Société des historiens médiévistes de l'enseignement supérieur ${ }^{x 7}$ : en revanche, en dehors d'une précieuse compilation récente, les travaux en langue française des universitaires portugais sont beaucoup plus difficiles à repérer, notamment pour les époques les plus anciennes, où ils sont fort nombreux ${ }^{\mathrm{N}}$. Mais c'est précisément l'inexistence de guides efficaces et commodes qui rend nécessaire la compilation qui suit".

Abréviations

* $A C C P=$ Arquivos do Centro cultural português.

* BEP $=$ Bulletin des études portugaises.

* Bretagne $($ La). Le Portugal = La Bretagne. Le Portugal. Le Brésil. Échanges et rapports. Actes du cinquantenaire de la création en Bretagne de l'enseignement du portugais. Paris. Université de Haute-Bretagne I Université de Bretagne Occidentale / Université de Nantes. 1973.

* DHGE = Dictionnaire d'histoire et de géographie ecclésiastiques. Paris. Letouzey et Ané.

* Diplomatik $($ Die $)=$ Die Diplomatik der Bischofsurkunden vor 1250. La diplomatique épiscopale avant 1250 . Referate zum VIII. Internationalen Kongress für Diplomatik, Innsbruck, 27 september - 3 oktober 1933. éd. Christoph Haidacher et al.. Innsbruck. Tyroler Landesarchiv, 1995.

* Espace rural $\left(L^{\prime}\right)=L^{\prime}$ espace rural au Moyen Âge. Portugal, Espagne, France (XII-XIV' siècle). Mélanges en l'honneur de Robert Durand). dir. Monique Bourrin et Stéphane BoIssellier. Rennes. Presses Universitaires de Rennes, 2002.

* FCG/CCP = Fondation Calouste Gulbenkian / Centre culturel portugais (ou Fundação Calouste Gulbenkian / Centro cultural português).

* Humanisme (L') portugais - L'humanisme portugais et l'Europe. Actes du XXI colloque international d'études humanistes. Tours, 3-1.3 juillet 1978. Paris. FCG/CCP. 1984.

* Mil anos = Mil anos de fortificações na Peninsula Ibérica e no Magreb (500-1500). Simpósio internacional sobre castelos, coord. Isabel Cristina Fernandes. Lisbonne. Colibri / Câmara municipal de Palmela. 2002 .

* RPII = Revista portuguesa de história.

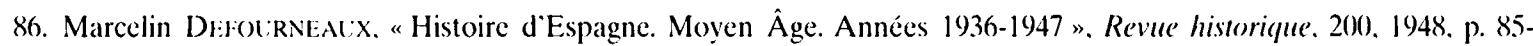
108 et 219-236 et Charles-Emmanuel DLfotre / Jean GAtTI:R-DAl. Hí. "Bulletin historique. Histoire de l'Espagne au Moyen Âge (publications des années 1948-1969)", ibid.. 497/98, 1971. p. 127-168 et 443-482.

87. Dernier bilan en date. la Bibliographie de lhistoire médiévale en France (1965-1990), dir. Michel Bal.ARD). Paris. Publications de la Sorbonne. 1992 (section ibérique réalisée par Adeline Rucquoi).

88. Linternational Medieval Bibliography. diffusée sous forme électronique par Brepols. dépouille surtout des revues et actes de colloques en langue anglaise et assez récents. avec un choix très arbitraire pour les autres médias. et elle se révèle done encore très loin de l'exhaustivité que elle annonce: ainsi. les travaux. méme récents. des médiévistes français sur le Portugal en sont presque totalement absents car publiés principalement dans des médias francophones.

89. On peut saider d'une "Bibliographie exhaustive et critique des livres disponibles en français sur le Portugal". dans Livres actualité. 12. 1972 et de la vicille "Bibliographie franco-portugaise" de Bernardo Xavier (outinho (1939). mais on a utilisé surtout un guide précieux. quoique malheureusement limité aux fonds de la bibliothèque de l'institution qui la édité (laquelle centralise. il est vrai. une bonne partie de ce qui existe) : Aperçu bibliographique sur le Portugal. Edition françatise. 18 salon du live de Paris / 20-25 mars 1998. Paris/Lisbonne. Fondation (alouste Gulbenkian. 1998. Pour les travaux portant sur le "Portugal" musulman. le Professeur Adel Sidarus $m$ a communiqué ses fichiers bibliographiques. ce dont je le remercie vivement (en particulier pour sa base de données BICLAI [BIblioteca Luso-Árabe e Islâmica|. dir. A. SIDARt's. Lisbonne. Instituto de Investigações Científicas Tropicais). 
Abrantes (D. Luís Gonzaga de Lancastre e Távora. Marquês de). "Quelques aspects de l'évolution de la noblesse portugaise vers la fin du Moyen-Âge ". $A C C P$, XXVI (La noblesse dans l'Europe méridionale du Moyen Âge : accès et renouvellement. Actes du colloque. Paris, 14-15 janvier 1988). 1989. p. 433452.

* Aillé (Cyrille), "Entre chrétiens et musulmans : le monastère de Lorvão et les marges du Mondego (878-1064)". Revue Mabillon, 15 (n.s. = t. 76). 2004, p. 27-50.

- "Aux marges de l'Islam : le château des Deux Frères et le dernier des Ghassanides », dans Guerre, pouvoirs et idéologies dans l'Espagne chrétienne aux alentours de l'an mil. Actes du colloque international organisé par le CESCM, Poitiers-Angoulême (26, 27 et 28 septembre 2002). dir. Philippe SÉNAC et Thomas Deswarite. Turnhout. Brepols, 2005 (Culture et société médiévales). p. 25-35.

* Alar(Âo) (Jorge de). S. Cucufate. Lisbonne, IPPAR. 1998 (Roteiros da arqueologia portuguesa. Guides archéologiques. Archeological guides, 5) [éd. trilingue].

* Albe (E.) et Coelho (José Júlio Gonçalves), " Notre-Dame de Rocamadour en Portugal », Bulletin de la Société scientifique, historique et archéologique de la Corrèze. 33 (vol. 4-6). 1912. p 569-622; 34 (vol. 12). p. $17-44$ et 34 (vol. 2-5), p. 233-266.

* Albuouerove (Luís de), "Un prince et son chroniqueur». ACCP. XXIII (Homenagem a Palul TEYssit:R). 1987. p. 319-331.

* Almeida (Fernando de), "L'art wisigothique au Portugal». Archeologia. Les dossiers de l'archéologie. 4. 1974. p. 103-107.

* Andrade (Amélia Aguiar). «Bilan bibliographique de l'histoire des villes médiévales portugaises ». L'information historique. 51/2. 1989. p. 90-92.

- «L'organisation de l'espace dans le Nord du Portugal au Moyen Âge », dans L'espace rural, 2002. p. $89-112$.

- «Le pouvoir royal et les villes portugaises au Moyen Âge», dans La ville européenne et ses pouvoirs (Moyen Âge-XX' siècle), coord. Olivier ZELLER, Lyon. Centre Pierre Léon [à paraître].

* Anselmo (Artur). Les origines de l'imprimerie au Portugal. Paris. EPHE. IV section. 1983.

- «Lactivité typographique de Valentim Fernandes au Portugal (1495-1518) ». dans L'humanisme portugais. 1984. p. 781-818.

* Antunes-Rambaud (Maria de Fátima), "Mère et fille dans les chansons dami galiciennes-portugaises ». dans Les Relations de parenté dans le monde médiéval. XIV'Colloque du Centre universitaire d'Études et de Recherches médiévales d'Aix. Aix-en-Provence. CUERMA. 1989 (Senefiance. 26), p. 131-139.

* Aouarone (Jean-Baptiste). «Un chapitre de la chronique de Jean Lefèvre, seigneur de Saint-Remy, relatif aux noces du roi Édouard de Portugal (1428) ». dans Mélanges de langue et de littérature médiévales offerts à Pierre LE GENTH, par ses collègues, ses élèves et ses amis, Paris. S.E.D.E.S. / C.D.U.. 1973. p. $33-54$.

* «Archives municipales du Portugal», Archivum, 13, 1963, p. 87-103.

* AsEnsio (Eugenio), «Une découverte bibliographique : Tratado de confissom (Chaves. 8.VIII.1489) », ACCP. XI, 1977, p. 35-40.

* Aubin (Jean), «D. João II et Henry VII », dans Congresso internacional "Bartolomeu Dias e a sua época ". Actas. Vol. I, Porto, 1989. p. 171-80.

- «D. João II devant sa succession », ACCP. XXVII (25 anos do Centro cultural português), 1990, p. 101140.

* Aux confins du Moyen Âge : art portugais XII-XV siècles /Catalogue de l'exposition] Centrum voor Kunst en cultuur, Sint-Pietersabdij, Gent 29 septembre 1991-5 janvier 1992. Bruxelles. Fondation Europalia international, 1991 (Europalia 91. Portugal).

* Azevedo (Francisco de Simas Alves de), "Présence héraldique hongroise au Portugal », dans Mélanges offerts à Szabolcs DE VAJAY à l'occasion de son 50 anniversaire par ses amis, ses collègues et les membres de l'Académie. éd. Adhémar DE PANAT, Xavier DE Gheldinck Vaernewyck et Pierre Brière, Braga, Livraria Cruz. 1971, p. 63-64.

* Backmini) (Norbert). "Les origines de l'Ordre de Prémontré au Portugal». Boletim cultural. Câmara municipal do Porto. XXII (3-4). 1959, p. 416-441.

* Balsf: (Thérèse). «D. Pedro I" de Portugal et Inês de Castro. Des sources historiques et littéraires portugaises à 'La reine morte' ". ACCP, XXXII. 1993, p 389-416. 
* Bandejra (Fernando), «Le notariat portugais», Archivum. 12. 1965.

* Beirante (Maria Ângela Rocha). "La 'herdade' alentejane au Moyen Âge ". dans Du latifundium au latifondo. Un héritage de Rome, une création médiévale ou moderne? Actes de la table ronde internationale du CNRS organisée à l'Université Michel de Montaigne - Bordeaux III les 17-19 décembre 1992. Paris. 1995 (Publications du Centre Pierre Paris [URA 991]. 25). p. 301-307.

* Belt-Arié (Malachi). "À propos des Manuscrits hébreux de Lisbonne ». Revue des études juives, 130/2-4. 1971. p. 311-3155 [CR de Sed-Rajna. 1970].

* Bensaude (Joaquim). Histoire de la science nautique portugaise : résumé. Genève. Kundig. 1917.

* Bessa (Carlos). "Le Portugal 1383-1385 : crise. art militaire et consolidation de l'independance », dans XXII. Kongre $\beta$ der Internationalen Kommission für Militärgeschichte / XXIInd Colloquium of the International Commission of Military History / XXII Congrès de la Commission Internationale d'Histoire Militaire. Von Crécy bis Mohács. Kriegswesen im späten Mittelalter (1.346-1526) / From Crécy to Mohács. Warfare in the Late Middle Ages (1.346-1526) / De Crécy à Mohács. Guerre et art militaire au bas Moyen Âge (1346-1526). Wien / Vienna / Vienne, 9.-13. September 1996 / September 9-13, 1996 / 9-13 septembre 1996. Vienne. Heeresgeschichtliches Museum / Militärhistorisches Institut, 1997 (Acta. 22). p. $28-50$.

* Blasco (Pierre). Les chansons de Pero Garcia Burgalês, troubadour galicien-portugais du xilr siècle. Introduction, édition critique, notes et glossaire. Paris. FCG/CCP. 1984.

* Blor (Jean-Yves) / Bló (Maria Luísa Pinheiro). « De la glaciation de Würm aux derniers temps de la marine à voile : éléments pour une carte archéologique du patrimoine immergé au Portugal». $O$ arqueólogo português. 4 s.. 8-10, 1990/92, p. 425-454.

* Boissellier (Stéphane), "Réflexions sur lidéologie portugaise de la Reconquête XII"XIV" siècles ", Mélanges de la Casa de Velazquez. Antiquité - Moyen Age, XXX/1, 1994, p. 139-165.

- "Archéologie rurale islamique dans le Sud du Portugal. Recension bibliographique ", Archéologie islamique. 6. 1996. p. 169-192.

- "Conquête chrétienne et acculturation dans le Sud du Portugal aux XII"XIV" siècles", dans Religion et identité. Actes du colloque d'Aix-en-Provence octobre 1996. dir. Gabriel Audisio. Aix-en-Provence. Publications de l'Université de Provence. 1998. p. 227-239.

- Naissance d'une identité portugaise. La vie rurale entre Tage et Guadiana de l'Islam à la Reconquête $\left(X^{\prime}\right.$-XIV siècles). Lisbonne. Imprensa Nacional/Casa da Moeda. 1998 (Estudos gerais. Serie universitária).

- «Lapport des sources diplomatiques chrétiennes à la connaissance d’al-Andalus : l’exemple du Garb 'portugais` (ressources documentaires et réflexions méthodologiques)". Qurtuba. Estudios andalusies, 3. 1998. p. 7-37.

- "Une tolérance chrétienne dans l'historiographie portugaise de la Reconquête (XII'-XIII" siècles)?". dans La tolérance. Colloque international de Nantes (mai 1998). Quatrième centenaire de l'édit de Nantes, dir. Guy SAupin et al.. Rennes. Presses Universitaires de Rennes, 1999. p. 371-383.

- "Les mudéjares dans le Sud portugais : l'étranger, l’intégration et le quotidien XIII-XIV" siècles". dans L'étranger au Moyen-Âge. Actes du XXX congrès annuel de la SHMES (Göttingen 3-6 juin 1999). Paris. Publications de la Sorbonne, 2000. p. 179-190.

- «Les conséquences de la Reconquête sur les situations et statuts sociaux inférieurs dans le Sud du Portugal (1147-1249) : un avilissement 'invisible'?". Mélanges de l'École française de Rome. MoyenÂge. 112 - 2 (La servitude dans les pays de la Méditerranée occidentale chrétienne au x'Ir siècle et au-delà : déclinante ou renouvelée? Actes de la table-ronde de Rome, 8 et 9 octobre 1999). Rome. École française de Rome. 2000). p. 715-743.

- "Lapport des sources d’archives chrétiennes à la connaissance du Gharb al-Andalus : les ressources documentaires et les problèmes de leur exploitation". dans Fontes da história de al-Andalus e do Gharb. éd. Adel SidARl'S. Lisbonne. IICT/Centro de Estudos Africanos e Asiáticos. 2000. p. 143-157.

- "Lappréhension des mudéjares par la société chrétienne dans le Midi portugais 1249-1496: quelques données et réflexions". Revista da Faculdade de Letras. História. 3 ' s.. 1. 2000) p. 183-210.

- "Les revendications paysannes collectives dans le Midi portugais (1275-1385) [publication de sources]". IIistoire et sociétés rurales, 15. 2001. p. 165-192.

- «Population musulmane. colonisation et encadrement municipal : une exploitation sociale de l'espace dans le Midi portugais?". dans L'espace rural. 2002. p. 57-79. 
- «Introduction au thème [II]. La réflexion sur l'espace rural au Portugal. jeu d’échelles ». ibid.. p. 8388.

- "Les dépenses d'un concelho portugais, Loulé (Algarve), à la fin du XIV" siècle à travers un livre de délibérations municipales (vereaçôes)", dans I.a fiscalité des villes au Moyen Âge (Occident méditerranéen). 3 : La redistribution de l'impôt. coord. Denis Menjot. Manuel Sanchl:z Martinfz. Toulouse. Privat, 2002. p. 175-192.

- «Les relations entre l'habitat et les châteaux dans le Sud du Portugal à la fin du Moyen-Âge (d'après le 'Livro das fortalezas' de Duarte Darmas) : ćvolutions depuis la Reconquête », dans Mil anos. 2002. p. 497-508.

- «La frontière luso-andalouse («marche inférieure ») X X-XIII" siècles : présentation générale et propositions de réflexions", dans Hommage à l'école d'Oviedo d'Études aljamiado (dédié au fondateur Álvaro Galmes dE Fuentes). dir. Abdeljalil Temimi. Zaghouan. Publications de la FTERSI. 2003. p. $109-128$.

- «Le rôle des églises dans la colonisation portugaise du Gharb al-Andalus et dans l'organisation postérieure de l'habitat au sud du Tage (XIl ${ }^{-} \mathrm{XV}^{\mathrm{c}}$ siècles) $)$. dans L'expansion occidentale $\left(X \mathrm{~V}^{-}-\mathrm{XV}^{\mathrm{V}}\right.$ s.). Formes et conséquences. XXXIII congrès de la SHMES (Madrid, Casa de Velázquez, 23-26 mai 2002), Paris. Publications de la Sorbonne. 2003. p. 115-131.

- Le peuplement médiéval dans le Sud du Portugal. Constitution et fonctionnement d'un réseau d'habitats et de territoires $X I I^{-}-X V^{\prime \prime}$ siècles. Paris. Centro cultural Calouste Gulbenkian. 2003.

- «Compte-rendu de Manuel Sílvio A. CONDE : Uma paisagem humanizada. O Médio Tejo nos finais da Idade Média. Patrimonia. Cascais. 2000 (2 vol.) ». Histoire et sociétés rurales. 19. 2003. p. 268-271.

- "Des franchises aux coutumes : la formation et l'évolution du prélèvement scigneurial (l'exemple d'Évora 1165-1280)", dans Pour une anthropologie du prélèvement seigneurial dans les campagnes médiévales (XI-XIV siècles). Réalités et représentations paysannes. Colloque tenu à Medina del Campo du 31 mai au 3 juin 2000. éd. Monique Bourin et Pascual Martinez Sopena. Paris. Presses de la Sorbonne. 2004 (Histoire ancienne et médiévale. 68), p. 443-496.

- «Les rois. la guerre. les Maures. La (re-)construction de l'idéologie de Reconquête dans une source portugaise généalogico-narrative tardive. les 'livres de lignages' ". dans Le pouvoir au Moyen Âge. Idéologies, pratiques, représentations. dir. Claude CAROZZI et Huguette TAVIANI-Carozzi. Aix-enProvence. Publications de l'Université de Provence. 2005 (Le temps de l'histoire), p. 123-145.

- "Le marché de la terre et la Reconquête : les transactions du monastère Saint-Vincent de Lisbonne (1147-1205)", dans Le marché de la terre au Moyen Âge. dir. Laurent FElleE / Chris Wickham. Rome. EFR. 2005 (Collection de l'EFR. 350). p. 445-477.

- «Sur quelques manuscrits concernant la fiscalité pontificale au Portugal». Archivum historiae pontificiae, 43, 2005, p. 13-45.

- "Organisation sociale et altérité culturelle dans l'hagionymie médiévale du Midi portugais ». Lusitania sacra. $2^{*}$ s. 17 [Clérigos e religiosos na sociedade medieval]. 2005. p. 255-298.

- "Les recherches sur les déplacements de bétail au Portugal au Moyen Âge, bilan des travaux et éléments de réflexion». dans Transhumance et estivage en Occident des origines aux enjeux actuels. Actes des XXVI" journées internationales d'histoire de l'abbaye de Flaran, 9, 10, 11 septembre 2004. éd. Pierre-Yves LafFont. Toulouse, Presses Universitaires du Mirail, 2006, p. 163-182.

- "La 'Vie de S. Isabelle de Portugal' en langue vulgaire : présentation et traduction française annotée». Revue Mabillon. 2006 [sous presse].

- L'autre Reconquête : la naissance du Portugal sous la dynastie de Bourgogne. 2006 [à paraître].

- "Le plus ancien registre de la gestion patronale royale portugaise (Afonso III. 1258) (édition et présentation des Gavetas. XIX. maço 14. doc. 2 et maço 15, doc. 46) ». Lusitania Sacra. 2“ s.. 18. 2006 [à paraître].

- Registres fiscaux el administratifs de bénéfices ecclésiastiques du royaume portugais XIIr-XIV siècles (édition et présentation). Contribution à l'étude du phénomène administratif. Toulouse. Framespa. 2007 [à paraître].

- I Baloup (Daniel) / Denjean (Claude), La Péninsule ibérique au Moven-Âge. Documents traduits el présentés. Rennes. Presses universitaires de Rennes. 2003 (Didact histoire). 
* BolÉo (Manuel de Paiva). «Linguistique. géographie et unités dialactales subjectives au Portugal ». dans ID. Estudos de linguística portuguesa e românica. Vol. I. Coimbra. Universidade de Coimbra. 1974. p. $349-473$.

* Bottinead (Yves), Le Portugal el sa vocation maritime. Histoire et civilisation diune nation. Paris. De Boccard. 1977 [chap. I-V].

* Boucharb (Ahmed). "Islamologie et moriscologie au Portugal durant les 30 dernières années", dans Actes du VI symposium international d'études morisques sur "État des recherches en moriscologie durant les 30 dernières années ". Zaghouan. FTERSI, 1995, p. 35-52.

* Bourdon (Léon). "Question de priorité autour de la découverte du manuscrit du Leal conselheiro". ACCP. XIV. 1979, p. 3-26.

* Braciança (Joaquim O.), La Vigile pascale du Missel de Mateus. Paris. Institut supérieur de liturgie de Paris, 1962 [thèse dactyl.].

- «Le symbolisme des rites baptismaux au Moyen Âge ». Didaskalia. Revista da Faculdade de teologia de Lisboa. 3 (fasc. 1), 1973. p. 37-56.

- «Linfluence de la liturgic languedocienne au Portugal (Missel. pontifical. rituel)». dans Liturgie et musique (IX'-XIV S.), éd. Marie-Humbert VICAIRE, Toulouse. Privat, 1982 (Cahiers de Fanjeaux, 17). p. 173-184.

- «Un rituel de baptême hors série ». Miscel.lània litúrgica catalana. 10, 200)1. p. 203-209.

* Brière (Pierre). "Contre-sceau d'Alphonse de Portugal, comte de Boulogne". Revue française d'héraldique et de sigillographie. 26 (42). 1973. p. 3-6.

* Brogua (Joseph, comte de), Le Portugal feudataire de Clairvaux. Communication historique au Congrès des Sociétés savantes de Dijon, juin 1927. Dijon. Impr Jobard. 1927.

* Carta (Helder), "Une influence islamique durable. Les palais et quintas des environs de Lisbonne», Monuments historiques de la France. 194, 1994, p. 46-51.

* Carvalho (Joaquim Barradas de). "Sur l'introduction et la diffusion des chiffres arabes au Portugal ", $B E P .20,1957$, p. $110-151$.

* Castelos medievais de Portugal. Il congresso do Centro europeu para o estudo dos castelos. Zurich. DGEMN. 1949 [notices en français].

* Catarino (Helena), «Châteaux et peuplement rural islamique et de la Reconquête en Algarve oriental : les données archéologiques », dans Liespace rural. 2002. p. 41-56.

* Chaves (Luís), «La toponymie des eaux. Les eaux dans la toponymic portugaise », dans 5 Congrès international de toponymie et danthroponymie. Salamanca, 12-15 avril 1955. Actes et mémoires. Tome I. éd. L. Cortes et al.. Salamanque. 1958.

* Cintra (Luís Filipe Lindley). "Toponymie léonaise au Portugal : la région de Riba-Coa ". dans 5 Congrès international de toponymie et d'anthroponymie. Salamanca (op. cit. supra). p. 245-257.

- "Une frontière lexicale et phonétique dans le domaine linguistique portugais". dans $I X^{\circ}$ Congresso internacional de linguística românica. Universidade de Lisboa, 31 de março - 4 de abril 1959. Actas, III. Lisbonne. Centro de estudos filológicos. 1962, p. 31-39 [rééd. dans ID., Estudos de dialectologia portuguesa, Lisbonne. Sá da Costa. 1983, p. 107-116].

- «Les anciens textes portugais non littéraires. Classement et bibliographie». Revue de linguistique romane. 27.1963 , p. $40-58$.

* Clermont (G. de). Helfferich (A.). Fueros francos. - Les communes françaises en Espagne et en Portugal pendant le moyen âge. Étude historique sur leur formation et leur développement, accompagnée d'un grand nombre de textes inédits tirés de manuscrits espagnols et portugais. Berlin / Paris. Auguste Durand. 1860.

* Cocheril (Maur) 1957 : «Les monastères cisterciens du nord du Portugal», Collectanea Ordinum cisterciensium reformatorum. XIX. 1957, p. 61-77.

- «Essai sur l'origine des Ordres militaires dans la Péninsule ibérique ». ibid., 1958/59. p. $317-329$ ct 228-250.

- "LOrdre de Cîteaux au Portugal : le problème historique ". Studia monastica. 1. 1959. p. 51-95 [également dans $A$ cidade de Évora. 39-40. 1957/58. p. 139-159].

- "Saint-Bernard et le Portugal : à propos d'une lettre apocryphe ". Revue dhistoire ecclésiastique. 54/23. 1959. p. $426-477$. 
- «Recherches sur l'Ordre de Cîteaux au Portugal», BEP. 22. 1959/60. p. 30-120.

- «Lhéraldique cistercienne portugaise». sep. Armas e trofeus, 2 s.. 2. 1961.

- «Les abbayes cisterciennes portugaises du XII" siècle "sep. Bracara Augusta. 14-15, 1963.

- Études sur le monachisme en Espagne et au Portugal, Lisbonne / Paris. Bertrand / Les Belles Lettres. 1966 (Collection portugaise).

- art. "Évora ». dans DHGE. XVI. 1967, col. 135-66.

- «Les Ordres militaires cisterciens au Portugal», BEP. 28-29. 1967/688, p. 11-71.

- «Une description du Portugal au XvI siècle ». ACCP. III. 1971. p. 76-111.

- Notes sur l'architecture et le décor dans les abbayes cisterciennes du Portugal. Paris. FCG/CCP. 1972.

- «Alcobaça. capitale de Cíteaux au Portugal», dans Papel das áreas regionais na formação histórica de Portugal. Actas do colóquio, Lisbonne. Academia portuguesa de história. 1975. p. 23-36.

- «Les infantes Teresa, Sancha et Mafalda et l'Ordre de Cîteaux au Portugal», RPH, 16. 1978. p. 3349.

- «D. Afonso Henriques et les premiers Cisterciens portugais", dans Congresso histórico de Guimarães e sua colegiada. Actas. Vol. 5. Braga, 1982, p. 321-332.

- «Le problème des fondations cisterciennes au Portugal». dans Mélanges à la mémoire du Père Anselme Dimitr. Tome II : Histoire cistercienne. Vol. 4 : Abbayes, éd. Benoît Chauvin, Arbois. Pupillin. 1984. p. 629-638.

- Routier des abbayes cisterciennes du Portugal. nouv. éd. rev. corr. et annotée Gérard LERoux. Paris. FCG/CCP. 1986.

* Coelho (Maria Helena da Cruz). "Permanences et mutations dans le monde rural au Portugal aux XIV" et $\mathrm{XV}^{*}$ siècles ». ACCP. XXVI (Le Portugal du XV siècle. Actes du colloque. Paris, 12 mars 1987). 1989. p. 67-96.

- «État et Cortes du Portugal sous la dynastie des Avis : le cas du régent Don Pedro». Parliaments, Estates and Representation / Parlements, États et représentation, 16. 1996. p. 47-58.

- "Les Cortes en temps de guerre - une médiation interactive entre le roi et les corps sociaux du royaume de Portugal aux XIV" et $X V^{c}$ siècles», ibid., 21. 2001. p. 37-56.

- "L'action de Sainte-Croix sur le paysage agraire du Bas Mondego aux XII" et XIII siècles», dans L'espace rural. 2002, p. 113-123.

- "Les relations du savoir et du pouvoir dans le Portugal médiéval (XIV" et XV" siècles)», dans Europa und die Welt in der Geschichte. Festschrift zum 60. Geburtstag von Dieter BE:RG, éd. Raphaela AverKorN et al., Bochum. 2004. p. 313-334.

- / Homen (Armando Luís de Carvalho). "Origines et évolutions du registre de la chancellerie royale portugaise (XIII'-XV" siècles) ". Revista da Faculdade de Letras. História. $2^{c}$ s., 12. 1995. p. 47-74.

- I - «Les actes judiciaires de Pierre I"r du Portugal (1357-1366)». dans La diplomatica dei documenti giudiziari (dai placiti agli acta - secc. XII-XV). Commission internationale de diplomatique, X congresso internazionale. Bologna, 12-15 settembre 2001, éd. G. NicoLAJ, Bologne. 2004.

* Corbin (Solange). Essai sur la musique religieuse portugaise au Moyen Âge (1100-1385), Paris, Les Belles Lettres. 1952 (Collection portugaise, 8).

- La déposition liturgique du Christ au Vendredi saint. Sa place dans l'histoire des rites et du théâtre religieux (Analyse de documents portugais). Paris/Lisbonne. Les Belles Lettres / Livraria Bertrand. 1960 (Collection portugaise. 12).

* Correia (Virgílio Hipólito) / Parreira (Rui). Cola. Circuit archéologique. Lisbonne. IPPAR. 2002 (Roteiros da arqueologia portuguesa, 8).

* CORTESÁo (Jaime), «L'influence des facteurs géographiques et économiques dans l'histoire du Portugal». dans ID.. L'expansion des Portugais dans l'histoire de la civilisation. Lisbonne. INCM. 1983 (Temas portugueses). p. 19-21.

* Costa (Adelaide Lopes Pereira Millán da). «Les artisans et le pouvoir municipal à Porto (XIV"-XV" siècles) 》. Razo. 14 (Liartisan dans la Péninsule ibérique. dir. Denis MeNJoT). 1994. p. 157-161.

* Costa (Avelino de Jesus), «La chancellerie royale portugaise jusquau milieu du XIIr" siècle ». RPH. 15. 1975. p. 143-169. 
- "Compte rendu de 'Le cartulaire Baio-Ferrado du monastère de Grijó (XI'-XIII' siècles). éd. Robert Dinand. Paris. FCG/CCP. 1971 (Fontes documentais portuguesas. II)' ». Cahiers de civilisation médiévale. 19. 1976. p. $385-392$.

* Costa (Mário Júlio Brito de Almeida). "La présence d’ $\Lambda$ ccurse dans l'histoire du droit portugais ». dans Atti del convegno internazionale di studi accursiani. Milan. 1968, vol. III. p. 1053-1066.

* Covtinho (Bernardo Xavier da Costa). "Lidée de croisade au Portugal au XV' siècle ", dans Miscellanea historica in honorem Alberti DE MEYER, Universitatis Catholicae in Oppido Lovaniensi jam annos XXV professoris, Louvain. Bibliothèque de l'Université, 1946 (Université de Louvain. Recueil de travaux d'histoire et de philologie. 3. s.. 22/3). p. 737-747.

* Cressif:R (Patrice). "Chapiteaux islamiques du Portugal (traditions, créations, importations) ». dans Muçulmanos e cristãos entre o Tejo e o Douro (séculos VIII a XIII). Actas dos Seminários realizados em Palmela (14 e 15 de Fevereiro de 2003) e no Porto (4 e 5 de Abril de 2003). éd. Mário Jorge Barroca. Isabel Cristina Ferreira Fernandes. Palmela. Câmara Municipal de Palmela / Departamento de Ciências e Técnicas do Património (FLUP). 2005.

* Crozi:t (René). "La Sé Velha de Coimbre (Portugal)». Bulletin monumental. 129/1. 1971. p. 39-48.

* Cunha (Maria Cristina Almeida e). «La chancellerie archiépiscopale de Braga (1071-1245) : quelques aspects », dans Die Diplomatik, 1995. p. 503-509.

- "Traces de la documentation pontificale dans les documents épiscopaux de Braga (1071-1244)". dans Papsturkunden und europäisches Urkundenwesen. Studien zu ihrer formalen und rechtlichen Kohärenz vom 11. bis 15. Jahrundert, dir. Peter Herde et al. Cologne/Weimar/Vienne. 1999. p. 259-269.

* Cinhal. (Alvaro). Les luttes de classes au Portugal à la fin du Moyen Âge. Paris. Centre d’études et de recherches marxistes. 1967.

* Dalllifz (Laurent). "Essai historique sur l'Ordre souverain de Saint-Jean de Jérusalem. de Rhodes et de Malte, au Portugal (XIr-XV" siècles)», $A C C P$. 1. 1969, p. 13-52 [réimpr. en tirage autonome sous le titre L'Ordre de Saint-Jean de Jérusalem au Portugal, $X I^{\prime}-X V^{\prime \prime}$ siècles. Nice. Alpes-Méditerranée-Impres'Sud. 1977].

* Darbord (Michel). João Álvares. Traité de la vie et des faits du vertueux infant D. Fernando. Introduction, traduction et notes [thèse complémentaire lettres]. Paris, 1965.

* Daveal (Suzanne). «Géographic historique du site de Coruche, étape sur les itinéraires entre Évora et le Ribatejo ". Revista da Faculdade de Letras [de Lisboa], 5" s., 2, 1984, p. 115-135.

* Davir) (Pierre). «La Sé Velha de Coimbra et les dates de sa construction (1140-1180)». BEP. 9/1, 1942. p. 12-34.

- «Les Français du Midi dans les évêchés portugais (1279-1382) ». ibid., 9/2. 1942, p. 16-70.

- «Sur une histoire de la littérature portugaise médiévale (à propos de la réédition du livre de M. Rodrigues Lapa) ». ibid.. p. 125-136.

- "Les saints patrons d’églises entre Minho et Mondego jusqu’à la fin du Xl“ siècle. Étude d’hagiotoponymie », RPII. 2. 1943. p. 221-254.

- «Le Missel de Mateus. Notes historiques et liturgiques". Biblos, 20. 1944. p. 319-358.

- "Études sur le livre de Saint-Jacques attribué au pape Calixte II ». BE, 10. 1945. p. 1-41.

- "Lorganisation ecclésiastique du royaume suève au temps de saint Martin de Braga ", dans ID.. Études historiques sur la Galice et le Portugal du $v r$ au $x \| t$ siècle. Lisbonne/Paris. Livraria Portugália editora / Les Belles Lettres. 1947 (Collection portugaise. 7). p. 1-82.

- "Le sanctoral hispanique et les patrons d’églises entre le Minho et le Mondego du IX" au XII" siècle ". ibid., p. 185-256.

- «Annales portugalenses veteres ». ibid.. p. 257-340.

- "Regula Sancti Augustini. À propos d’une fausse charte de fondation du chapitre de Coimbra". RPH, 3. 1947. p. 27-39.

- «Études sur le livre de Saint-Jacques... II : les livres liturgiques et le Livre des Miracles ». BEP, 11.1947. p. 113-185.

- "Sur la relation de la prise de Lisbonne (1147) par un clerc anglo-normand». ibid.. p. 241-254.

- "Études sur le livre de Saint-Jacques... III : le pseudo-Turpin et le Livre du Pèlerin ». ibid., 12. 1948. p. 7()$-223$. 
- «Études sur le livre de Saint-Jacques... IV : Révision et conclusion», ibid.. 13. 1949. p. 52-104.

- «Saint Martin de Braga est-il l'auteur d'un traité de comput pascal? », ibid., 14. 1950, p. 283-299.

- «La première campagne d'Abou Yousof al Mansour contre Silves (1190)», ibid., 16. 1952. p. 177-184.

- "Coimbre", dans DHGE. XIII. 1956, col. 204-212.

* David-Peyre (Yvonne). "Quelques suggestions au sujet du mot 'rossio" ". Bulletin hispanique. 56, 1954. p. 401-411.

- «L'immigration française au Portugal pendant le Moyen Âge ». Langues néo-latines. 68 (210). 1974. p. 112-124.

- «Neurasthénie et croyance chez D. Duarte de Portugal». ACCP, XV, 1980, p. 521-540.

* Delaville Le Roulx (Joseph). "Notice sur les Archives de Torre do Tombo à Lisbonne". Revue des bibliothèques. II. 1892. p. 117-180.

- "Les archives de l'Ordre de l'Hôpital dans la Péninsule ibérique ". Nouvelles archives des missions scientifiques et littéraires. 4. 1893, p. 1-283 [ou ID.. Les archives de l'Ordre de l'Hôpital dans la Péninsule ibérique, Paris. Ernest Leroux. 1893].

* Deluy (Henri), Troubadours galégo-portugais. Une anthologie. Paris. POL. 1987.

* Demersay (Alfred). "Rapport sur les résultats d'une mission dans les archives d'Espagne et de Portugal », sep. Archives des missions scientifiques et littéraires. 2 ' s.. II. 1865.

* DenuCE (Jean). «Privilèges commerciaux accordés par les rois du Portugal aux Flamands et aux Allemands (XV" et XVl" siècles)". Archivo histórico portuguez. 7. 1909. p. 310-319 et 377-392.

* Diogo (Américo António Lindeza). «Des chevaux et des bœufs : le chevalier et son seigneur dans la satire galégo-portugaise". dans Le cheval dans le monde médiéval. Actes du XVII colloque du CUERMA, Aix-en-Provence 1992. Aix-en-Provence. CUERMA. 1992 (Senefiance. 32). p. 173-185.

* Dolbeau (François), «Le légendier d'Alcobaça. Histoire et analyse ". Analecta Bollandiana, 102/3-4, 1984, p. $263-296$.

- "Le légendier perdu de la cathédrale de Coimbra », ibid., 105/1-2, 1987, p. 130-131.

* Dominciues (José D. Garcia). "Les plus récentes contributions des arabisants étrangers à l'étude de l'histoire luso-arabe ». BEP. 19.1955/56. p. 161-172.

- Silves. Guide touristique de la ville et de sa région. Faro. Região de Turismo do Algarve. 1989 (Monografia, 4).

* Dony (Paul). Batalha : un problème d'influences. Lisbonne. Instituto da Alta Cultura. 1957 (Cadernos do Centro de estudos de arte e museologia. VII).

* Drozdowiez (Nathalie). «Un très ancien port né du Tage. Historique de la ville (Lisbonne) ». Monuments historiques de la France. 194. 1994, p. 118-120.

* Duarte (Luís Miguel), Justice et criminalité au Portugal au Moyen Âge et au début de l'Époque Moderne : les traces, les silences. les problèmes", dans La Leopoldina : criminalità e giustizia criminale nelle riforme del '700 europeo. coord. Luigi BerLINGUER. Milan. Giuffré, 1990, p. 449-460.

* Dufourco (Charles-Emmanuel). "Les Mozarabes du XII" siècle et le prétendu évêque de Lisbonne", Revue d'histoire et de civilisation du Maghreb. 5. 1968. p. 125-130.

* DuRANi) (Robert). éd. introd.. Le cartulaire Baio-Ferrado du monastère de Grijó (XI'-XIIr siècles). Paris. FCG/CCP, 1971 (Fontes documentais portuguesas. II).

- «La vigne et le vin dans le bassin du Mondego au Moyen Âge (XIr-XIII" siècles)». ACCP, V. 1972. p. 13-37.

- Les campagnes portugaises entre Douro et Tage aux XII et XIIr siècles, Paris, FCG/CCP. 1982 (Civilisation portugaise, IX).

- «L'économie cistercienne au Portugal». dans L'économie cistercienne. Géographie - Mutations du Moyen Âge aux temps modernes. Centre culturel de l'abbaye de Flaran. Troisièmes journées internationales d'histoire, 16-18 septembre 1981. Auch, 1983, p. 101-117.

- «Habitats fortifiés et organisation des pouvoirs au Portugal», dans Habitats fortifiés et organisation de l'espace en Méditerranée médiévale. Table ronde tenue à Lyon les 4 et 5 mai 1982. éd. André BAZZANA et al.. Lyon. Maison de l'Orient méditerranéen. 1983. p. 69-75.

- "Réflexions sur la féodalité au Portugal ( $\mathrm{X}^{*}$-XIII" siècles). À propos d’un livre récent ». sep. RPH. XXI. 1985. 
- «Pouvoir et société politique dans le royaume du Portugal», dans Pouvoirs et sociétés politiques dans les royaumes ibériques au bas Moyen Âge. Nice. Publications de l'Université de Nice. 1986. p. 7-28.

- «La seigneurie portugaise (XI"-XII" siècles) : anomalies et conformités", dans Histoire du Portugal, histoire curopéenne. Actes du colloque. Paris, 22-23 mai 1986. Paris. FCG/CCP, 1987. p. 19-25.

- «Village et seigneurie au Portugal (X“-XII" s.)». Cahiers de civilisation médiévale. 30. 1987. p. $205-217$.

- "Guerre et fortification de l'habitat au Portugal aux XII" et XII" siècles". dans Castrum 3. Guerre, fortification et habitat dans le monde méditerranéen au Moyen Âge. Colloque organisé par la Casa de Velázquez et l'École Française de Rome. Madrid, 24-27 novembre 1985. Rome/Madrid. École française de Rome/Casa de Velázquez, 1988, p. 179-186.

- "Frontière. fortifications et villes au Portugal d’après le Livro das Fortalezas (début XVI siècle)". dans Villes, bonnes villes, cités et capitales. Mélanges offerts à Bernard CHEvaLIER. Tours. 1989. p. 231-237.

- «La mémoire des campagnes portugaises (XII" siècle)», dans Campagnes médiévales : l'homme et son espace. Études offertes à Robert FOSSIER. Paris. Publications de la Sorbonne. 1995. p. 363-373.

- «Trois siècles de dénomination aristocratique portugaise d’après la littérature généalogique ", dans Genèse médiévale de l'anthroponymie moderne. Tome III : Enquêtes généalogiques et données prosopographiques, dir. Monique Bourin et Pascal Chareille, Tours, Publications de l'Université de Tours, 1995. p. $43-54$.

- «De urso manus : l'exploitation de la faune du saltus au Portugal», dans Milieux naturels, espaces sociaux. Études offertes à Robert DELORT. Paris. Publications de la Sorbonne. 1997. p.

- "Châteaux et frontière au Portugal au XIII" siècle : de la guerre à la paix », dans Mil anos, 2002. p. 239-250.

- "Dénomination d'esclaves au Portugal (fin IX“-début XIII siècle)", dans Genèse médiévale de l'anthroponymie moderne. Tome V-1 : Intégration et exclusion sociale : lectures anthroponymiques. Serfs et dépendants au Moyen Âge (VIII'-XII' siècle), dir. Monique Bourin et Pascal Chareille, Tours. Publications de l'Université de Tours, 2002.

- «Le souverain vu du cloitre. Hagiographie et idéologie royale au Portugal : le cas de Sainte-Croix de Coïmbre ". dans Religion et mentalités médiévales au Moyen Âge. Mélanges en l'honneur d'Hervé Martin. dir. Sophie Cassagnes-Brouquet et al., Rennes. PUR. 2003. p. 55-63.

- "Les moulins hydrauliques dans le Portugal médiéval ", dans I mulini nell'Europa medievale. Atti del convegno di San Quirino d'Orcia, 2l-23 settembre 2000. éd. Paola GaletTl et Pierre Racine, Bologne, Clueb, 2003 (Biblioteca di storia agrarie medievale, 21).

- "Animal-outil et animal-aliment au Moyen Âge : le cas portugais", dans Élevage d'hier, élevage d'aujourd'hui. Mélanges d'ethnozootechnie offerts à Bernard DENIS, Rennes, PUR, 2004 (Histoire). p. 8995.

* Farelo (Mário Sérgio) 1999 : La peregrinatio academica portugaise vers l'Alma Mater parisienne, XII$X V^{\prime \prime}$ siècles. Montréal. Université de Montréal, 1999 [polycop.].

- "Les Portugais à l'Université de Paris au Moyen Âge et l'acheminement de leurs ressources ", Memini. Travaux et documents publiés par la Société des études médiévales du Québec. 5. 2001. p. 101-129.

* Farinha (António Dias), "Mots portugais dérivés de l’arabe hispanique classés par matières ", dans Mélanges dislamologie. Volume dédié à la mémoire de Armand ABEL. éd. Pierre SALMON. Leyde. Brill. 1974. p. $143-159$.

* Fathi (André). Quelques aspects du développement urbain au Portugal pendant la présence musulmane. Paris. Université de Paris III - Sorbonne Nouvelle. 1977 [maîtrise dactyl.].

* Ftrnandes (Isabel Maria), "Les centres producteurs de poterie noire du nord du Portugal ". dans La céramique médiévale en Méditerranée. Actes du VI congrès de l'AIECM. Aix-en-Provence 113-18 novembre 1995), éd. Gabrielle DrMians D’AR(Himbaud, Aix-en-Provence, Narration Éditions, 1997. p. 575-578.

- "Les ateliers de poterie noire de Lanheses (Viana do Castelo) : un phénomène de migration ». dans Material Culture in Medieval Europe. Papers of the "Medieval Europe Brugge 1997 " Conference. 7. éd. Guy dE BoE et Frans Verhafcihf. Zellik. Instituut voor het Archeologisch Patrimonium. Wetenschappelijke instelling van de Vlaamse Gemeenschap. 1997 (I.A.P. Rapporten. 7). p. 87-93.

* Fi:Rnandos (José Manuel). Sỵnthèses de la culture portugaise. L'architecture. Lisbonne. INCM. 1991. 
* Fernandes (Raúl Miguel Rosado). «Méthodologie et histoire dans De antiquitatibus Lusitaniue d'André de Resende ". dans L'humanisme portugais. 1984. p. 487-505.

* Fernão Lopes. Chronique du roi D. Pedro I. Crónica do rei D. Pedro I. éd. Giuliano Macchi. trad. Jacqueline STFINNOU, Paris, CNRS, 1985 (Sources d'histoire médiévale publiées par l'IRHT).

* Ferreira (José de Azevedo) éd.. Alphonse X. I : Édition el étude. Braga. INIC. 1980.

- "Un nouveau fragment de la Terceira Partida d'Alphonse X». dans Mélanges de linguistique dédiés à la mémoire de Petar SKоK (1881-1956). éd. Mirko DeAnovic. Zagreb. Académie yougoslave des sciences et des arts. 1985, p. 45-64.

- «Traduction et paraphrase dans les premiers textes juridiques portugais ». Cahiers de linguistique hispanique médiévale. 14/5, 1990. p. 63-77.

* Filgueiras (Octávio Lixa). "Les bâteaux de pêche de Póvoa de Varzim et le 'sinagot'». dans La Bretagne. Le Portugal. 1973, p. 63-73.

* Folz (Robert). Les saintes reines du Moyen Âge en Occident ( $V I$-XIIr siècles). Bruxelles. Société des Bollandistes. 1992 (Subsidia hagiographica, 76). p. 145-158 [sur sainte Isabelle de Portugal].

* Fonseca (Fernando Venâncio Peixoto da). «Les chroniques portugaises des Portugaliae Monumenta Historica ". Revue des langues romanes, 77. 1967, p. 55-84.

* Fonsec'A (Luís Adão da). «Le Portugal entre Méditerranée et Atlantique au XV siècle ». ACCP. XXVI (Le Portugal du Xv' siècle. Actes du colloque. Paris, 12 mars 1987), 1989. p. 145-160.

* Franco (Isabel Maria Madureira). «Les dynamiques familiales et sociales dans un village de pêcheurs des environs de Porto (1449-1497)». dans The Medieval Household in Christian Europe, c. 850 c. 1550. Managing Power, Wealth, and the Body. éd. Cordelia BeATTIE et al.. Turnhout. Brepols. 2003 (International Medieval Research, 12). p. 271-292.

* Franco (Luís Farinha), «Fonds manuscrits pour l'histoire du Portugal - Instruments de travail (19781988) ». La recherche en histoire du Portugal. 1. 1989. p. 11-20.

* Frias (Agostinho Figueiredo) / Maroves (Bernardino Fernando da Costa). «Theologia. scientia et ars dans les Sermones de Frater Pelagius Parvus Colimbriensis, O.P.». dans Le vocabulaire des écoles des Mendiants au Moyen Âge. Actes du colloque. Porto (Portugal), 11-12 octobre 1996. éd. Maria Cândida PACHECO. Turnhout. Brepols. 1999 (Études sur le vocabulaire intellectuel du Moyen Âge. 9). p. 1625.

* GalfFier (Baudouin de). "Le bréviaire d'Évora de 1548 et l'hagiographie ibérique ». Analecta Bollandiana, 60. 1942. p. 131-138.

* Gaspar (Jorge). "Le réseau urbain et la campagne au Portugal (XII-XVII" siècle)». Storia della Città. 36 (Città e campagne in Europa), 1989. p. 113-129.

* Godinho (Helder). "La description de l'Europe dans le Livro de Arautos (Livre d'un hérault. écrit en latin (1416) : Ms. Manchester. John Rylands Library. lat. 28)». dans Terres médiévales, éd. Bernard RibÉmONT, Paris. Klincksieck, 1993 (Sapience. 8), p. 119-128.

* Godinho (Vitorino Magalhães), "Les Grandes Découvertes », BEP 16. 1952. p. 3-54.

- «Innovation et changement au XV" et au XVI" siècle». dans Lhumanisme portugais. 1952. p. 347-375.

* Gomes (Rita Costa). "L'émergence du politique dans le Portugal du bas Moyen Âge - perspectives récentes », La recherche en histoire du Portugal. 1. 1989. p. 25-32.

- «Usages de Cour et cérémonial dans la Péninsule ibérique au Moyen Âge». dans Les traités de savoir-vivre en Espagne. Clermont-Ferrand. 1995. p. 3-18.

* Gomes (Saul António). "Les ouvriers du bâtiment à Batalha ». Razo, 14 (Liartisan dans la Péninsule ibérique, dir. Denis Mensot), 1994, p. 33-51.

* Gomez (Maria Carmen). "Les musiciens du roi de Portugal : une mention de Jacquemart le Cuvelier». Revue de musicologie, 73/1. 1987, p. 99-106.

* Graf (Gerhard N.) et al., Portugal roman. La Pierre-qui-Vire. Zodiaque. 1986/87 (La nuit des temps. 66/7). 2 vol.

* Grangé (Mathieu), «Le Cerro do Castelo de Alferce (Monchique. Faro) : premières hypothèses sur la genèse et l'évolution du peuplement médiéval dans la Serra de Monchique ( $V^{\prime-X I I I ~ s i e ̀ c l e s) " ~ d a n s ~}$ Xelb. Silves. 2005 (2" Encontro Arqueológico do Algarve [Silves. 2003/) [à paraître]. 
* Guichard (Pierre), "Introduction au thème 'Dans l'Ouest d'al-Andalus. le modèle de peuplement andalou et la Reconquête" ". dans L'espace rural. 2002. p. 25-30.

- "La société du Garb al-Andalus et les premiers husûn ». dans Mil anos, 2002, p. 177-187.

* Gurron (Francis). L'Ordre du Temple, l'Ordre du Christ, l'Ordre d'Avis, l'Ordre de Santiago : la chevalerie militaire alu Portugal. Paris. Lethielleux. 1982.

* HeErs (Jacques). "Lexpansion maritime portugaise à la fin du Moyen Âge : la Méditerranée ». Revista da Faculdade de letras. 2* s.. 22. 1956.

- «Portugais et Génois au $X v^{\prime}$ siècle : la rivalité Atlantique-Méditerranée », dans ID.. Société et économie à Gênes (XI'-XV' siècles). Londres, Variorum Reprints, 1979 (Variorum Reprints. Collected Studies Series. 101) [art. IV] p. 138-147.

* Hélotor (Pierre), "Les débuts de l'architecture gothique dans le Midi de la France, l'Espagne et le Portugal », Anuario de estudios medievales, 8. 1973, p. 105-141.

* Henrifi (Patrick). "Y a-t-il une hagiographie de la 'Reconquête' hispanique (XI'-XIII siècles) ? ", dans L'expansion occidentale (XI'-XV's.). Formes et conséquences. XXXIII congrès de la SHMES (Madrid, Casa de Velázquez, 23-26 mai 2002). Paris. Publications de la Sorbonne. 2003, p. 47-63.

* Henry (A.). Histoire du Portugal, époque musulmane. Arabes et Berbères. Les Arabes - Émirat - Califat - Décadence. Fontenay. Procure Mato Grosso. 1989.

* Hespanha (António Manuel), "Savants et rustiques. La violence douce de la raison juridique », Ius commune. Veröffentlichungen des Max-Planck-Instituts für europäische Rechtsgeschichte, 10, 1983. p. 1-48.

* Heullant-Donat. «La perception des premiers martyrs franciscains à l'intérieur de l'Ordre au XIII" siècle ». dans Religion et mentalités médiévales au Moyen Âge. Mélanges en l'honneur d'Hervé MARTIN. dir. Sophie Cassacines-Brouquft et al., Rennes. Presses Universitaires de Rennes, 2003, p. 211-220.

* Heur (Jean-Marie D'). Troubadours d'Oc et troubadours galiciens-portugais. Recherches sur quelques échanges dans la littérature d'Europe au Moyen Âge. Vol. I, Paris. FCG / CCP. 1973.

- «Sur la généalogie des chansonniers portugais d'Ange Colocci », Boletím de Filologia, 29/1-4, 1984, p. 23-34.

* Hoffmann (R. C.) et Johnson (Harold B.). «Un village portugais en mutation. Póvoa d'El Rey à la fin du quatorzième siècle ", Annales. ESC, 26/5, 1971, p. 917-940.

* IIOMEM (Armando Luis de Carvalho). “L'État portugais ct ses scrvitcurs (1320-1433) », Journal des savants, 1987. p. 181-203.

- «État. institutions et société politique sous Jean $\mathrm{I}^{\mathrm{*}}$ et Edouard I" ». ACCP. XXVI (Le Portugal du $X V^{\prime \prime}$ siècle. Actes du colloque. Paris, 12 mars 1987), 1989, p. 35-48.

- "Les officiers royaux (XIII"-XV" siècles) : une élite politique?". Anais da Universidade autónoma de Lisboa. História. 2. 1995. p. 23-27.

- "Prosopographie et histoire de l'État. La bureaucratie des rois portugais aux XIV“ et $\mathrm{XV}^{*}$ siècles : recherches faites, recherches à faire", dans L'État moderne et les élites, XIII-XVIII siècles. Apports et limites de la méthode prosopographique. Actes du colloque international, éd. Jean-Philippe GenET, Paris, Publications de la Sorbonnc. 1996. p. 29-37.

- «Législation el compilation législative au Portugal au début du XV siècle. La genèse des Ordonnances d'Alphonse V». dans Saint-Denis et la royauté. Études offertes à Bernard GUENEE. éd. Françoise At:trand et al.. Paris. Publications de la Sorbonne. 1999. p. 671-689.

* Horkeni (Jules). «Un écho de la Chanson de Roland au Portugal : la Geste de médisance de D. Afonso Lopes de Baiam". Revue des langues vivantes, 14, 1948, p. 133-141 et 193-203.

* Hyddact. Chronique. éd. trad. Alain Tranoy. Paris. Cerf. 1974 (Sources chrétiennes, 218/9), 2 vol.

* IbN ARABi. Les soufis d'Andalousie. Ruh al-quds et Ad-Durrat al fâkhirah, trad. R. W. J. Alsstix et Gérard LECONIE. Paris. Sindbad. 1979 (La bibliothèque de l'Islam. Témoins) [trad. de plusieurs biographies de soufis " portugais"].

* JAKHill. (Fr.). "Prise du castel de Sintra par un roi de Norvège ». O instituto. 95. 1939. p. 72-73.

* Johnson (Harold B.). «Les comptes d'un hôpital portugais 1379-1383 ». Eutudes rurales. 51. 1973. p. 67-84.

* Jorge (Ana Maria C. M.). Lépiscopat de Lusitanie pendant l'Antiquité tardive (IIr-vir siècles). Lisbonne. Instituto português de arqueologia. 2002. 
* Jorge (Virgolino Ferreira), "Captage, adduction, distribution et évacuation de l'eau dans l'abbaye cistercienne d'Alcobaça (Estremadure. Portugal)". dans L'hydraulique monastique, milieux, réseaux, usages. dir. Léon Pressoliyre et al., Grâne. Créaphis, 1996 (Rencontres à Royaumont), p. 221-233.

- I MAScarinhas (José Manuel). "Le système hydraulique de l'abbaye cistercienne d'Almoster (Ribatejo, Portugal) », ibid.. p. 235-245.

* Kemnitz (Eva Maria Von). «Les études arabes du Portugal». Rocznik Orientalistyczny, 46, 1988, p. 7995.

* Khawli (Abdallah). «La famille des Banû Wazîr dans le Gharb al-Andalus aux XII" et XIII" siècles ". Arqueologia Medieval. 5. 1997. p. 103-116.

- «Le Gharb al-Andalus à l'époque des 'secondes Taifas' (539-552 / 1144-1157)», ibid., 7. 2001 (Actas do colóquio : Lisboa, encruzilhada de muçulmanos, judeus e cristãos 1850 ' aniversário da reconquista de Lisboal), p. 23-36.

- «Quelques réflexions sur l'histoire de l'Algarve pendant les premiers siècles de l'islamisation (VIII"$\mathrm{XI}^{\mathrm{c}}$ siècles) », Xarajîb, 2, 2002, p. 21-40.

* Lambert (Élie). «Les anciens quartiers musulmans dans le plan de la ville de Lisbonne ». dans ComptesRendus du Congrès International de Géographie (Lisboa, 1949;. Tome 3 : Travaux de la Section IV. Lisbonne. Publications du CIG. 1951. p. 397-399.

- Art musulman et art chrétien dans la Péninsule Ibérique. Toulouse. Privat. 1958 (L'Esprit et l’Art), p. $247-297$.

* Le Bars (Dominique), «Étude archéo-anthropologique de la nécropole musulmane de Rossio do Carmo. Mértola : bilan des fouilles anciennes (1981-1990)». Arqueologia medieval. 9. 2005, p. 233-259.

* Lencart (Joana), "Consuetudines monasterii Palumbari. Une communauté bénédictine portugaise au XIII siècle ", dans Roma, Magistra Mundi : Itineraria Culturae Medievalis. Mélanges offerts au Père L. E. BOYLE à l'occasion de son 75 anniversaire, éd. Jacqueline HAMESSE. Louvain-la-Neuve. Fédération Internationale des Instituts d'Études Médiévales, 1998. p. 227-241.

* Leroy (Béatrice). "Espagnols et Portugais dans les chroniques de Froissart », Revue de Pau et du Béarn. 3. 1975, p. 57-80.

* Lévi-Provençal (Évariste). "L'inscription almohade de Silves ", dans Mélanges d'Études Portugaises offerts à M. Georges LE GENTIL, Lisbonne. Instituto para a Alta Cultura, 1949, p. 257-262.

* Lisboa e arredores. Lisbonne. IPPAR. 1986 (Roteiros da arqueologia portuguesa. Guides archéologiques. Archeological guides, 1) [éd. trilingue].

* Lopes (Isabel Alexandra). Dordio (Paulo) et Teixeira (Ricardo Jorge). « La maison d'Henri le Navigateur. Les maisons médiévales de la Douane et de la Monnaie, un centre de la couronne portugaise dans la ville de Porto (Portugal)". dans Exchange and Trade in Medieval Europe. Papers of the "Medieval Europe Brugge 1997 "Conference. vol. 3. éd. Guy DE BOE / Frans VERHAF(iHF. Zellik. Instituut voor het Archeologisch Patrimonium. Wetenschappelijke instelling van de Vlaamse Gemeenschap. 1997 (I.A.P. Rapporten. 3). p. 171-182.

* Lopez Quiroga (Jorge). Du Minho au Douro : histoire et archéologie du peuplement entre l'Antiquité tardive et le haut Moyen Âge. Paris. Université Paris IV. 1997 [thèse dactyl.].

- / Lovelle (Mónica R.). «De la cité antique aux évêchés du haut Moyen Âge en Galice et dans le Nord du Portugal », dans La ville au Moyen Âge 1. Ville et espace. dir. Noël Coulet. Olivier GuyorJEANnin. Paris. CTHS. 1998 (120' Congrès national des sociétés historiques et scientifiques. Aix-enProvence. 23-29 octobre 1995 - Section d'histoire médiévale et de philologic), p. 15-39.

- / «L'habitat dispersé de la Galice et du Nord du Portugal entre le $v^{*}$ et le $x$ siècle. Essai d'interprétation à partir de l'analyse macro et microrégionale », dans L'habitat dispersé dans l'Europe médiévale et moderne. Actes des XVIII" journées internationales d'histoire de l'abbaye de Flaran 15-16-17 septembre 1996. éd. Benoît Cursente. Toulouse. PUM, p. 97-119.

* Losa (António), "Les mourarias portugaises au XV siècle. Un code de droit successoral ". Quaderni di studi arabi. 5-6 ( $\mathrm{n}^{\circ}$ spécial Atti del XIII congresso dell'Union européenne d'arabisants et islamisants). 1987/88. p. $457-478$.

- "Le statut légal des Maures et des Juifs portugais pendant les XII-XV" siècles ». Medievalia. 5-6. 1994. p. 277-307.

- "La vie municipale à Coimbra en 1145 ". dans Proceedings of the 14th Congress of the Union Européenne des Arabisants et Islamisants, 2, Budapest, 29th August - 3rd September 1988. éd. Alexander 
Fodor, Budapest. Csoma de Körös Society, Section of Islamic Studies, 1995 (The Arabist : Budapest Studies in Arabic, 14), p. 297-308.

* Macias (Santiago). "Mértola. Société et vie matérielle à l'époque almohade dans le Gharb al-Andalus ". dans Averroès et l'averroüsme. Un itinéraire historique du Haut Atlas à Paris et à Padoue. Actes du colloque international organisé à Lyon, les 4 et 5 octobre 1999. dir. André BAzzANA et al.. Lyon. Presses universitaires de Lyon. 2005 (Collection d'histoire et d'archéologie médiévales, 16). p. 29-38.

* Marin (Manuela), "À l'extrémité de l'Islam médiéval. Élites urbaines et islamisation en Algarve ". Annales. Histoire, sciences sociales, 53/2, 1998, p. 361-381.

* Marques (A. H. de Oliveira). "Le Rossio de Lisbonne : son rôle social au cours des siècles ". dans $L a$ rue, lieu de sociabilité ?. dir. Alain LemÉnOREL. Rouen. Publications de l'Université de Rouen. 1994. p. $83-86$.

- "Les villes portugaises au Moyen Âge (XIV" - XV" siècles)". dans Villes et sociétés urbaines au Moyen Âge. Hommage à M. le Professeur Jacques HeERs. Paris. Université de Paris Sorbonne. 1994 (Culture et civilisation médiévales. XI). p. 105-112.

- «Lintroduction des chiffres arabes dans les documents médiévaux portugais ". dans Graphische Symbole in mittelalterlichen Urkunden. Beiträge zur diplomatischen Semiotik. éd. Peter RücK. Sigmaringen. Thorbecke. 1996, p. 503-508.

* Maroues (José), "Le nord du Portugal au XV" siècle : société et institutions ». ACCP. XXVI (Le Portugal du XV siècle. Actes du colloque. Paris, 12 mars 1987 ). 1989. p. 11-33.

- «L'écriture de Francesco Cavalcanti, une nouveauté au Portugal - 1482 ». Revista da Faculdade de Letras. História, 2‘ s., 12. 1995. p. 151-182.

- "La chancellerie et la diplomatique archiépiscopales de Braga à la fin du Moyen Âge ». dans Die Diplomatik, 1995, p. 511-527.

- I Cunha (Maria Cristina Almeida e). "Conflit de juridictions et documents judiciaires. Le cas de Braga », dans La diplomatica dei documenti giudiziari (dai placiti agli acta - secc. XII-XV). Commission internationale de diplomatique, X congresso internazionale. Bologna, 12-15 settembre 2001. éd. G. Nicolas, Bologne. 2004.

- I et al. "Diplomatique municipale portugaise (XIII-XV" siècles) ». dans La diplomatique urbaine en Europe au Moyen Âge. Actes du congrès de la Commission internationale de Diplomatique (Gand, 25 29 août 1998), éd. W. Prévenier. Louvain/Apeldoorn. Garant, 2000, p. 281-305.

* Martel (Gérard de), "Les textes pénitentiels du ms. Lisbonne 232 ». Sacris Erudiri. Jaarboek voor Godsdienstwetenschappen. 27. 1984, p. 443-460.

* Martinez (Carlos Paulo). «Au sujet des chevaux inexistants dans la poésie satirique galicienne-portugaise du Moyen Âge ". dans Le cheval dans le monde médiéval. Actes du XVIr colloque du CUERMA, Aix-en-Provence 1992, Aix-en-Provence. CUERMA. 1992 (Senefiance. 32), p. 367-384.

* Matos (José Luís de), "Céramiques musulmanes du Sud du Portugal», dans Segındo colóquio internacional de cerámica medieval en el Mediterráneo occidental (Toledo, 1981). Madrid. Ministerio de Cultura. Dirección General de Bellas Artes y Archivos. Subdirección General de Arqueología y Etnología. 1986. p. 149-154.

* Martos (J. M. Mello de), Les "compromissos" de la côte d'Algarve. Paris. Impr. Lahure, 1904.

* Matroso (José). «Labbaye de Pendorada des origines à 1160», RPII, 7, 1957. p. 1-192.

- Le monachisme ibérique et Cluny. Les monastères du diocèse de Porto de l'an mille à 1200. Louvain. Publications universitaires de Louvain. 1968.

- «Lintroduction de la règle de St Benoît dans la Péninsule ibérique ». Revue d'histoire ecclésiastique. 70. 1975. p. $731-742$.

- "Les nobles dans les villes portugaises du Moyen Âge », dans Les Espagnes médiévales. Aspects économiques et sociaux. Mélanges offerts à Jean GALTIER-DAL,CHE. Paris, Belles Lettres. 1983 (Annales de la Faculté des lettres et sciences humaines de Nice, 46). p. 125-140.

- art. "Géraud de Braga. saint ». dans DHGE. XX. 1984. col. 835-837.

- art. "Portugal. A - De l'évangélisation au XV" siècle", dans Dictionnaire de Spiritualité. tome XII/2. Paris. Beauchesne, 1986. col. 1952-1957.

- «Sur les proverbes médiévaux portugais". dans Littérature orale traditionnelle populaire. Actes du colloque, Paris, 20.22 novembre 1986. Paris. FCG / CCP. 1987. p. 533-560. 
- art. "Guarda », dans DHGE, XXII, 1988), col. 527-531.

- "Sur les sources du Comte de Barcelos", dans Lihistoriographie médiévale en Europe. Actes du colloque organisé par la Fondation Européenne de la Science au Centre de Recherches Historiques et Juridiques de l'Université Paris I du 29 mars au l"r avril 1989. éd. Jean-Philippe GFNFT, Paris, CNRS, 1991. p. 111-116.

- "Les Wisigoths dans le Portugal médiéval : état actuel de la question". dans L'Europe héritière de l'Espagne wisigothique. Colloque international du CNRS tenu à la Fondation Singer-Polignac (Paris, 14-16 mai 1990). éd. Jacques FonTaine. Madrid. Casa de Velázquez. 1992, p. 325-339.

- «Le Portugal de 950 à 1550 », dans Hagiographies. Histoire internationale de la littérature hagiographique latine et vernaculaire en Occident des origines à 1550. Vol. II. dir. Guy PHILIPPART. Turnhout. Brepols. 1996. p. 83-102.

- « À propos du couronnement des rois portugais". dans Chemins d'historiens. Mélanges pour Robert DURAND. Rennes. Apogée. 1999. p. 133-146.

* Mauro (Frédéric). "Portugais et Bretons dans l'Atlantique. Histoire nautique. histoire maritime ", dans La Bretagne. Le Portugal. 1973, p. 113-123.

- «Le Portugal, la Méditerranée et l'Atlantique en 1493 et en 1993 ». Portuguese Studies, 8. 1992. p. 98104.

- "Colomb et le Portugal». dans Christophe Colomb et la décotiverte de l'Amérique, mythe et histoire. Actes du colloque international organisé à l'Université de Franche-Comté les 21, 22, et 23 mai 1992. éd. Jacques HotiriE\%. Paris, Les Belles Lettres, 1994 (Collection du Centre de Recherches Jacques Petit. 67 / Annales littéraires de l'Université de Besançon. 532). p. 9-16.

* Medeiros (Carlos Alberto). "Environnement, agriculture et élevage au Portugal à l'époque des découvertes maritimes ", dans L'homme, l'animal domestique et l'environnement du Moyen Áge au XVIII' siècle. dir. Robert Durand. Nantes. Ouest Éditions, 1993 (Enquêtes et documents. Centre de recherches sur l'histoire du monde atlantique, 19). p. 307-313.

* Meciale (Heitor). "Le texte portugais de la Demanda do Santo Graal : les éditions de 1944 et de 1955 1970". dans Arturus Rex, vol. II : Acta Conventus Lovaniensis 1987. éd. Willy vAN HoE(KE et al.. Louvain. Leuven University Press, 1991 (Mediaevalia Lovaniensia. Series 1. Studia, 17). p. 436-461.

* Meneses (Paulo). «Le récit hagiographique, expression doctrinaire de la spiritualité médiévale ". Diogèn, 139. 1987. p. 53-72.

* Metzger (Thérèse). Les manuscrits hébreux copiés et décorés à Lisbonne dans les dernières décennies du $x V^{\prime}$ siècle. Paris. FCG/CCP, 1977.

- «Les manuscrits hébreux décorés à Lisbonne dans les dernières décennies du XV" siècle ", dans Lhumanisme portugais, 1984, p. 761-780.

- «Lillustration biblique dans la bible hébraïque Ms. iluminado 72 de la Bibliothèque Nationale de Lisbonne" sep. Revista da Biblioteca Nacional. 2“ s.. 5 12. 1990. p. 61-100.

* Miranda (José Carlos Ribeiro), «Le surgissement de la culture troubadouresque dans l’occident de la Péninsule Ibérique. I : les genres. les thèmes et les formes". dans Le rayonnement des troubadours. Actes du colloque de l'AIEO, Amsterdam 16-18 octobre 1995, éd. Anton TOUBER. Amsterdam/Atlanta. Rodopi. 1998 (Internationale Forschungen zur Allgemeinen und Vergleichenden Literaturwissenschaft. 27). p. $97-105$.

* Monteiro (João Gouveia) 2002 : «Lhomme armé au Portugal, aux XIV" el XV" siècles ", Cahiers d'études et de recherche du Musée de l'Armée. 3 (L'homme armé en Europe, XIV' siècle - XvI siècles). 2002. p. 67-94.

- «La Bataille d'Aljubarrota (14 août 1385)". Cahiers du CRISIMA (Centre de Recherche Interdisciplinaire sur la Société et l'Imaginaire au Moyen Âge, Université Paul Valéry, Montpellier III). 2006 [sous presse].

- "Entre Lisbonne et Jérusalem - la poliorcétique lors des quatre premières croisades ", Revista de História da Sociedade e da Cultura [à paraître].

- I et al. La rencontre de D. Pedro et D. Inês. Coimbra. Associação para o Desenvolvimento do Turismo da Região Centro. 1999.

* Moriara (António Montes). Potamias de Lisbonne el la controverse arienne. Louvain. Bibliothèque de I'Université, 1969 (Travaux de doctorat en théologie et en droit canon. n.s.. 1). 
* Moreira (Domingos A.), "L'anthroponymie chrétienne du haut moyen âge au nord-ouest de l'Espagne et du Portugal ". Onoma. Bibliographical and Information Bulletin Published by the International Centre of Onomastics 22/1-2. 1978. p. 112-115.

* Mordira (Rafael). "La cité des templiers. Le couvent du Christ à Tomar ". Monuments historiques de la France, 194. 1994. p. 81-85.

* Morfmbert (Henri Tribout de). «Les commanderies antoniennes d'Espagne et de Portugal». Bulletin philologique et historique du CTHS, 1. 1969. p. 373-385.

* Morfano (Humberto Baquero). "Les révolutions portugaises de la fin du Moyen Âge ". dans Histoire du Portugal, histoire européenne. Actes du colloque. Paris, 22-23 mai 1986. Paris. FCG/CCP. 1987. p. 3742.

- «La lutte de la noblesse portugaise contre la royauté à la fin du Moyen Âge». ACCP. XXVI (Le Portugal du Xv siècle. Actes du colloque. Paris, 12 mars 1987 ). 1989. p. 49-65.

- "La noblesse portugaise pendant le règne d Alphonse V ". ibid., XXVI (La noblesse dans l'Europe méridionale du Moyen-Áge : accès et renouvellement. Actes du colloque. Paris, 14-15 janvier 1988). 1989. p. 399-415.

- "Quelques aspects des villes médiévales portugaises. Les corps militaires et la démographie ". dans Villes et sociétés urbaines au Moyen Âge. IIommage à M. le Professeur Jacques IIEkRS. Paris. Presses de l'Université Paris Sorbonne. 1994 (Culture et civilisation médiévales. XI). p. 113-118.

* Morujão (Maria do Rosário Barbosa). «La collaboration dans le scriptorium de la cathédrale de Coimbra ». dans La collaboration dans la production de l'écrit médiéval. Actes du XIII colloque du Comité international de paléographie latine (Weingarten, 22-25 septembre 2000)). éd. Herrad SPELLING. Paris. École des Chartes, 2003 (Matériaux pour l'histoire publiés par l'École des Chartes, 4), p. 131-149.

- "La famille d'Ébrard et le clergé de Coïmbra aux XII" et XIV" siècles", dans La Chiesa e il Clero Portoghese nel Contesto Europeo. Atti del Colloquio Internazionale (Roma-Viterbo, 2004). Lisbonne, 2005 [sous presse].

- I Saralva (Anísio Miguel de Sousa). "Frontières documentaires : différences dans les chartes des chancelleries épiscopales portugaises avant et après le XIIr siècle (Coimbra et Lamego) ", dans Actes du III Congrès Européen d'Études Médiévales. Jyvaskÿlä, 2003. Turnhout. Brepols. 2005 [sous presse].

* Mota (Avelino Teixeira da), "Éléments de la Méditerranée occidentale dans l'histoire maritime portugaise ". dans L'Homme méditerranéen et la mer. Actes du III Congrès International d'études des cultures de la Méditerranée occidentale (Jerba, avril 1981). éd. Micheline Galley / Leïla Ladjimi Sebai. Tunis. Salammbô. 1985. p. 104-107.

* Movicheron (Pierre Antoine, comte de). Sainte Élisabeth d'Aragon, reine de Portugal et son temps. Paris. Firmin-Didot. 1896.

* Munter (S. de), "Élisabeth de Portugal», dans DIIGE, XV, 1963, col. 218-219.

* Nascimento (Aires Augusto). "Notes codicologiques sur un ms. daté du monastère cistercien d'Alcobaça : le BNL 6747 ». dans Miscellanea codicologica F. MASAl dedicata, Gand. Story-scientia. 1979. p. 491496.

- "Les reliures médiévales du fonds Alcobaça de la Bibliothèque Nationale de Lisbonne ". dans Calames et cahiers. Mélanges de codicologie et de paléographie offerts à Léon GillissEN. éd. Jacques LemAiRE. Bruxelles. Centre d'Études des Manuscrits. 1985 (Publications de Scriptorium. 9). p. 107-117.

- «Le scriptorium d’Alcobaça : identités et corrélations ". Lusitania Sacra. 2* s.. 4. 1992. p. $149-162$.

- "La réception des auteurs classiques dans lespace culturel portugais : une question ouverte». dans The Classical Tradition in the Middle Ages and the Renaissance. Proceedings of the First European Science Foundation Workshop on "The Reception of Classical Texts" (Florence, Certosa del Galluzzo, 26-27 June 1992), éd. Claudio Lronardi / Birger Munk Olsfin. Spolète. Centro Italiano di Studi sull'Alto Medioevo. 1995 (Biblioteca di Medioevo Latino. 15). p. 47-56.

- "Terminologie du livre dans les sources documentaires portugaises médiévales : fragments d'un discours incomplet ". dans Le Vocabulaire des écoles des Mendiants au Moyen Âge. Actes du colloque. Porto (Portugal), 11-12 octobre 1996. éd. Maria Cândida PA(HEc(o. Turnhout. Brepols. 1999 (Études sur le vocabulaire intellectuel du Moyen Âge. 9). p. 119-138.

* Nitibalter : «Notes sur les manuscrits hébreux existant dans quelques bibliothèques de l'Espagne et du Portugal ». Archives des missions scientifiques et littéraires. 2“ s.. 5. 1868. p. 424-435. 
* Neves (Carlos M. L. Baeta). «Quelques aspects fondamentaux de la politique forestière au Portugal avant le XVII siècle", dans Actes du Symposium international dhistoire forestière, Nancy, 24-28 septembre 1979, Nancy, École nationale du génie rural des eaux et des forêts. 1982, p. 247-251.

* Oliveira (António Braz de). "Les manuscrits de la Bibliothèque nationale (Lisbonne)", Liber bulletin, 29, 1987, p. 55-56.

* Oliveira (António Resende de). "Le surgissement de la culture troubadouresque dans l'occident de la Péninsule ibérique. I : compositeurs et cours", dans Le rayonnement des troubadours. Actes du colloque de l'AIEO, Amsterdam 16-18 octobre 1995. éd. Anton TOUBEr. Amsterdam/Atlanta. Rodopi. 1998 (Internationale Forschungen zur Allgemeinen und Vergleichenden Literaturwissenschaft. 27), p. 85-95.

* Oliveira (Ernesto Veiga de). «Le culte de saint Martin au Portugal. Saint Martin de Tours et saint Martin de Dume ". Revista de etnografia, 10. 1968, p. 313-328.

* Omnes (Robert), "Yann Koatanlem, amiral du Portugal et son neveu Nicolas ». dans La Bretagne. Le Portugal, 1973, p. 79-89.

* Pacheco (Maria Cândida Monteiro), "Exégèse et prédication chez deux auteurs portugais du XIII" siècle : saint Antoine et frère Pelagius», dans De l'homélie au sermon. Histoire de la prédication médiévale. Actes du Colloque international de Louvain-la-Neuve (9-11 juillet 1992), éd. Jacqueline HAMESSE. Louvain-la-Neuve, Université Catholique de Louvain. 1993 (Université Catholique de Louvain. Publications de l'Institut d'Études Médiévales, Textes, Études, Congrès, 14), p. 169-81.

- «Le sens de la paix dans la tradition et dans le témoignage de la génération d'Avis ". dans Diálogo filosófico-religioso entre Cristianismo, Judaísmo e Islamismo durante la Edad Media en la península Iberica. Actes du Colloque international de San Lorenzo de El Escorial 23-26 juin 1991 organisé par la Société Internationale pour l'Étude de la Philosophie médiévale, éd. Horacio Santiacio-O'Tero. Turnhout. Brepols, 1994 (Société Internationale pour l'Étude de la Philosophie Médiévale. Rencontres de Philosophie Médiévale. 3), p. 259-275.

* Palla (Maria-José), "Jeux d'église et jeux de cour dans le Portugal du XV siècle ". dans Jeux, sports et divertissements au Moyen Âge et à l'Âge classique. Actes du 116 Congrès national des Sociétés savantes (Chambéry, 1991), Section d'Histoire médiévale et de philologie, Paris. CTHS. 1993. p. 281-287.

- "Manger et boire au Portugal à la fin du Moyen Âge ", dans Banquets et manières de table au Moyen Âge. Aix-en-Provence. CUERMA, 1996 (Senefiance. 38). p. 93-123.

* Par les terres de la Maure enchantée. L'art islamique au Portugal. Paris. Édisud. 2001 (Musée sans frontières. Lart islamique en Méditerranée).

* Paviot (Jacques), "Portugal el Bourgogne au Xv" siècle. Essai de synthèse ». ACCP. XXVI (Le Portugal du XV' siècle. Actes du colloque. Paris, 12 mars 1987). 1989, p. 121-143.

* Pereira (F. J.). « Note sur le revenu des abbayes de l'Ordre de Cîteaux au Portugal», Comentarii cistercienses, 44, 1993, p. 321-353.

* Pereira (Isaías da Rosa), «Les statuts synodaux d'Eudes de Sully au Portugal », Lannée canonique, 15. 1971, p. $459-480$.

- "Notes sur le scriptorium du monastère d'Alcobaça". Miscellanea codicologica F. MASAl dedicata, Gand. Story-scientia, 1979.

- «Quelques manuscrits datés du fonds Alcobaça (Lisbonne)». dans Calames et cahiers. Mélanges de codicologie et de paléographie offerts à Léon GILISSEN. éd. Jacques LEMAIRE, Bruxelles, Centre d'Études des Manuscrits, 1985 (Publications de Scriptorium, 9), p. 133-137.

- "L'écriture et la décoration de quelques mss du XII" et XIII" siècle provenant du monastère de Santa Cruz de Coimbra", dans Actas del VIII" coloquio del Comité internacional de paleografía latina, Madrid-Toledo, 29 setembro - 1 octubre 1987. Madrid. 1990 (Estudios y ensayos y joyas bibliograficas), p. 203-210.

- «Symboles graphiques dans les chartes médiévales portugaises», dans Graphische Symbole in mittelalterlichen Urkunden. Beiträge zur diplomatischen Semiotik, éd. Peter Rück. Sigmaringen. Thorbecke. 1996, p. 491-502.

- "Les signes exprimant le nombre '40' dans les manuscrits portugais", dans Signo : revista de historia de la cultura escrita. 3. 1996. p. 9-10 [déjà édité dans Revue d'histoire suisse. 31 (Actes du V colloque international de paléographie latine). 1981].

- / Guerra (António Joaquim Ribciro), "La chancellerie de l'évêque de Lamego au XII" siècle », dans Die Diplomatik. 1995. p. 483-501. 
- I et al.. "La conservation des chartes dans les archives privées au Portugal (XII-XV" siècles)". Scriptorium. 50. $\mathrm{n}^{\circ} 2$ (La conservation des manuscrits et des archives au Moyen Âge. XI colloque du Comité international de Paléographie latine. Bruxelles, 19-21 octobre 1995. éd. Pascale Bourcialn et al.). 1996, p. 390-396.

- I et al., "Diplomatique royale portugaise : Alphonse IV (1325-1357)". dans Diplomatique royale du Moyen Âge XII-XIV siècles, Actes du colloque du Comité international de diplomatique, Porto/Braga/Coimbra, septembre 1991, éd. José Maroues. Porto. Faculdade de letras. 1996. p. 133-161.

* PICARD (Christophe). "La fondation de Badajoz par Abd al-Rahman Ibn Yunus al-Jilliki (fin IX" siècle) 》. Revue des études islamiques. XLIX / 2. 1981. p. 215-229.

- «Les mozarabes dans l'Occident ibérique (VIII-XI" siècles)". ibid.. LI. 1983. p. 77-88.

- "Quelques aspects des relations entre chrétiens et musulmans dans les zones de confins du NordOuest de la Péninsule ibérique (IX'-XI' siècles)". dans Études dhistoire de l'Université de Saint-Étienne. Saint-Étienne. Centre de recherches historiques. 1990, p. 5-26.

- "Lévolution des localités de l'Algarve du XI" au XII" siècle". Cahiers d'histoire, 37/1, 1992, p. 3-21.

- "Quelques remarques sur la propriété du sol dans le Gharb al-Andalus pendant la période musulmane ". Revue des études islamiques. LX / 2, 1992. p. 471-519.

- "Minorités religieuses et pouvoirs au Portugal : mozarabes et mudéjars à Lisbonne et Santarém ". dans Maisons de Dieu et hommes d'Église. Florilège en l'honneur de Pierre-Roger GaUssıN. SaintÉtienne. Publications de l'Université de Saint-Étienne. 1992. p. 165-178.

- "Le renouveau urbain en Occident ibérique aux $I X^{\prime}-X^{\prime}$ siècles. sous l'impulsion de seigneurs muwalladun ". dans Les princes et le pouvoir au Moyen-Âge (XXIII congrès SHMES, Brest 1992). Paris. Publications de la Sorbonne. 1993, p. 49-67.

- "La recherche historique dans les zones frontalières : spécificités et perspectives ". Mélanges de la Casa de Velázquez. 31/1, 1994, p. 95-104.

- "Le commerce des produits agricoles entre le Maghreb occidental et l'Andalus au XII" siècle ". dans Productions et exportations africaines en Afrique du Nord antique et médiévale. Congrès national des Sociétés savantes (6 colloque d'Afrique du Nord), Pau, 1993. Paris, 1995, p. 177-187.

- "Sanctuaires et pèlerinages chrétiens en terre musulmane : l'Occident d'al-Andalus ( $X^{*}$-XII" siècle)". dans Pèlerinages et Croisades. 118 Congrès national des Sociétés savantes, Pal, 1993. Paris. CTHS. 1995. p. 235-247.

- "Fortifications et fonctions portuaires sur le littoral atlantique musulman ». Archéologie islamique. 6. 1996. p. 45-66.

- «La 'piraterie’ musulmane sur l'océan Atlantique ». Qurtuba. Estudios andalusies, 3. 1998, p. 153-169.

- «La mémoire religieuse des lieux : des cultes chrétiens aux cultes musulmans sur les rivages d’alAndalus", dans Faire mémoire. Solıvenir et commémoration au Moven Âge. dir. Claude CARozzI / Huguette Taviani-Carozzi. Aix-en-Provence. PUP. 1999. p. 259-275.

- Le Portugal musulman (VIIr-XIIr siècle). L'Occident d'al-Andalus sous domination islamique. Paris. Maisonneuve \& Larose. 2000.

- "La connaissance du Garb al-Andalus. Une documentation variće ". dans Fontes da história de alAndalus e do Gharb, éd. Adel Sidsarus, Lisbonne. IICT/Centro de Estudos Africanos e Asiáticos. 2000). p. 55-74.

- "Les chrétiens mozarabes : encadrement religieux et déclin (l'exemple du Gharb al-Andalus) », dans Mutations d'identités en Méditerranée. Moyen Âge et époque contemporaine. dir. Henri Briss. Paris. Bouchène. 2000), p. 97-110.

- «Les mozarabes de Lisbonne : le problème de l'assimilation et de la conversion des chrétiens sous domination musulmane à la lumière de l'exemple de Lisbonne ". Arquelogia medieval. 7 ( 1 ctas do colóquio : Lisboa, encruzilhada de muçulmanos, judeus e cristãos - 850' aniversário da reconquista de Lisboa). 2001. p. 89-94.

- «Les défenses côtières de la façade atlantique d’al-Andalus ". Castrum. 7. Zones côtières littorales dans le monde méditerranéen au Moyen Âge : défense, peuplement, mise en valeur. Actes du colloque international organisé par l'École française de Rome et la Casa de Velázquez, en collaboration avec le College de France et le C.I.II.A.M. (UMR 5648 - Université Lyon II - EHESS). Rome, 23-26 octobre 1996. éd. Jean-Marie MARTIx. Rome/Madrid. École française de Rome/Casa de Velázquez. 2001 (Collection de l'EFR. 105-7/Collection de la Casa de Velázquez. 76). 
- «L'évolution du rôle et de la place des husûn dans le Gharb al-Andalus au regard de l'histoire : quelques hypothèses". dans L'espace rural. 2002. p. 31-40.

- «Les ribats au Portugal à l'époque musulmane : sources et définitions », dans Mil anos, 2002. p. 203212.

- "Le changement du paysage urbain dans le Gharb al-Andalus ( $\mathrm{X}^{\circ}$-XII" siècle) : les signes d'une dynamique », dans Muçulmanos e cristãos entre o Tejo e o Douro (séculos VIII a XIII). Actas dos Seminários realizados em Palmela (14 e 15 de Fevereiro de 2003) e no Porto (4 e 5 de Abril de 2003), coord. Mário Jorge Barro('A. Isabel Cristina Ferreira Fernandes. Palmela, Câmara Municipal de Palmela / Departamento de Ciências e Técnicas do Património (FLUP). 2005.

- / Fernandes (Isabel Cristina Ferreira), «La défense côtière du Portugal à l'époque musulmane : l'exemple de la presqu'île de Setúbal ", Archéologie islamique, 8-9, 1999, p. 67-94.

* Pimenta (Alfredo), art. «Braga », dans DHGE, X, 1938, col. 352-361.

* Pinoteau (Hervé), " À propos des armes d'Alphonse de Portugal. comte de Boulogne ", Cahiers d'héraldique. 2. 1975. p. 93-117.

- "Le ciel dans la symbolique capétienne au XIII siècle : les solutions française et portugaise ". dans De l'aventure épique à l'aventure romanesque. Mélanges offerts à André DE MANDACH par ses amis, collègues et élèves, éd. Jacques Chocheyras, Berne. Lang. 1997. p. 135-145.

* Pinto (Fernando), «Les visages du pays profond. Villages du Portugal». Monuments historiques de la France, 194 1994. p. 18-21.

* Ponte (Salete da), "Témoignages et expériences archéo-historiques des deux cultures à Tomar ». dans Judeus e árabes da Península ibérica. Encontro de religiões, diálogo de culturas. Lisbonne. Comissão nacional da UNESCO Portugal. 1994, p. 171-173.

* Pontes (José Maria da Cruz), «À propos d'un centenaire. Une nouvelle monographie sur Petrus Hispanus Portugalensis. le pape Jean XXI (m. 1277) est-elle nécessaire?". Recherches de théologie ancienne et médiévale. 44. 1977. p. 220-230.

* PradaliÉ (Gérard), «Les faux de la cathédrale et la crise à Coïmbre au début du XII siècle ». Mélanges de la Casa de Velázquez. 10. 1974. p. 77-98.

- "Occupation du sol et cultures autour de Cö̈mbre au XII" siècle". dans Actas de las I jornadas de metodologia aplicada de la ciencias historicas. Vol. Il : Historia medieval. Saint-Jacques-de-Compostelle, Secretariado de Publicaciones de la Universidad de Santiago, Facultad de Geografía e Historia. 1975, p. 79-87.

- "Quercynois et autres Méridionaux au Portugal à la fin du XIII" et au XIV" siècle : l'exemple de Coïmbre ». Annales du Midi. 94 (n ${ }^{\circ}$ 159), 1982, p. 369-386.

- «Du Portugal mozarabe au Portugal romanisé : l'exemple de Coïmbre», dans Histoire du Portugal, histoire européenne. Actes du colloque. Paris, 22-2.3 mai 1986. Paris. FCG / CCP. 1987. p. 15-17.

* Ramos (Maria Ana). "La satire dans les Cantigas d'escarnho e de mal dizer : les péchés de la langue ". Atalaya. Revue française d'études médiévales hispaniques, 5, 1994. p. 67-84.

* Ramos Lissón (Domingo), "Le rôle de la Bible dans les conciles bracariens du vi" siècle au royaume Suève ". Annuarium historiae conciliorum, 18/1. 1986. p. 41-50.

* RaU (Virginia) "Une famille de marchands italiens au Portugal au Xv" siècle : les Lomellini ". dans Studi in onore di Armando SAPORI. Vol. I. Milan. Istituto editoriale cisalpino. 1957. p. 717-726.

- «Aspects et problèmes historiques de l'exploitation agraire au Portugal. du Moyen Âge au XIX" siècle ". Mediterranea. 8. 1965. p. 6-12.

- «Un document portugais sur la peste noire de 1348 ». Annales du Midi. 77/8. 1966. p. 331-334.

- "Note sur les facteurs portugais en Andalousie au Xv" siècle", Jahrbuch für Geschichte von Staatskunst, Wirtschaft und Gesellschaft Lateinamerika, 4. 1967. p. 122-127.

- "Les courants du trafic du sel portugais du XIV" au XVIII" siècle», dans Le rôle du sel dans l'histoire. éd. Michel Moldat. Paris. PUF. 1968 (Publications de la Faculté des Lettres et Sciences Humaines de Paris-Sorbonne. Série Recherches. 37), p. 53-71.

- «Les emblèmes et l'histoire des techniques au Portugal au cours des XV" et XVI siècles ", dans Mélanges en honneur de Fernand BRACDFLL. I : Histoire économique du monde méditerranéen (1450)1650). Méthodologie de l'histoire et des sciences humaines. Toulousc. Privat. 1973, p. 487-496. 
- "Conclusions". dans A pobreza e a assistência aos pobres na Península ibérica durante a Idade Média. Actas das I" jornadas liso-espanholas de história medieval. Lisboa, 25-30 de setembro de 1972. éd. Virgínia RAU, Lisbonne. Instituto de alta cultura. 1973. vol. II. p. 925-943.

* Rebelo (Luís de Sousa). "Millénarisme et historiographie dans les chroniques de Fernão Lopes ". $A C C P$. XXVI (Le Portugal du XV siècle. Actes du colloque. Paris, 12 mars 1987). 1989. p. 97-120.

* Renoljard (Yves). "Un Français du Sud-Ouest évêque de Lisbonne au XIV" siècle. Thibaud de Castillon (1348-1356) : sa fortune. ses placements et ses relations avec les hommes daffaires de son temps". BEP. 13, 1949, p. 29-51 [repris dans ID., Études d'histoire médiévale. Paris, SEVPEN, 1968, p. 10351049].

* Ribeiro (Orlando). "L'habitat rural au Portugal», dans Comptes Rendus du Congrès International de Géographie, Amsterdam 1938. II. Leyde. UGL. 1938 (Travaux des Sections A-F). p. 137-144.

- La Formation du Portugal (Conférence faite le 25 avril à l'Instituto de Cultura Portuguesa, à Bruxelles). Bruxelles. Instituto de Cultura Portuguesa. 1939.

- «Villages et communautés rurales au Portugal ». Bulletin de l'Association des Géographes Français. 130/1, 1940, p. 51-60.

- "Sur quelques traits de la campagne portugaise». dans Mélanges géographiques offerts en hommage i M. Daniel FAUCHER. Toulouse. Éditions toulousaines de l'Ingénieur, 1948, p. 427-437.

- I et al.. "Les recherches de géographie historique au Portugal», dans Géographie historique et culturelle de l'Europe. Mélanges offerts au Professeur Xavier DE PLANHOL. Paris. PUPS. 1995, p. 329-351.

* Ricard (Robert). "Episcopus et Cadi. L'évêque mozarabe de Lisbonne (1147)». Revue du Moyen Âge latin, 7, 1951. p. 111-112.

- «Recherches sur la toponymie urbaine du Portugal et de l'Espagne », Bulletin hispanique. 56.1954. p. 133-166.

- Lïnfant D. Pedro de Portugal et "O livro da virtuosa bemfeitoria ". Coimbra, Coimbra editora. 1954.

- «La relation portugaise de la bataille du Salado (1340) ». Hespéris, 43. 1956, p. 7-27 [présentation et traduction française du récit].

- Études sur l'histoire morale et religieuse du Portugal, Lisbonne/Paris. FCG/CCP. 1970.

* Riocreux (Jean-Louis). "Situation de la période arabe dans le développement de Lisbonne ", Revue d'histoire et de civilisation du Maghreb. 4. 1968, p. 6-16.

* Rocha (Pedro Romano). Lioffice divin au Moyen Âge dans l'église de Braga. Originalité et dépendance d'une liturgie particulière au Moyen Âge. Paris. FCG/CCP. 1980.

- «Le rayonnement de l'Ordre de Saint-Ruf dans la Péninsule ibérique, d'après sa liturgie ", dans Le Monde des chanoines $\left(X I-X I V^{r}\right.$ s.). éd. Marie-Humbert VICAIRE. Toulouse, Privat, 1989 (Cahiers de Fanjeaux, 24), p. 193-208.

* Rodriciues (Ana Maria Seabra de Almeida). L'esclave dans les sociétés portugaises avant l'Amérique. Paris, Université de Paris IV - Sorbonne. 1979 [mémoire de maîtrise, dactyl.].

- La collégiale de São Pedro de Torres Vedras (fin XIIr - fin XV" siècle). Étude économique et sociale. Paris. Universitć Paris IV - Sorbonne, 1981 [thèse doctor., dactyl.].

- «La formation et l'exploitation du domaine de la collégiale de S. Pedro de Torres Vedras (fin XIII" fin $\mathrm{XV}^{\prime \prime}$ siècle) ". $A C C P .19 .1983$, p. 3-37.

- "Le taureau dans les fêtes aristocratiques et populaires du Moyen Âge ", dans Jelı, sports et divertissements au Moyen Âge et à l'Âge classique. Actes du 116 Congrès national des Sociétés savantes (Chambéry, 1991), Section dHistoire médiévale et de philologie, Paris. CTHS. 1993. p. 181-192.

- "Les relations de clientélisme en milieu urbain. L’exemple d’une ville portugaise au $X V^{*}$ siècle ". dans Villes et sociétés urbaines au Moven Âge. Hommage à M. le Professeur Jacques HEERs. Paris, Presses de lUniversité de Paris-Sorbonne, 1994 (Culture et civilisation médiévales. XI), p. 149-161.

- "Les artisans au Portugal : état de la question". Razo, 14 (L'artisan dans la Péninsule ibérique. dir. Denis MeNJ(OT). 1994. p. 21-26.

- "Torres Vedras. La ville et ses campagnes à la fin du Moyen Âge ", dans Proceedings of the $11^{\text {th }}$ International Economic History Congress. Vol. D. Milan. 1994. p. 37-43.

- "Les transformations du peuplement en Portugal à la fin du Moyen Âge : Torres Vedras du XIV" au début du XV" siècle". dans Population et démographie au Moyen Âge. Actes du 118 congrès national 
des sociétés historiques et scientifiques, Pau, 25-29 octobre 1993, Section Histoire médiévale et philologie, éd. Olivier GuYOTJeannin. Paris. CTHS. 1995, p. 85-110.

- "Le sport aristocratique selon les princes d'Avis". dans Légendes, mythologies, histoire et imaginaire sportif. Actes des journées d'études Bernard Jeu. Lille. 1995. p. 113-121.

- «Le pouvoir royal et les villes au Portugal au Moyen Âge ». Le Moyen Âge. 103/2. 1997. p. 293-307.

- "Des rues en fête. Les festivités publiques au Portugal au Xv' siècle", dans La rue, lieu de sociabilité ?. dir. Alain LEMÉNorel, Rouen. Publications de l'Université de Rouen. 1997. p. 359-367.

- "La lutte pour la prise et la conservation du pouvoir dans les villes portugaises à la fin du Moyen Âge ». dans Enjeux et expressions de la politique municipale. coord. Denis MeNoot / Jean-Luc PINOL. Paris. L'Harmattan. 1997. p. 21-40.

- «Un projet de recherche en histoire religieuse et sociale : le chapitre de la cathédrale de Braga à la fin du Moyen Âge ", Revue d'histoire ecclésiastique. 93/3-4. 1998. p. 450-460.

- "Les capitulaires de Braga des $13^{*}$ et $14^{*}$ siècles : réflexion sur une enquête prosopographique en cours ». dans Chemins d'historiens. Mélanges pour Robert DURAND. Rennes. Éditions Apogée. 1999. p. 117-131.

- / RILEy (Carlos Guilherme). "Les joutes d'Alvaro Gonçalves Coutinho à Paris : un épisode portugais du conflit entre les maisons de Valois et de Bourgogne». dans Théâtre et spectacles hier et aujourd'hui, Moyen Âge et Renaissance. Actes du 115 Congrès national des sociétés savantes (Avignon, 1990), Section d'histoire médiévale et de philologie, Paris. CTHS, 1991. p. 305-319.

- I VILAR (Hermínia Vasconcelos), «Les chanoines à l’échelle de la Chrétienté : l'exemple du Portugal». Mélanges de l'École française de Rome. Moyen Âge. 116/2. 2004. p. 611-629.

- I et al. "Petrus Hispanus : un médecin portugais dans l'Europe de son temps". dans $A$ igreja e o clero português no contexto europeu. Lisbonne. Centro de estudos de história religiosa/UCP. 2005. p. $153-167$.

* Rosa (Maria de Lurdes). «Mariage et empêchements canoniques de parenté dans la société portugaise (1455-1520) ». Mélanges de l'Ëcole française de Rome. Moyen Âge et Temps Modernes. 108/2. 1996. p. $525-608$.

- «Promesses, dons et mécénat. Le pèlerinage noble au Portugal entre salut et représentation. $X V^{c}$ XVIII" siècle". dans Rendre ses voux. Les identités pèlerines dans l'Europe moderne (XVI-XVIIr siècle). dir. Philippe Bourry et al. Paris. EHESS. 2000, p. 341-362.

- "Lieux d'assistance médiévale et architecture hospitalière au Portugal». dans Archéologie et architecture hospitalière de l'Antiquité tardive à l'aube des temps modernes. dir. François-Olivier Tovatı. Paris, Boutique de l'histoire. 2004. p. 261-293.

* Rosenberger (Bernard). "La Croisade africaine et le pouvoir royal au Portugal au $\mathrm{xv}^{*}$ siècle», dans Genèse de l'État moderne en Méditerranée. Approches historiques et anthropologiques des pratiques et des représentations. Rome. EFR. 1993 (Collection de l'EFR. 168). p. 329-348.

* SÁ (Artur Moreira de). "Les origines de l'Université portugaise et son évolution jusqu'en 1537 ». ACCP. II. 1970. p. 13-46.

* Santos (Maria José de Azevedo). «Manuscrits non datés au Portugal. Contribution à l'étude du problème ", RPH, 26, 1991. p. 153-173.

- "Remarques sur les conditions de conservation des actes et des livres au Portugal (XII ${ }^{c}$-XV" siècles)". Scriptorium, $50 . \mathrm{n}^{\circ} 2$ (La conservation des manuscrits et des archives au Moyen Âge. XI colloque du Comité international de Paléographie latine. Bruxelles, 19-2l octobre 1995. éd. Pascale Bourgain et al.). 1996. p. 397-406.

- «Les 'clercs-notaires' au Portugal (XI"-XII" s.)». dans Septuaginta Paulo SPUNAR oblata (70)+2), éd. Jirí K. Kroupa, Prague. 2000, p. 76-87.

- «La production des chartes et des registres à la chancellerie du roi Alphonse II (1211-1223)», dans La collaboration dans la production de l'écrit médiéval. Actes du XIII colloque du Comité international de paléographie latine (Weingarten, 22-25 septembre 2000). éd. Herrad Spelling, Paris. École des Chartes. 2003 (Matériaux pour l'histoire publiés par l'École des Chartes. 4). p. 427-438.

* São Payo (Marques de). "L'héraldique de la reine sainte Élisabeth de Portugal. nièce de sainte Élisabeth de Hongrie», dans Mélanges offerts à Szabolcs DE VAJAY à l'occasion de son 50 anniversaire par ses amis, ses collègues et les membres de l'Académie. éd. Pierre BRIËRE et al.. Braga. Livraria Cruz. 1971. p. $527-528$. 
* Schaefer (Claude). "Deux enluminures du maître de Jouvenel des Ursins à la Biblioteca Nacional à Lisbonne », $A C C P$. VII. 1973. p. 117-147.

- "Le maître de Jouvenel des Ursins (Coppin Delf ?), illustrateur du Speculum historiale de Vincent de Beauvais (Ms. 126 de la Biblioteca Nacional à Lisbonne)", ibid., VIII, 1974, p. 81-114.

- "Un livre d'heures ganto-brugeois, ms. 16 de la Biblioteca Nacional à Lisbonne". ibid.. IX. 1975. p. 399-415.

* Schippers (Arie), "Ibn Bassâm al-Shantarînî et la Bataille de Zallâqa ». dans Literatura e Cultura no Gharb al-Andalus (Simpósio Internacional - Lisboa, Abril de 2000). éd. Bruna Soravia / Adel Sidarus. Lisbonne. IICT/Hugin. 2005. p. 109-119.

* Sed-Rajna (Gabrielle). Manuscrits hébreux de Lisbonne. Un atelier de copistes et d'enlumineurs au XV' siècle. Paris. CNRS. 1970 (Documents, études et répertoires publiés par l'IRHT. 16).

* Serra (Pedro Cunha). «Les études onomastiques au Portugal (1957-1974)». Onoma. 18/3. 1974. p. 535536.

* Serrào (Joaquim Veríssimo). «Les étudiants portugais dans les Universités du Midi de la France à la fin du XIV" siècle ". Bulletin philologique et historique (jusqu'en 1715) du CTHS. 1953/544. p. 265-272.

- Les Portugais à l'Université de Toulouse (XIIr-Xvill siècles). Paris, FCG/CCP. 1970).

- Les Portugais à lUniversité de Montpellier (XII-XvIr siècles), Paris. FCG/CCP. 1971.

* Seybold (C. F.), "Monchique et Arrifana d'Algarve chez les auteurs arabes". O archeólogo portuguez. VIII, 1903, p. 123-126.

* Sidarus (Adel), "Manuscrits arabes du Portugal». dans La signification du bas Moyen-Âge dans l'histoire et la culture du monde musulman. Actes du 8 congrès de l'Union Européenne des Arabisants et Islamisants, Aix-en-Provence. 1976. p. 283-288.

- «Un recueil [manuscrit] de traités philosophiques et médicaux à Lisbonne ». Zeitschrift für die Geschichte der Arabisch-Islamischen Wissenschaften, 6, 1990, p. 179-189.

- «Le Livro da corte enperial entre l'apologétique lullienne et l'expansion catalane au XIV" siècle ". dans Diálogo filosófico-religioso entre cristianismo, judaísmo e islamismo durante la Edad Media en la Península ibérica. Acies du colloque international de San Lorenzo del Escorial 23-26 juin 1991. éd. Horacio Santiago Orero. Turnhout, Brepols, 1994. p. 129-170.

- "Un projet de recherche portugais sur le Gharb al-Andalus". M.A.R.S. (Le Monde Arabe dans la Recherche Scientifique). 9 (vol. thématique Le mythe andalou ), 1998, p. 125-128.

* Silva (José-Gentil da). "L’autoconsommation au Portugal (XIV“-XX“ siècles)», Annales ESC. 24/2. 1969. p. $250-281$.

* Silva (Maria Helena Santos). "La conscience de province et la division géographique officielle au Portugal ". dans $I X "$ congresso internacional de linguística românica. Universidade de Lisboa, 31 de março - 4 de abril 1959. Actas II. Lisbonne. Centro de estudos filológicos. 1961. p. 369-376.

* Simon (Isidore), «La vie et l'œuvre des médecins juifs d’origine espagnole et portugaise du Moyen Âge à la fin du XVIII" siècle (à suivre)". Revue d'histoire de la médecine hébräque. 33 (132). 1980. p. 1720.

* SoARes (Torquato de Sousa). "Les bourgs dans le Nord-Ouest de la Péninsule ibérique. Contribution à l'étude des origines des institutions en Espagne et en Portugal», BEP. n.s., 9. 1943. p. 5-15.

— «La contribution de Picrre David à l'étude des origines du Portugal ». ibid.. n.s.. 19. 1955/56. p. 312318.

* Soravia (Bruna). Lees fonctionnaires épistoliers (kuttab al-inša') en Espagne musulmane à l'époque des Taifas ( $V^{\prime}$ s. $/ I . / X I$ s. up. J.-C.). Paris. Université Paris 111 - Sorbonne nouvelle. 1998 [polycop.].

* Sousa (Bernardo Vasconcelos e). "La résurgence de lidéal de Croisade au Portugal au XIV" siècle ". dans Limaginaire de la nation. Actes du colloque européen de Bordeaux (1989). Bordeaux. Presses Universitaires de Bordeaux. 1991. p. 203-211.

* Sucarrat Bolvtet (Francine). "Les allusions à la toponymie du terroir dans la poésie médiévale galicienne ». dans Provinces, régions, terroirs au Moyen Âge : de la réalité à limaginaire. Actes du colloque international des "Rencontres européennes de Strasbourg". Strasbourg, 19-21 septembre 1991, dir. Bernard Guidor. Nancy. Presses universitaires de Nancy. 1993. p. 125-141.

* Sur les traces de la Maure enchantée : lart islamique au Portugal? Aix-en-Provence. Édisud. 2001 (Lart islamique en Méditerranée. Cycle international dexpositions "Musée sans frontières»). 
* Tavares (Maria José Pimenta Ferro). "La noblesse portugaise au XIV" siècle ». ACCP. XXVI (La noblesse dans l'Europe méridionale du Moyen-Âge : accès et renouvellement. Actes du colloque. Paris, 14 15 janvier 1988). 1989. p. 389-398.

* TAZI (Abdelhadi). "Abu Abd-Allah al-Yaburi : un cheikh marocain du 7\%/XIII" siècle », dans Islão e arabismo na península ibérica. Actas do XI congresso da União Europeia de Arabistas e Islamólogos (ÉvoraFaro-Silves, 29 setembro-6 outubro 1982), éd. Adel Sidarus, Évora. Universidade de Evora, 1986. p. 363-364.

* Teichner (Felix), "Céramique de l'époque de l'Ordre des templiers, mobilier du Moyen Âge d'Idanhaa-Velha ". dans La céramique médiévale en Méditerranée. Actes du VI congrès de l'AIECM. Aix-enProvence (13-18 novembre 1995). éd. Gabrielle Démians D Archimbaud. Aix-en-Provence. Narration Éditions. 1997, p. 347-352.

* Teixeira (Francisco), «Les monastères cisterciens féminins au Portugal », dans Unanimité et diversité cisterciennes. Filiations - Réseaux - Relectures du XIr au XVIr siècle. Actes du quatrième colloque international du CERCOR, Dijon, 23-25 septembre 1998. Saint-Étienne. Publications de l'Université de Saint-Étienne. 2000, p. 557-566.

* Terrasse (Henri), «Une 'qubba' funéraire d'époque almohade au Portugal». Al-Andalus, 34/2, 1969. p. 421.

* Torres (Cláudio), Mértola almoravide et almohade : catalogue [Exposition organisée par le Campo Arqueológico de Mértola. Rabat. Galerie Bab Oudaya (22 fév. au 7 mars 1988)]. Rabat. Ministc̀rc des Affaires Culturelles du Royaume du Maroc. 1988.

- «Le Gharb dans le contexte de la civilisation islamique péninsulaire ». dans Judeus e árabes da Península ibérica. Encontro de religióes, diálogo de culturas, Lisbonne. Comissão nacional da UNESCO Portugal. 1994. p. 202-204.

* Trindade (Maria José Lagos). "Marchands étrangers de la Méditerranée au Portugal pendant le Moyen Âge ». Anuario de estudios medievales, 10, 1980. p. 343-359.

* Vaux de Foletier (E. de), L'organisation des archives portugaises, 1935/36.

* Verlinden (Charles), «Quelques aspects de l'histoire de la tenure au Portugal», dans Recueils de la société Jean Bodin. Vol. III : La tenure, Bruxelles, 1938, p. 321-343.

- «Le problème de l'expansion commerciale portugaise au Moyen Âge ». Biblos. Revista da Faculdade de Letras da Universidade de Coimbra, XXIII, 1948. p. 453-467.

- «Deux aspects de l'expansion commerciale du Portugal au Moyen Âge (Harfleur au XIV" siècle. Middlebourg au XIV et XV' siècle) », RPH, 4. 1949. p. 169-209.

- «La colonie italienne de Lisbonne et le développement de l'économie métropolitaine et coloniale portugaise », dans Studi in onore di Armando SAPORI. Vol. I. Milan. Istituto editoriale cisalpino. 1957. p. 617-628.

- «Draps des Pays-Bas et du nord-ouest de l'Europe au Portugal au XV siècle ». Anuario de estudios medievales, 1, 1966, p. 235-262.

- «Les Génois dans la marine portugaise avant 1385 ». Bracara Augusta, XVI-XVII (Actas do congresso histórico de Portugal medievo, II), 1966, p. 388-407.

* VILAR (Hermínia Vasconcelos). "Réseau paroissial et droit de patronage dans le diocèse d'Évora (XIIIXIV" siècles) », dans L'espace rural, 2002, p. 125-140.

* Williman (Daniel) éd., Bibliothèques ecclésiastiques au temps de la papauté d'Avignon. I (I. Inventaires de bibliothèques et mentions de livres dans les Archives du Vatican (1287-1420) - répertoire; II. Inventaires de prélats et de clercs non français - édition). Paris. CNRS. 1980. 